\title{
Arbor
}

\section{José Echegaray: entre la ciencia, el teatro y la política}

José Manuel Sánchez Ron

Arbor CLXXIX, 707-708 (Noviembre-Diciembre 2004), 601-688 pp.

\section{Introducción}

José Echegaray y Eizaguirre (Madrid, 19 de abril de 1832-Madrid, 14 de septiembre de 1916) fue un personaje polifacético. Ingeniero de Caminos, matemático, físico-matemático, divulgador científico, dramaturgo, economista y político, alcanzó en todas estas actividades renombre: número 1 de su promoción en la Escuela de Ingenieros de Caminos, más tarde profesor en ella de diversas materias (como cálculo y mecánica), ministro primero de Fomento y de Hacienda después, ateneísta distinguido, figura prominente en la creación -con, esencialmente, las funciones que hoy desempeña- del Banco de España, académico de Ciencias y de la Española, presidente del Ateneo, del Consejo de Instrucción Pública, de la Junta del Catastro, de la Real Academia de Ciencias, de la Sociedad Española de Física y Química, de la Asociación Española para el Progreso de las Ciencias, premio Nobel de Literatura, catedrático de Física matemática en la Universidad Central, o senador vitalicio, son títulos que ningún otro español, de su época, de antes o de después, ha conseguido reunir. Ocurre, no obstante, que la lejanía temporal ha difuminado, haciéndola casi desaparecer, la figura de Echegaray. Su importancia como literato hace mucho que ha sido puesta en entredicho, y su obra como matemático o físico-matemático es ignorada por la mayoría, salvo por algunos estudiosos de la historia de la ciencia española, y aún aquí hay que señalar que son muy pocos, y limitados, los estudios que se han dedicado a su obra científica. Muy diferente fue en su tiempo, en el que su fama brilló descomunal, como atestigua la semblanza que nada menos que Santiago Ramón y Cajal realizó de él, al recibir en 1922, de manos del rey 
Alfonso XIII la medalla Echegaray instituida por la Real Academia de Ciencias. He aquí lo que manifestó entonces el responsable de la teoría neuronal: ${ }^{1}$

«diríase que las hadas prodigaron a nuestro inolvidable D. José todas las gracias: elocuencia subyugadora; intelecto agudísimo y generalizador; ansía irrefrenable de aprender y de enseñar; don de expresar por escrito y en lenguaje esmaltado de pensamientos brillantes y de comparaciones felicísimas, las más abstrusas teorías e invenciones; soberana aptitud para la ciencia del cálculo; bondad sólo equiparable con su modestia, y, en fin, por tenerlo todo, salud robusta, física y mental, conservada en bien de la enseñanza, hasta la hora de su muerte. Porque harto sabéis: la vida de Echegaray no tuvo ocaso. Tan propicios le fueron los hados, que le preservaron piadosos de las decadencias, regresiones y tristezas de la decrepitud, suplicios intolerables para los espíritus fuertes que no comprenden la vida sin acción, ni apetecen más deleites que los asociados al severo cimplimento del deber y a la soberana función de escrutar los enigmas de la naturaleza.

Yo, que aprendí a admirarle desde muy joven, con ocasión de sus brillantes discursos políticos en las Cortes Constituyentes, troqué mi admiración en fanatismo; allá por el año 1883, cuando, siendo a la sazón profesor en Valencia, devoré su maravilloso libro titulado Teorías modernas de la física, muy superior a las celebradas obras de vulgarización de Tyndall, en Inglaterra, y de J. H. Fabre, en Francia. Y siempre seguí su carrera de triunfos profesionales, políticos, literarios y científicos, con noble envidia y creciente asombro. Era incuestionablemente el cerebro más fino y exquisitamente organizado de la España del siglo XIX. Él lo fue todo, porque podía serlo todo: ministro, orador, hacendista, maestro, escritor, dramaturgo, investigador, etc. ¡Lástima que las brutales tiránicas exigencias de la vida no le permitieran desplegar, en plena juventud, las alas de su genio por el espacio sin fin de la Física matemática, que fue, según es notorio, el amor de sus amores y la ocupación favorita de su apacible y serena senectud! Así y todo, su obra científica -descuento el magno repertorio teatral, el más copioso, intenso y original que poseemos desde Calderón y Lope de Vega-, con sus maravillosas lecciones de Física matemática y sus libros de vulgarización, quedarán para la posteridad como modelos insuperables.»

El presente trabajo pretende aliviar la carencia de estudios sobre Echegaray científico, explicando sus aportaciones a la matemática y física matemática españolas de la segunda mitad del siglo XIX y dos primeras décadas del XX, situando, al mismo tiempo, esas contribuciones en el contexto de la ciencia internacional de la época. Antes, sin embargo, me gustaría efectuar un comentario: tendremos ocasión de comprobar en las páginas que siguen que las aportaciones de Echegaray carecieron, casi por completo, de la originalidad y profundidad que solemos exigir en la actualidad a los grandes científicos, o, si se quiere, al, simplemente, investigador auténticamente profesional. Desde semejante perspectiva, la importancia de Echegaray se vería radicalmente disminuida. Sería, no obstante, un error, un ejemplo escandaloso de historia anacrónica enfocar el estudio del polifacético matemático madrileño -y de otros científi- 
José Echegaray: entre la ciencia, el teatro y la política

cos españoles de su tiempo- de esta manera. Echegaray fue lo que López Piñero, Navarro Brotons y Portela Marco (1988: 315-316) han denominado, acertadamente, una "figura intermedia» ${ }^{2}$. Aunque no se puede decir, por supuesto, que no existieran aportaciones a las matemáticas en España antes que las que realizó Echegaray ${ }^{3}$, sí que hay que reconocer que debido a diversas circunstancias - entre las que figura la complicada historia política de, especial aunque no únicamente, la primera mitad del siglo XIX español- ${ }^{4}$, esta ciencia se encontraba en una situación bastante difícil en nuestro país, aislada de los desarrollos que estaban teniendo lugar en otras naciones. En este sentido, la labor de Echegaray, al igual que, un poco más tarde, la de otra figura intermedia, Zoel García de Galdeano (1846-1924) ${ }^{5}$, fue importante para comenzar a conectar con la comunidad matemática internacional.

Y no es sólo hoy que, con el beneficio de la perspectiva histórica, vemos a Echegaray de esta manera; en una nota necrológica, escrita tres días después de su fallecimiento, García de Galdeano (1916)-nadie mejor que él para apreciar realmente las contribuciones de su coetáneoexpresó, en general certeramente, las mismas ideas que acabo de mencionar: «Echegaray en matemáticas, no fue un Cauchy ni un Riemann, ni como estadista un Bismarck o un Metternich, ni como poeta un Petrarca o Dante o un Lope de Vega; pero aquéllos arriba citados respiraron un ambiente ya purificado por las corrientes ideales de ilustres predecesores. Un Cauchy tuvo por predecesores un Lagrange y un Laplace, como un Petrarca o un Calderón lo tuvieron en un Virgilio o en el bullicioso Aristófanes... y los actuales físicos y químicos los tuvieron, desde Pascal y Newton hasta Davy, Cavendish, Gay-Lussac y otros muchos eminentes guías, sobre cuyos resultados pudieron hacer progresar la Ciencia. Pero cuando Echegaray apareció como alumno brillante, excepcional y sin rival alguno en la Escuela de Ingenieros de Caminos, Canales y Puertos, apenas en España se había constituido la segunda enseñanza bajo la ley de Moyano, ni la Real Academia de Ciencias, que por entonces se hallaba en estado embrionario, cuando ya las otras Reales Academias de San Petersburgo, de Berlín, de París y de Londres estaban pletóricas de los trabajos de Euler, de Gauss, de Lagrange, de Laplace y de otros muchos talentos. Echegaray llegó a un desierto azotado por el simoun de las luchas civiles, cuando el edificio nacional se hallaba en estado de equilibrio inestable, flotando bajo los más encontrados impulsos. Y desde este momento entró en la lucha por la vida, aromatizada, no obstante, por una invencible aspiración a los purísimos ideales de la Ciencia, como infatigable obrero que se propone rotu- 
604

\section{José Manuel Sánchez Ron}

rar campos estériles, a fin de obtener, con labor pertinaz, abundantes y sabrosos frutos».

\section{Estudiante en la Escuela de Caminos ${ }^{6}$}

José Echegaray y Eizaguirre nació en la calle del Niño (hoy calle Quevedo) de Madrid, el 19 de abril de 1832. Hijo de José Echegaray Lacosta, médico aragonés, y de Manuela Eizaguirre Chale, navarra, permaneció en Madrid hasta los cinco años, momento en que se trasladó a Murcia ya que su padre se instaló en esa ciudad como profesor de Instituto, para explicar botánica y agricultura? ${ }^{7}$ En Murcia estudió el Bachillerato, que completó en junio de 1846, con la calificación de sobresaliente, y en Murcia nacieron sus hermanos Miguel, futuro autor teatral, y Eduardo, que sería ingeniero ${ }^{8}$.

En sus Recuerdos, la autobiografía que escribió en sus años postreros, Echegaray se refirió a sus intereses de aquellos años de la manera siguiente: "Mis aficiones eran bien sencillas, y se manifestaban de este modo: un interés extraordinario por el teatro, y en el teatro por los dramas... Además del teatro, se desbordaban mis aficiones por el campo inagotable de la novela... Pero a la par que se desarrollaban mis afanes y apetitos por el género novelesco y el género dramático, se desarrollaban poderosísimos, con intensidad creciente, y tan invencibles, que todavía no han sido vencidos, por el estudio de las ciencias matemáticas; mejor dicho, por las Matemáticas puras. Tanto o más gozaba yo estudiando un teorema de la geometría de Vincent o resolviendo un problema de geometría descriptiva de Leroy, que por mí mismo y sin profesor estudiaba, que leyendo las primeras entregas de El Conde de Monte Cristo, o que viendo representar El Trovadorm ${ }^{9}$.

En otro lugar de sus memorias, se refirió de manera más explícita a la formación matemática que adquirió durante sus años de estudiante de bachillerato: «en la segunda enseñanza yo había estudiado y comprendido la Aritmética, el Álgebra elemental, la Geometría y la Trigonometría rectilínea. Más aún: había comprado la Geometría descriptiva, de Leroy, y estudiándola por mí y sin profesor, no sólo la había comprendido, sino que había hecho varios modelos con cartón y seda negra» ${ }^{10}$. También quiso estudiar geometría analítica con un texto de Vallejo, pero ahí fracasó por completo ${ }^{11}$.

Tras finalizar el bachillerato en Murcia, y pasar un año preparándose, regresó, en agosto de 1848, a Madrid ${ }^{12}$, para estudiar en la Escue- 
José Echegaray: entre la ciencia, el teatro y la política

la de Ingenieros de Caminos, una elección no demasiado extraña para alguien entre cuyos intereses figuraba la matemática, especialmente si tenemos en cuenta el estado de la enseñanza de esta disciplina en la España de mediados del siglo XIX. En efecto, en 1850 no existían en España Facultades de Ciencias, estando incluido este tipo de estudios dentro de la Facultad de Filosofía (fue la ley Moyano de 1857 la que remedió tal situación). El escalafón de catedráticos de la universidad española de 1847 demuestra que el número de catedráticos de matemáticas no era muy elevado; eran éstos: Francisco Travesedo (Cálculos sublimes ${ }^{13}$, Madrid), y en cátedras de Matemáticas sublimes, Demetrio Duro (Valladolid), Alberto Lista (Sevilla), José Basse Court (Valencia), Lorenzo Presas Puig (Barcelona) y Antonio Aguilar Vela (Santiago) ${ }^{14}$. Así, y aunque el propósito de la Escuela de Caminos era formar técnicos (ingenieros) y no matemáticos, la componente matemática existente en ella era lo suficientemente fuerte como para hacer de esa institución uno de los principales centros de enseñanza superior en lo que a las matemáticas se refiere (esto no quiere decir, naturalmente, que el nivel matemático que se alcanzó en la Escuela o, en general, entre los ingenieros de Caminos fuera muy elevado, si se le compara con el estado en que se encontraba la matemática en otros países).

En más de una ocasión Echegaray se refirió a la aportación de su Escuela a la matemática en España; así, por ejemplo, en 1897 señalaba (Echegaray 1897): «En lo que va de siglo, grandes esfuerzos se han hecho en nuestra patria para salir [del] estado tan vergonzoso [en que estaba la matemática en España]... En esta obra, que pudiéramos llamar de regeneración matemática, la Escuela de Caminos ha tenido una parte importantísima. Merced a su influjo, a la severidad de sus exámenes de ingreso, y a la preferencia que siempre dio a los estudios matemáticos puros, formóse, en pocos años, un profesorado libre de matemáticas elementales» ${ }^{15}$.

$\mathrm{Al}$ margen de otras consideraciones, la fuerte componente matemática en la enseñanza ofrecida en la Escuela de Caminos madrileña es una manifestación del hecho de que en las Escuelas Especiales de Ingeniería españolas de la segunda mitad del siglo XIX la influencia predominante era la de las Escuelas Técnicas francesas, especialmente la École Centrale des Arts et Manufactures y la École Polytechnique, fundadas, respectivamente, en 1829 y $1794^{16}$. En esta última, en particular, las matemáticas fueron, durante las primeras décadas del siglo XIX, una componente importantísima; así, el programa de estudios incluía: ${ }^{17} 108$ sesiones dobles ( 1 hora y media cada una) de Análisis; de Aplicaciones 
del análisis a la geometría; 153 de Geometría descriptiva; 175 de Aritmética; y 94 de Mecánica. Veremos en seguida el contenido específico de matemáticas en la Escuela de Caminos al tratar del examen de ingreso, basado en su mayor parte en esta disciplina, así como al citar las asignaturas de los dos primeros cursos de la carrera, pero antes mencionaré un ejemplo significativo de la relación existente en España, a mediados del siglo XIX, entre matemáticas e ingenieros de Caminos: el de la composición de la sección de Ciencias Exactas de la Real Academia de Ciencias Exactas, Físicas y Naturales de Madrid, institución fundada en 1847. De las doce plazas fundacionales de la sección de Exactas, seis estaban ocupadas por ingenieros de Caminos, de los cuales cuatro eran o habían sido profesores de la Escuela. Echegaray llegaría a ser un ejemplo más de semejante composición.

La Escuela de Caminos, Canales y Puertos en la que estudió Echegaray corresponde a la tercera época de la misma ${ }^{18}$. Al igual que las Escuelas Especiales de Ingenieros de Minas, Industriales, Agrícolas y Montes, el establecimiento de estas escuelas forma parte de la remodelación institucional que siguió a la muerte de Fernando VII, y que patrocinó el primer gobierno liberal del reinado isabelino; se trataba, en definitiva, de crear cuerpos de técnicos capaces de impulsar el desarrollo industrial que España necesitaba a todas luces ${ }^{19}$. En particular, fue gracias a una decisión del ministro de Fomento, Francisco Javier de Burgos, que una nueva Escuela de Caminos, Canales y Puertos reabrió sus puertas (había sido fundada por Betancourt en 1803) a la enseñanza en noviembre de 1834 (la siguieron las Escuelas de Minas [1835], Montes [1846], Industriales [1850] y Agrícolas [1855]). Inicialmente, fue elegida como sede el caserón de la Aduana Vieja, en la plazuela de la Leña, que había quedado vacante al clausurarse un cuartel de voluntarios realistas, pero en 1847 fue trasladada a la calle del Turco, al edificio ocupado hasta entonces por el Real Conservatorio de Artes. Antonio Gil de Zarate (1855, tomo III: 322), director general de Instrucción Pública, describió de la manera siguiente aquella sede: «El edificio de la calle del Turco... es de mucha longitud, pero de poca profundidad, y ocupado, en parte, por otros establecimientos. Algunos salones largos se hallaban destinados al Gabinete de Máquinas, donde se habían reunido los restos, que pudieron encontrarse, del que se formó a principios de siglo en el Retiro. Pero el local de las cátedras y del laboratorio era estrecho y mezquino, y en su totalidad nada a propósito para dar a la enseñanza el desarrollo que se proyectaba.»

Para ingresar en la Escuela de Caminos, Canales y Puertos (que entonces dependía de Instrucción Pública, en el Ministerio de Fomento) era 
José Echegaray: entre la ciencia, el teatro y la política

necesario pasar un duro examen centrado especialmente en las matemáticas. En el caso de Echegaray, el programa de pruebas a realizar estuvo determinado por una Real Orden de 8 de julio de 1847. Eran estas las materias de las que se examinaba:

«1 $1^{\mathrm{a}}$. Aritmética.- Álgebra, con inclusión de la teoría y resolución de las ecuaciones superiores y teoría de las cantidades exponenciales y logarítmicas. $2^{\mathrm{a}}$. Geometría.- Trigonometría rectilínea y esférica, con el uso de las tablas de logaritmos y líneas trigonométricas para la resolución de los triángulos de una y otra especie. $3^{\mathrm{a}}$. Aplicación del álgebra a la geometría, incluyendo la teoría de las curvas y superficies de segundo grado, y las curvas de doble curvatura. $4^{\mathrm{a}}$. Elementos de topografía. $5^{\mathrm{a}}$. Traducción del francés. $6^{a}$. Principios de dibujo".

Durante los primeros quince años de existencia de la Escuela fueron 485 los aspirantes a ingresar en ella, de los cuales aprobaron 298, es decir, el 61 por ciento. El siguiente cuadro, preparado por Peset, Garma y Pérez Garzón (1978: 67) y extraído de datos publicados en la Revista de Obras Públicas, da idea de la dureza que fue adquiriendo el examen de ingreso en la Escuela, una vez que ésta hubo pasado sus primeros años:

\section{Curso}

$1859-60$

$1860-61$

$1861-62$

$1862-63$

$1863-64$
Presentados 72

99

108

123

141

\section{Admitidos} 37

48

49

28

28
$\%$ Acaban

$51,4 \quad 10$

$48,5 \quad 13$

$45,4 \quad 9$

$22,8 \quad 21$

$19,9 \quad 18$

Cuando Echegaray iba a intentar entrar en la Escuela de Caminos, se acababa de fundar una Escuela Preparatoria para las carreras de ingenieros de Caminos y de Minas y para la de Arquitectura, que empezó a funcionar el 1 de diciembre de 1848. Para el ingreso en aquella Escuela, que en realidad constituía un nivel intermedio entre los estudios secundarios y los superiores, Echegaray asistió, al igual que otros cinco aspirantes más, como oyente, al primer año de la Escuela de Caminos ${ }^{20}$. Cumplido este requisito, tuvo que someterse a un examen para el que la Dirección general de Instrucción pública nombró un Tribunal con los profesores de matemáticas de universidad, Francisco Travesedo, Alejandro Bengoechea y Juan Cortázar (este hecho es un indicio de la importancia que se daba a la matemática en el examen de ingreso). 
El examen tuvo lugar entre el 13 y el 17 de diciembre de 1848 y Echegaray fue el que obtuvo la calificación más alta de todos los aspirantes (en particular, obtuvo sobresaliente en las pruebas matemáticas). Entró, por consiguiente, en esa Escuela Preparatoria, en la que los estudios duraban dos años, tras los cuales se pasaba a la Escuela de Caminos propiamente dicha. Del severo régimen, una auténtica disciplina militar, que regía entonces en la Escuela habló el propio Echegaray en sus $R e$ cuerdos $^{21}$ :

«La Escuela de Caminos, en aquella época, estaba sometida a un régimen severísimo; pudiera decir que casi a un régimen militar. Entrábamos a las nueve de la mañana, y los minutos de retraso se contaban, y si pasaban de quince, constituían falta, y si no llegaban a quince, se iban sumando; de modo que, al subir la suma a cierto límite, constituía causa suficiente para perder el curso. Duraba éste todo el año solar, desde el $1 .^{\circ}$ de octubre al 31 de agosto: en nada se diferenciaban, para el alum. no, los meses abrasadores del verano de los helados meses de invierno; y el mes de septiembre se destinaba a los exámenes. De esta manera se empalmaban cinco años seguidos, y no había más reposo que los ocho últimos días de diciembre, Semana Santa, Carnaval, domingos y fiestas enteras. Entrábamos, repito, a las nueve de la mañana y permanecíamos en la Escuela hasta las cuatro de la tarde, sin más descanso que media hora que se nos concedía para el almuerzo. Las seis horas y media restantes estaban destinadas a las lecciones orales y al Dibujo, siempre con un profesor o un ayudante a la vista.»

Naturalmente, un punto importante a la hora de estudiar a Echegaray es el tipo de formación que recibió durante sus años de estudiante en la Escuela de Caminos; veamos, por consiguiente, cual era el plan de estudios y el profesorado en 1848.

El director de la Escuela, al comienzo del curso de 1848, era Juan Subercase (1783-1856), Inspector General del Cuerpo de Ingenieros de Caminos, pero dejó de serlo, tras once años en el cargo, en octubre, siendo sustituido, ya entrado 1849, por Gabriel Gómez Herrador ${ }^{22}$. Las asignaturas y profesorado se repartían en los diferentes cursos de la siguiente manera: ${ }^{23}$

\section{Primer curso}

Cálculo diferencial e integral. Geometría analítica de tres dimensiones (ambas asignaturas explicadas por Joaquín Ortega, ingeniero $1^{\circ}$.). Geometría descriptiva, con sus aplicaciones a las sombras y a la perspectiva. Trabajos gráficos relativos a estas materias (explicadas por Manuel Caravantes, ingeniero $1 .^{\circ}$ ). Física. Principios de Química (Venancio González Valledor, catedrático de Física de la Facultad de Filo. sofia).

Segundo curso

Mecánica racional (Gerónimo del Campo, ingeniero jefe de 1. ${ }^{a}$ clase). Topografía y Geodesia. Gnomónica. Aplicación de la Geometría descriptiva al figurado del terreno, y a la construcción de las cartas geográficas y cuadrantes solares. Operaciones 
José Echegaray: entre la ciencia, el teatro y la política

prácticas correspondientes (José Morer, ingeniero 1. ${ }^{\circ}$ ). Tratado y construcción de los engranajes y demás partes de las máquinas, y transmisión de movimientos por medio de dichas partes. Estereotomía, o corte de maderas y de piedras, con sus aplicaciones a la arquitectura civil y a las obras públicas. Trabajos gráficos y construcción de modelos correspondientes a estas materias (Ramón de Echevarría, ingeniero jefe de 2. ${ }^{\mathrm{a}}$ clase.)

\section{Tercer curso}

Mecánica aplicada a las construcciones. Hidráulica que comprende la salida del agua de un depósito; su movimiento en los canales, en los ríos y en las cañadas; su choque y resistencia; su aforo (José de Azas, inspector de distrito). Arquitectura civil (Fernando Gutiérrez, ingeniero jefe de 2. ${ }^{a}$ clase). Mineralogía. Geología (Rafael Amar de la Torre, ingeniero $1 .^{\circ}$ de Minas.)

Cuarto curso

Curso de construcción. Primera parte: conocimiento y uso de los materiales, tanto naturales como artificiales; métodos de construir según la diversidad de terrenos, tanto en seco como dentro del agua; construcción de caminos ordinarios; puentes de piedra, de madera, de hierro, colgados, etc. Proyectos, lecturas y trabajos gráficos y prácticos relativos a esta clase (Baltasar Hernández, inspector de distrito). Cálculo del efecto de las máquinas, principalmente de las de vapor fijas: descripción y establecimiento de las mismas. Construcciones relativas a la conducción, elevación y distribución de aguas en las poblaciones. Proyectos, dibujos y trabajos prácticos correspondientes a estas materias (José Subercase, ingeniero $1 .^{\circ}$ )

\section{Quinto curso}

Caminos de hierro: origen, historia, diferentes sistemas, trazado, proyectos, ejecución. Locomotoras: su descripción y cálculo de sus efectos. Proyectos, dibujos, lecturas relativas a estos objetos. (José Subercase, ingeniero $1 .^{\circ}$ ). Torrentes: obras de defensa contra los estragos que pueden ocasionar. Navegación de los ríos. Canales de navegación, de riego, de desecamiento y sus combinaciones; pantanos. Puertos de mar: faros y demás obras relativas a los puertos. Proyectos, lecturas y dibujos correspondientes (Juan Subercase, inspector general).

Además de las asignaturas citadas existía un Dibujo topográfico en $2 .^{\circ}, 4 .^{\circ}$ y $5 .^{\circ}$ cursos, otro de Delineación y lavado, común a todos los cursos, y un Dibujo de paisaje.

Con referencia a los libros de texto que estudió Echegaray durante su carrera, tenemos que éstos fueron casi exclusivamente franceses: ${ }^{24}$ sólo «por casualidad estudiábamos alguna memoria en inglés, o alguna del alemán traducida al francés, y esto en los últimos años... El francés, y siempre el francés, y autores franceses dominaban en la Escuela de Caminos $\varkappa^{25}$. En cuanto a algunos nombres: «la Geometría de Vincent, el Álgebra de Bourdon, la Analítica de Biot, la Geometría analítica de tres dimensiones de Leroy: éstos en la preparación. Y luego, dentro de la Escuela, siempre obras francesas, no las traducidas, sino las originales; por ejemplo: los 
Cálculos de Navier y Duhamel, la Mecánica de Poisson, la Descriptiva de Leroy, el Corte de piedras de Adhémar, la Mecánica aplicada de Poncelet, la Conducción de aguas de Dupuit» (como iremos viendo, en sus estudios particulares Echegaray tampoco salió demasiado del círculo de los matemáticos franceses) ${ }^{26}$. Si nos atenemos a la parte matemática de esta educación, hay que señalar que muy probablemente servía los intereses de una enseñanza que pretendía formar ingenieros y no matemáticos que contribuyesen al avance de su disciplina; en otras palabras: los textos matemáticos franceses utilizados en la Escuela de Caminos no eran, en general y especialmente en los primeros tiempos, realmente obras modernas, propias del siglo XIX; hecho éste que señaló Julio Rey Pastor (1915: 14) en su discurso inaugural en la sección 1. ${ }^{a}$ (Ciencias Matemáticas) del Congreso de la Asociación Española para el Progreso de las Ciencias, celebrado en Valladolid en 1915, cuando manifestaba, revisando la situación de la matemática en España a mediados del siglo pasado:

"Comienza por entonces la importación de obras francesas: los libros de Ciroddle, el Álgebra de Lefebure de Fourcy, la de Bourdon, la Geometría de Vincent, el Cálculo de Navier, el de Cournot..., obras anodinas todas, incapaces de inspirar amor a esta Ciencia en un país que nace a ella. Si alguna obra original existe entre los libros importados, como son los Elementos de Legendre, es del siglo XVIII; y todas, sin excepción, entran de lleno en esa centuria, si nos atenemos a su contenido, aunque lleven fecha posterior.

Estas eran las fuentes en que bebían nuestros antepasados, cuando Gauss, Abel y Cauchy habían renovado todo el Análisis; y habían nacido las Geometrías no euclidianas; y la Geometría proyectiva había llegado con Staudt a completa madurez; y Riemann había creado la moderna teoría de funciones; en una palabra, cuando ya había nacido, no solamente toda la Matemática que conocemos actualmente, sino muchas otras teorías...?

El gran mérito de Echegaray sería el que contribuyó, más que ningún otro matemático de los años que van desde, aproximadamente, 1860 hasta 1890, a introducir en España algunas de las nuevas teorías a las que se refería Rey Pastor.

Echegaray finalizó sus estudios de Caminos en septiembre de 1853, siendo el número 1 de su promoción y habiendo obtenido la calificación de sobresaliente en todas las asignaturas que cursó. Como recién graduado el título que le correspondió, en el jerarquizado cuerpo de ingenieros de Caminos, Canales y Puertos, fue el de Ingeniero segundo y su primer destino el distrito de Granada ${ }^{27}$. Pero antes de referir algunos detalles relativos a su estancia en tierras andaluzas, conviene retroceder un poco; a su último año en la Escuela.

Durante ese último año de carrera, Echegaray (1853 a) publicó su primer trabajo científico: «Del movimiento continuo». Este artículo, primero 
José Echegaray: entre la ciencia, el teatro y la política

de una serie de tres ${ }^{28}$, apareció en el tomo inicial de la Revista de Obras Públicas, órgano de expresión -y de presión- de los ingenieros de Caminos y, al mismo tiempo, círculo en el que se reunían los mismos, y con el que nuestro personaje estuvo muy relacionado ${ }^{29}$.

"Del movimiento continuo" es, en realidad, un trabajo que pertenece al campo de la física y a la aplicación de ésta al funcionamiento de máquinas. En lo referente a su posible originalidad ${ }^{30}$, es preciso reconocer que a nivel de principios básicos no tiene ninguna, siendo su única posible aportación la aplicación de las leyes físicas tradicionales que se hace en la parte tercera (Echegaray 1854), para demostrar la imposibilidad de una "máquina de movimiento continuo" que había inventado un relojero de la Puerta del Sol y «que por entonces metía mucho ruido en Madrid» ${ }^{31}$. Este primer artículo del joven Echegaray es una exposición, con pretensiones pedagógicas, de la futilidad de la búsqueda de máquinas de movimiento continuo, búsqueda que -señalaba Echegaray (1853 a: 43)- ha llevado a "la formación de sociedades cuyo fin inevitable y desastroso ha causado y causará la pérdida de capitales tan sin prudencia expuestos», así como a la «publicación de obras llamadas científicas, que seguramente no darán a los extranjeros la mejor idea del estado en que se encuentra la ciencia en nuestro país». Los elementos teóricos que manejaba en estos artículos no pasaban de la noción de fuerza (en particular las motrices y resistentes), trabajo, energía cinética ( $o$, en la nomenclatura de entonces, "fuerza viva») y principio de "variación de la energía cinética igual a trabajo realizado»; nada, en definitiva, que no fuera conocido en la física -en la estática y la dinámica- ya el siglo anterior, e incluso antes $^{32}$. El punto central de Echegaray, en el que basaba toda su argumentación, es el de que «en una máquina pueden equilibrarse fuerzas muy distintas en intensidad, pero siempre sus trabajos serán iguales» ${ }^{33}$; de este principio se podía concluir fácilmente que «si no existieran resistencias pasivas, ni fuerza alguna que se opusiese al movimiento, este se prolongaría indefinidamente; pero... ni aún en tal caso podrían hacer aplicaciones industriales, porque todo el trabajo motor de los pesos en una semi-oscilación descendente, se emplearía en elevarlos al punto de donde partieron, y desde el instante en que hubiese una resistencia útil que vencer, la fuerza viva iría disminuyendo hasta hacerse nula si aquélla se prolongaba bastante tiempo. No se habría conseguido mas que trasmitir por la máquina el trabajo motor correspondiente a la impusión primitiva $x^{34}$. Es interesante señalar que aunque los artículos que estoy estudiando trataban en última instancia del principio de conservación de la energía, principio que Hermann von Helmholtz (1847) había formula- 
do con precisión y generalidad seis años antes, Echegaray mostraba en su trabajo la gran distancia que le separaba del conocimiento que había ofrecido el científico alemán; baste con decir que mientras que el ingeniero español no salía del ámbito de la mecánica, Helmholtz (al igual que otros - pero él de manera más acusada-como Julius Mayer o James Prescott Joule) se movió en campos tan variados como la teoría del calor, la electricidad, la mecánica, la química y la fisiología. De hecho, durante bastante tiempo Echegaray dio muestras de no estar familiarizado con los trabajos relativos a la conservación de la energía de Helmholtz ${ }^{35}$. Así, en el artículo "De la conservación de la energía en el mundo material» (Echegaray 1883: 129-169), que incluyó en la segunda serie de su Teorías modemas de la Física, no se menciona, en absoluto, el nombre del investigador germano. El contenido de ese artículo es, aproximadamente, el «Del movimiento continuo»; más aún, las referencias citadas por Echegaray muestran su -excesiva-dependencia de la ciencia francesa (incluso cuando se refiere al libro -poco sofisticado y bastante primitivo, dicho sea de paso- de Balfour Stewart, The Conservation of Energy [1874], cita la edición francesa, La conservation de l'énergie). Aunque lo mencionó en alguna ocasión anterior, claramente se puede asegurar que ya tenía conocimiento de las aportaciones realizadas por Helmholtz cuando desarrolló sus cursos (1905-1915) de física matemática en la Facultad de Ciencias de la Universidad Central. Tendremos ocasión de comprobarlo cuando citemos el programa que tenía en mente al comenzar aquel curso.

Pero volviendo a "Del movimiento continuo», tal vez sea lo más apropiado decir que el joven José no pasó, en este su primer trabajo con ciertas pretensiones científicas, de las preocupaciones que caracterizan a un buen ingeniero, a uno interesado por los principios generales que subyacen a los instrumentos de los que se ocupa.

Terminaré mis comentarios relativos a «Del movimiento continuo» señalando que en esos tres artículos sí que se puede apreciar tanto la claridad expositiva de Echegaray como el vigor de su pluma. Nada más apropiado, en este sentido, que citar los párrafos finales de su tercer y último artículo (Echegaray 1854: 151):

«Si al examinar el problema del movimiento continuo, y al estudiar la máquina a que hemos dedicado este artículo, hemos hablado a veces con demasiado calor, hemos sido, hasta cierto punto, excesivamente severos con los que se dedican a semejante investigación y con sus admiradores, no ha sido nuestro objeto dirigirnos a tal o cual inventor, ni mucho menos ajarlos en lo más mínimo. Hemos hablado en nombre de la ciencia, por poco dignos que seamos de tal cargo; nos hemos dirigido al error $y$ como personificación de él al ente moral representado por el nombre siguiente: autor de tal o cual máquina. Hemos preferido examinar detenidamente esta máquina, 


\section{José Echegaray: entre la ciencia, el teatro y la política}

que goza al presente de gran celebridad, a describir otras muchas que ya pasaron, que ya fueron a donde en breve irá ésta y cuantas se inventen con tal objeto, por el doble motivo de estar llamando en el día la atención pública y de ser una de las que más ilusión pueden producir. Ilusión hemos dicho y lo repetimos, porque movimiento continuo y espontáneo, es una ilusión, y aunque se vea mover una máquina una semana y otra, y aunque sea uno y otro año, esto nada prueba; no será la primera que por tanto tiempo ha parecido desmentir a la ciencia; pero al fin ha cesado de moverse, porque la ciencia no miente, y los sentidos sí; porque las leyes de la naturaleza jamás se contradicen.»

\section{Ingeniero de Caminos}

En 1854, tras finalizar su carrera, Echegaray fue destinado, como ya señalé, al distrito de Granada, con 2.250 pesetas de sueldo anual. Llegó a esta ciudad en enero de 1854 y el Ingeniero Jefe del distrito le envió a Almería, trasladándose a esta ciudad a caballo, ya que no existía ninguna carretera (tardó tres días). Allí su función consistía en conservar una carretera de cinco kilómetros y medio que había hasta Gador y vigilar la, ciertamente monótona, prolongación de un muelle de escollera.

En la soledad de Almería, lejos de su familia y de sus amigos ${ }^{36}$, sin la activa vida teatral madrileña que tanto le atraía, una de las pocas distracciones a las que tenía acceso era el estudio de las matemáticas, su «primera afición, la más intensa, la perdurable» ${ }^{37}$. Y puesto que he tocado este punto, aprovecharé para dejar claro que las matemáticas $-\mathrm{y}$, como él mismo indicaba, "por extensión de éstas, [la] Física matemática»- fue una de sus grandes pasiones, no importa que a lo largo de su vida se viese embarcado en actividades de todo tipo. Pero dejemos que sea él mismo quien lo explique: ${ }^{38}$

«Las Matemáticas fueron, y son [Echegaray escribió estas líneas hacia 1913. 1915], una de las grandes preocupaciones de mi vida; y si yo hubiera sido rico o lo fuera hoy, si no tuviera que ganar el pan de cada día con el trabajo diario, probablemente me hubiera marchado a una casa de campo muy alegre y muy confortable, y me hubiera dedicado exclusivamente al cultivo de las Ciencias Matemáticas. Ni más dramas, ni más argumentos terribles, ni más adulterios, ni más suicidios, ni más duelos, ni más pasiones desencadenadas, ni, sobre todo, más críticos; otras incógnitas y otras ecuaciones me hubieran preocupado. Pero el cultivo de las Altas Matemáticas no da lo bastante para vivir. El drama más desdichado, el crimen teatral más modesto, proporciona mucho más dinero que el más alto problema de cálculo integral; y la obligación es antes que la devoción, y la realidad se impone, y hay que dejar las Matemáticas para ir rellenando con ellas los huecos de descanso que el trabajo productivo deja de tiempo en tiempo. Jamás, ni en las épocas más agitadas de mi vida, he abandonado la ciencia de mi predilección; pero nunca me he dedicado a ella como quisiera.» 
Estas líneas, muy sinceras, no deben ser olvidadas a la hora, no sólo de comprender a Echegaray, sino también, en particular, cuando se intenta evaluar su obra científica.

Pero volvamos a su tiempo libre en Almería. A esta ciudad se había llevado, «entre otras, las [obras matemáticas] tituladas: Recherches Arithmétiques, por Gauss; La teoría de los números, de Legendre, y la Mecánica analítica, de Lagrange» ${ }^{39}$.

No es sorprendente que recordase con precisión cuándo estudió estos tres tratados, obras fundamentales de la literatura matemática. En particular, las Disquisitiones arithmeticae que Carl Friedrich Gauss publicó en 1801 , cuando únicamente tenía veinte años ${ }^{40}$. Se trata de una obra cumbre de la matemática, con la que se abrió una nueva era en la teoría de los números. Hasta entonces ese apartado de las matemáticas consistía de una serie de resultados aislados, por muy brillantes que fuesen; eso es lo que ocurría, por ejemplo, con el Essai sur la théorie des nombres (1798) de Adrien-Marie Legendre, otro de los tres libros estudiados por Echegaray en Almería. En las Disquisitiones, Gauss sistematizó y desarrolló la teoría existente entonces, clasificó los problemas a estudiar y los métodos de resolución conocidos, introduciendo al mismo tiempo otros nuevos. Uno de los aspectos más fascinantes de esta obra es que contiene claros prototipos de las modernas demostraciones y conceptos algebraicos. Un ejemplo en este sentido es el de la teoría de Gauss de las ecuaciones ciclotómicas ("De aequationibus circuli sectiones definientibus», artículos 335-366), que constituyó un paso importante en el desarrollo de la teoría de la resolución de ecuaciones algebraicas mediante la utilización del concepto de permutación ${ }^{41}$. Ahora bien, como se sabe, el uso del concepto de permutación en la investigación del problema de la solución de ecuaciones de grado mayor que cuatro fue una de las claves que llevó, a través de Cauchy, Abel y, sobre todo -ya lo veremos- Galois, a la teoría de grupos. Si recordamos ahora que una de las aportaciones más notables de Echegaray a la introducción de la matemática moderna en España, fue su obra Resolución de ecuaciones y teoría de Galois (Echegaray 1897 a, 1898-1902), basada en cursos que impartió en el Ateneo de Madrid a partir de 1896, tenemos que hacia 1854 y mientras estudiaba las Disquisitiones, Echegaray se estaba preparando para comprender la obra de Galois.

Para valorar mejor el hecho de que a comienzos de la década de los cincuenta estuviese estudiando ese gran texto de Gauss, recordemos que esa obra atrajo inicialmente poca atención; así, únicamente las contribuciones algebraicas contenidas en la última sección consiguieron la apro- 
José Echegaray: entre la ciencia, el teatro y la política

bación de los matemáticos franceses de la época. En general, las Disquisitiones sólo pasaron a un primer plano a raíz de las investigaciones, a finales de los años veinte, de Jacobi y Dirichlet, que sacaron a la luz las profundas consecuencias que se podían extraer de ella. Fue, por consiguiente, con un retraso de poco más de diez años con respecto a la mayoría de los matemáticos europeos que Echegaray se incorporó a los estudiosos de la famosa obra de Gauss.

En cuanto a la Mécanique analytique, el libro que Joseph-Louis Lagrange publicó en 1788, basta con decir que constituye una de las obras cumbres de toda la historia de la física matemática, la disciplina a la que Echegaray consagró una buena parte de sus energías (recordemos que, como veremos con detalle más adelante, llegaría a ocupar la cátedra de Física matemática de la Universidad Central); asimismo, conviene señalar que una de las asignaturas que -también lo veremos- explicó en la Escuela de Caminos, fue la de Mecánica racional, el mismo tema de la obra de Lagrange (de hecho, como el propio Echegaray reconoció repetidas veces, su gran amor científico fue la mecánica).

En Almería pasó casi todo el año 1854, pero una infección palúdica le obligó a pedir una licencia. Regresó a Madrid para recuperarse, y en la capital de España recibió un nuevo destino: Palencia. No parece, sin embargo, que llegase a incorporarse a su nuevo destino, ya que pronto fue llamado a la Escuela de Caminos como profesor. A partir de entonces, Madrid sería el centro de sus múltiples actividades.

\section{Profeşor en la Escuela de Caminos}

El que Echegaray entrase a formar parte del claustro de la Escuela fue consecuencia, en cierta medida, de los acontecimientos políticos que tuvieron lugar durante aquel año: ${ }^{42}$ se efectuaron bastantes cambios en la Administración y, en particular, salieron algunos profesores de la Escuela de Caminos para ocupar otros puestos. Se produjeron, en definitiva, vacantes y Echegaray fue nombrado para ocupar una de ellas. Ese primer año de profesor estuvo encargado de la clase de Estereotomía, que comprendía el corte de piedras, metales y maderas ${ }^{43}$. En el curso de 1855 tuvo como compañeros de claustro a Fernando Gutiérrez, Pedro Celestino Espinosa, José Almazán, José Giménez, Miguel Alcolado, Francisco de Salas Carvajal y a Eduardo Saavedra, todos ingenieros de Caminos ${ }^{44}$.

Durante los años que formó parte del profesorado de la Escuela de Caminos, explicó, además de la mencionada Estereotomía, las siguientes 
materias: Cálculo diferencial e integral (esta fue la disciplina que más veces enseñó), Mecánica racional, Mecánica aplicada a las construcciones, Geometría descriptiva, Aplicaciones de la geometría a las sombras y a la perspectiva, Hidráulica y, en ocasiones, interinamente, Distribución de $\operatorname{aguas}^{45}$.

Pasando ahora a la obra y estudios matemáticos de Echegaray a lo largo de los años que van desde su ingreso en el claustro de la Escuela de Caminos hasta la revolución de septiembre de 1868, que tanto influyó en el desarrollo posterior de su vida, comenzaré por retomar un tema que ya toqué cuando consideré su época de estudiante en la Escuela. Señalé entonces que su formación fue eminentemente francesa, y aunque sus horizontes matemáticos se ampliaron un tanto posteriormente, el peso principal lo continuó llevando la tradición gala. Significativamente, en sus Recuerdos escribió: ${ }^{46}$ "Mi cariño y mi simpatía por la nación francesa eran y son naturales, además de ser justos.» Más concretamente, manifestó que su «educación científica, artística y social fue hasta los treinta y tantos años [la época que estoy considerando ahora] puramente francesa». Y, como ejemplos, citaba los siguientes: ${ }^{47}$

"Cauchy, el gran Cauchy, uno de los más admirables genios creadores de las ciencias matemáticas, el de las funciones imaginarias y de la teoría de la luz, después de Fresnel; Legendre, uno de los primeros fundadores de las funciones elípticas, y el autor de la Teoría de los números, obra verdaderamente clásica; Poncelet, el de las propiedades proyectivas; Poisson, el eminente analista; y Chaesles [sic], el eminente geómetra del siglo; y Liouville, autor de tantos trabajos fundamentales y del teorema sobre los números trascendentales; y tantos y tantos autores más...

En mis estudios y mis consultas no salía de los Anales de Terquem, del Journal de Liouville ${ }^{48}$, del Journal de la Escuela Politécnica, de los Anales de la Escuela Normal y del periódico oficial: Comptes rendus de la Academia...

En fin... en aquella época, para mí el mundo se reducía a dos naciones: España, mi patria; Francia, la patria adoptiva de mi inteligencia y de mis gustos estéticos."

Más adelante nos encontraremos de nuevo con alguno de los nombres que mencionaba en la anterior cita.

Ya profesor en la Escuela, no pasó mucho tiempo hasta que publicase su primer libro: Cálculo de variaciones; surgió éste de sus clases de Cálculo diferencial e integral, para las que utilizaba como texto la obra de Cournot, Teoría de las funciones y del cálculo infinitesimal ${ }^{49}$. Uno de los temas que abordaba Echegaray en su curso era el del cálculo de variaciones, y resultó que los estudiantes no comprendían las explicaciones que el libro de Cournot dedicaba a este asunto. Sobre este punto, leemos en la introducción del libro de Echegaray (1858: 5): «Sencillo en el fondo [el texto de Cournot]; pero fundándose en transformaciones y artificios de 
José Echegaray: entre la ciencia, el teatro y la política

análisis, ingeniosísimos sin duda alguna, mas un tanto nuevos para el alumno que por vez primera estudia esta teoría, aparece a su vista con formas vagas, indecisas, que no acierta a comprender y a definir bien» ${ }^{50}$. Echegaray se empeñó entonces en «demostrarles que la cuestión, a pesar de los pesares, era elemental y sencilla, y en el fondo idéntica a los métodos empleados en los problemas ordinarios de máximos y mínimos ${ }^{51}$ ”.

Como la mayor parte de su obra científica, Cálculo de variaciones responde a motivos eminentemente pedagógicos ${ }^{52}$; en el presente caso esto es particularmente notorio si tenemos en cuenta el hecho de que el cálculo de variaciones venía siendo desarrollado desde el siglo XVIII (dos obras fundamentales en este sentido fueron la Théorie des fonctions analytiques de Lagrange y el Traité du calcul différentiel et du calcul intégral de Lacroix, ambas publicadas en 1797$)^{53}$. En cuanto a España, tampoco se puede decir que este apartado de las matemáticas fuese una novedad: había sido introducido al menos en 1772 por Benito Bails en sus Elementos de Matemáticas, y se le podía encontrar en libros de texto de la época que estamos considerando (al margen de la obra de Cournot, citaré la traducción al castellano -de Gerónimo del Campo- del libro de Boucharlat, Cálculo diferencial e integral, publicada en 1830, que incluía una sección de más de cincuenta páginas dedicada al cálculo de las variaciones; este libro fue, además, utilizado en la Escuela de Caminos).

En lo relativo al contenido, señalaré que tras resumir la teoría de máximos y mínimos de funciones de muchas variables, Echegaray presentaba las teorías de máximos y mínimos para integrales con integrados del tipo $V\left(x, y, y^{\prime} \ldots . . . y^{(n)}\right), y V\left(x, y, y^{\prime}, \ldots, z, z^{\prime}, \ldots\right)$, donde $y=y(x), z=z(x), y^{\prime}=d y / d x$, $\mathrm{y}^{(\mathrm{n})}=\mathrm{d}^{\mathrm{n}} \mathrm{y} / \mathrm{dx}^{\mathrm{n}}$, incluyendo, además, el caso de existencia de ligaduras y límites de integración fijos y variables. Las trece últimas páginas estaban dedicadas a ejemplos (algunos de los que resuelve son todavía clásicos en los cursos de análisis matemático o de mecánica analítica).

Poco antes de la aparición de Cálculo de variaciones, Echegaray había contraído matrimonio (el 16 de noviembre de 1857) con la asturiana Ana Perfecta Estrada. Las nuevas obligaciones, a las que se sumó pronto una hija (y algún tiempo después un hijo), llevaron a que se esforzase en conseguir ingresos suplementarios, para lo cual estableció una academia particular de matemáticas para preparar a los estudiantes de la Escuela, o a los que querían ingresar en ella ${ }^{54}$. El éxito inicial que obtuvo se vio truncado por una disposición ministerial que declaraba incompatibles simultanear la enseñanza privada y la pública. Intentó entonces salir transitoriamente del Cuerpo, abandonando toda posición oficial, pero el director de la Escuela, Calixto Santa Cruz, y después también el director 
de Obras Públicas, le negaron el permiso, y él no se atrevió a dejar definitivamente el Cuerpo, solución a la que, por supuesto, podría haberse acogido $^{55}$. «Por ser un buen profesor, según ellos decían, se me cerraba el porvenir y se me condenaba a una decorosa miseria, encerrándome en mi cátedra como una gloriosa prisión y anticipada tumba", escribió en sus Recuerdos ${ }^{56}$.

Como compensación, recibió durante los años siguientes algunas comisiones atractivas: en 1860 se le encargó, junto a tres estudiantes de la Escuela, observar, desde la provincia de Castellón, el eclipse de Sol que tuvo lugar aquel año, e ir a continuación a estudiar los trabajos y nuevas máquinas perforadoras que se estaban empleando en el túnel de MontCenis, bajo los Alpes ${ }^{57}$. Este encargo le permitió conocer Italia y hacer unas breves excursiones a París y Londres. Dos años más tarde, esto es, en 1862, recibió la comisión de ir a Londres para estudiar las máquinas expuestas en la Exposición Universal que se celebraba allín. Tres meses duró su estancia en la capital británica.

Continuando con sus obras matemáticas, tenemos que en 1865 publicó sus colecciones de Problemas de geometría plana y Problemas de geometría analítica en dos dimensiones, que según él mismo, le había solicitado un amigo de la infancia, Bernardino Sánchez Vidal, que tenía en Madrid una clase particular de matemáticas. De nuevo, y en esta ocasión de forma todavía más acusada que con el Cálculo de variaciones, estos libros no aportaban nada nuevo a la matemática practicada en España. Se trata de dos colecciones de problemas, bastante elementales, resueltos. Así, en la "Advertencia» inicial de Problemas de geometría plana, Echegaray (1865 a) señalaba que había «reunido una colección de problemas en su mayor parte sencillísimos, enlazados en serie gradual, y cuya dificultad crezca lentamente... Los problemas que hoy publico son: $1 .^{\circ}$ Los que se proponen como ejercicios sin resolver en las geometrías de Cirodde y Legendre, modificada esta última por Blanchet... 2. ${ }^{\circ}$ Gran número de los problemas que se han propuesto en los exámenes públicos de admisión de la Escuela de Caminos en estos últimos años. $3 .^{\circ}$ Otros varios que sirven para enlazar ordenadamente los anteriores». En concreto, los temas estudiados eran: lugares geométricos; determinación de puntos y rectas, segmentos, líneas proporcionales; contactos de rectas y circunferencias, determinación de circunferencias; construcción de triángulos y polígonos; áreas; máximos y mínimos y problemas numéricos.

Si pasamos a Problemas de geometría analítica (Echegaray 1865 b), nos encontramos con que contiene problemas sobre tres temas: determinación de las coordenadas de un punto, determinación de los pará- 
José Echegaray: entre la ciencia, el teatro y la política

metros o constantes de una ecuación cuya forma analítica se conoce de antemano, y determinación de un lugar geométrico definido por ciertas condiciones.

$\mathrm{Y}$, a pesar de todo este en realidad escaso (contemplado desde nuestro punto de vista actual), bagaje científico, ese mismo año de 1865 (el 3 de abril), Echegaray era elegido miembro de la Real Academia de Ciencias Exactas, Físicas y Naturales, corporación que había sido creada pocos años antes, en febrero de 1847.

\section{Académico de Ciencias}

La propia elección de Echegaray como miembro de la Academia de Ciencias indica el escaso nivel científico que existía en la España de entonces (cuando menos, si medimos «desarrollo científico» en términos de "capacidad investigadora", o de contribuciones originales, aunque fuesen modestas, al avance de la ciencia). Ni siquiera se puede decir que Echegaray ya hubiese contribuido significativamente a introducir nuevas ideas matemáticas en España, aunque comenzaría a hacerlo enseguida (en el volumen XVI de la Revista de los Progresos de las Ciencias Exactas, Fisicas y Naturales, publicada por la Academia, correspondiente al año 1866, iniciaba la publicación de su Introducción a la Geometría superior, obra de la que me ocuparé más adelante; una simple ojeada a ese volumen basta para comprobar que los dos artículos de Echegaray eran de los pocos debidos a un autor español: la gran mayoría de los artículos que componen ese tomo de la Revista eran traducciones o noticias de trabajos de científicos extranjeros).

En 1865, cuando fue elegido para la Academia, de las 35 medallas de la corporación (a las que hay que añadir la de Echegaray) 10 estaban ocupadas por ingenieros, 7 por militares, 5 por médicos, 3 por farmaceúticos, 2 por astrónomos, 2 por físicos, encontrándonos, además, con un, respectivamente, arquitecto, profesor de Agronomía, catedráticos de Matemáticas, Fitografía y Geografía botánica, y Química, y un personaje polifacético, Vicente Vázquez Queipo. De todos éstos, los únicos con alguna eminencia en ciencias físico-matemáticas eran: Juan de Cortázar, catedrático de Complementos de álgebra y de Geometría analítica, Venancio González Valledor, catedrático de Física, Antonio Aguilar Vela, catedrático de Astronomía y director durante muchos años del Observatorio Astronómico, y Manuel Rico y Sinobas, catedrático de Física superior (todas las cátedras eran de la Universidad Central). En otras 
palabras, a pesar de que con nuestros criterios actuales no se pueda decir que Echegaray era un matemático verdaderamente notable por los años sesenta, en la Academia de Ciencias no desentonaba; probablemente todo lo contrario, si tenemos en cuenta el magnífico historial académico que podía exhibir. En cuanto a un posible despliegue de influencias para entrar en la Academia, Echegaray (1917, tomo II: 271) hizo notar en sus Recuerdos que fue «elegido espontáneamente, sin haberlo yo solicitado, sin haber hablado a nadie, sin ambicionarlo siquiera".

La medalla que ocupó en la Academia fue la número 6, perteneciente a la sección de Exactas, que había quedado vacante por la renuncia (basada en que vivía habitualmente fuera de Madrid) de Francisco Chacón y Orta, un brigadier del Cuerpo general de la Armada, autor de un Tratado de Física y Meteorología y de una obra sobre Máquinas de vapor y sus aplicaciones a la Navegación. La toma de posesión tuvo lugar el 11 de marzo de 1866 y su discurso de entrada versó sobre La historia de las Matemáticas puras en nuestra España, incluido en el presente volumen como «Documento I» ${ }^{59}$.

El discurso de Echegaray es importante por el papel que ha desempeñado en la denominada "polémica de la ciencia española" ${ }^{60}$. Brevemente expuesta, la tesis que defendió allí es que mientras que España ha tenido grandes literatos, artistas, militares, músicos, filósofos, navegantes y conquistadores, jamás ha tenido un matemático de categoría: «la ciencia matemática», declaraba Echegaray (1866: 28), «nada nos debe: no es nuestra; no hay en ella nombre alguno que labios castellanos puedan pronunciar sin esfuerzo».

Analizando el discurso desde un punto de vista historiográfico, el problema es que el nuevo académico manejaba un concepto muy estrecho de matemática; implícito en su exposición estaba el que matemática era únicamente lo que habían producido, creado, hombres como Pitágoras, Tartaglia, Descartes, Newton, Leibniz, Monge, Lagrange, Abel, Cavalieri, Euler, Fourier, Jacobi, Cauchy, Gauss, Galois, o similares. Evidentemente, si la matemática se pudiese reducir a tales términos, entonces se podría decir que, efectivamente, no había habido matemáticas en España, pero, naturalmente, la historia de una actividad, sea ésta la que sea, no se puede limitar a la historia de sus más distinguidos exponentes. Otra limitación del discurso es el de su pobreza de datos históricos, cuando no de flagrantes errores. Su tratamiento fue el de un matemático familiarizado con los clásicos de su disciplina, pero que no mostraba ningún conocimiento especial de la historia de la matemática en España -el tema del que se suponía estaba hablando-, más allá de que en ella 
nunca hubo un Newton, un Leibniz, o científicos de talla parecida. Este sería uno de los puntos al que se acogerían los muchos que, a lo largo de los años, se pararon con ojo crítico ante el discurso de Echegaray. El primero que lo comentó desfavorablemente fue Felipe Picatoste, profesor de Matemáticas en el Instituto San Isidro de Madrid, en un artículo que publicó anónimamente en el periódico Las Novedades el 17 de marzo ${ }^{61}$. Representativas de este artículo son las siguientes líneas:

«El señor Echegaray se ha propuesto por único tema demostrar que las ciencias nada deben a España; y aunque esto fuera cierto, aunque no tuviéramos una parte en muchos descubrimientos; aunque no hubieran existido siglos en que dábamos los libros de texto a toda Europa, en que los astrónomos y matemáticos venían a buscar aquí catedráticos para muchas universidades extranjeras; aunque nuestro nombre no hubiera figurado nunca en ciencias, y no tuvieran fama alguna en Academias de otros países Medina y Caramuel, Ciruelo y Chacón, Cibramonte y Ortega; aunque no hubiese hoy cierto espíritu de reacción favorable a España, que impulsa a Francia, a Inglaterra y a Bélgica a estudiar el pasado de nuestra ciencia; aunque no hubiese nada de eso, decimos, nos parece poco conveniente elegir a la Academia de Ciencias para hacer discursos de ese género, que serán remitidos a las demás Academias de Europa, llevando allí el propio descrédito».

No fue, ni mucho menos, el de Picatoste el único de estos artículos, pero no es mi intención desarrollar semejante tema, que nos llevaría a personajes como Manuel de la Revilla, Marcelino Menéndez y Pelayo, José del Perojo, Gumersindo de Azcárate, Gumersindo Laverde, Alejandor Pidal y Mon, José Augusto Sánchez Pérez o Julio Rey Pastor ${ }^{62}$. Muy brevemente, mencionaré, en primer lugar, una conferencia que pronunció en el Ateneo de Madrid el 15 de febrero de 1935, el matemático, historiador, novelista y periodista Francisco Vera ${ }^{63}$. En esa conferencia Vera, un magnífico historiador de la matemática en España ${ }^{64}$, pasaba revista a Los historiadores de la matemática española, dedicando bastante atención, y no pocas críticas, a Echegaray; su intervención constituyó un espléndido y sólidamente documentado (además de cruel en más de una ocasión) estudio para contrarrestar los puntos esgrimidos en el discurso de Echegaray ${ }^{65}$.

Es conveniente también citar unas palabras de Rey Pastor (1913: 8), que tal vez sirvan para comprender mejor el talante, las manifestaciones de Echegaray en su recepción en la Academia: «El discurso de Echegaray, discurso fogoso y brillante como todos los suyos, matizado de bellas imágenes y de símiles oportunos, se escribió en una época en la que la lucha de ideales políticos opuestos alcanzaba su período álgido; época que imprimió un sello especial a toda una generación casi ya desaparecida, la cual llena un período importante de la Historia de España; época más 
propicia para la vehemencia de la polémica, que para la serena calma del trabajo científico. Toda labor de entonces, caldeada al contacto con el medio ambiente, se convertía en arma de combate; y el discurso de Echegaray lo fue. En ocasión reciente procuraba justificarlo. "Cuando el suelo tiembla -decía- tiemblan los palacios y tiemblan las chozas"».

Aunque no trataré demasiado la cuestión de Echegaray el político, sí diré, en su momento, lo suficiente como para que se pueda apreciar que la explicación de Rey Pastor es bastante razonable. Por el momento basta con recordar, como apoyo al comentario de Rey Pastor, aquellas palabras del discurso de Echegaray (1866: 27) en las que señalaba que España no podría tener ciencia mientras no se conquistase en ella «la libertad filosófica, que es la libertad del pensamiento», concluyendo con amargura que la historia de la ciencia que estaba repasando, no era, ni podía ser, la de una nación en la que «no hubo más que látigo, hierro, sangre, braseros y humo». Todavía más claramente, en sus Recuerdos escribió: «Había exagerado yo esta nota... para deducir consecuencias de orden político» ${ }^{6}$.

Y a todo esto ¿qué opinaba, además de lo que acabo de señalar, el propio Echegaray de su discurso? Para contestar a esta pregunta continuaré recurriendo a sus Recuerdos ${ }^{67}$.

Para él, su recepción en la Academia de Ciencias «fue la primera batalla que reñí... Allí empezaron mis batallas y luchas en la vida, porque las anteriores en favor del librecambio eran, por decirlo así, colectivas... Tenía yo que escoger tema para mi discurso de recepción; y, después de pensarlo mucho, yo, que soy hombre pacífico, que no me gusta reñir con nadie... he ido metiendo ruido por todas partes y provocando luchas $\mathrm{y}$ conflictos, que odio y maldigo, pero que me cercan y me asaltan, bien contra mi voluntad... De suerte que entre los cien temas pacíficos que pude escoger, escogí uno que había de levantar tempestades en ciertos círculos, sobre todo entre los hombres de ciencia; que había de resultar antipático y hasta antipatriótico; que había de producir escándalo en la Academia y aún en la Prensa." Y pasaba a resumir el contenido de su discurso, recordando que como respuesta a la pregunta de «¿En qué consiste que no hayamos tenido grandes matemáticos?», había echado toda la culpa "al fanatismo religioso, a la Inquisición y sus hogueras, que habían ahogado los instintos científicos de los españoles ahumando sus cerebros con los gases desprendidos de los braseros inquisitoriales en los autos de fe.» Cerca de cuarenta años después, reconocía que, "pensándolo fríamente [esta] explicación no es completa ni es suficiente; pero en aquellos tiempos así lo creía y así lo dije." No obstante, con respecto al 


\section{José Echegaray: entre la ciencia, el teatro y la política}

conjunto de su discurso no dudaba en declarar: «A esta distancia de treinta y seis años, sin pasiones ni enojos, ni ideas preconcebidas, declaro que pienso hoy lo mismo que entonces pensaba: que patrióticamente me duele el no encontrar en la historia de la ciencia ni un gran matemático español; pero que no lo encuentro, ni lo encuentra nadie... Ahora bien: aún sosteniendo la tesis de mi discurso, hoy confieso que fué inoportuno e indiscreto.» En cuanto a los comentarios que suscitó su discurso, esto es lo que recordaba:

«Muchos artículos se escribieron en contra de mi discurso; pero sus autores, personas distinguidas y de mérito; y aún hubo, en tiempo posterior, un hombre eminente, gloria de la nación española, que también la emprendió conmigo a propósito del discurso en cuestión; ${ }^{68}$ todos ellos, repito, respetables y de cultura, eran incompetentes en materias matemáticas, y no podían combatirme más que con frases sonoras o con alardes patrióticos. La verdad es que los más competentes era dudoso que supiesen resolver una ecuación de segundo grado, ni iqué sabían ellos de los grandes problemas matemáticos! ${ }^{19}$

Yo contesté en el mismo tono del discurso a varios de estos artículos; y la polé mica se hubiera prolongado uno o dos meses, si graves acontecimientos políticos no hubieran distraído la atención del público y no hubieran alejado a la Prensa de esta clase de torneos científicos e históricos.»

Como he apuntado antes, Echegaray entró en la Academia ocupando una medalla, la número 6, de la sección de Ciencias Exactas; no permaneció mucho tiempo, sin embargo, en aquel puesto, ya que el 27 de enero de 1868 pasó a ocupar la medalla número 15, de la sección de Ciencias Físicas, sustituyendo a Venancio González Valledor. El motivo de este cambio lo explicó el propio Echegaray muchos años después, en 13 de diciembre de 1914, al contestar al discurso de ingreso en la Academia de Augusto Krahe. Dijo en aquella ocasión Echegaray (1914: 35-36):

¡Algo después [de entrar yo en la Academia] ocurrió una vacante en [ella], pero fue en la Sección de Ciencias Físicas; y yo deseaba vivamente, era para mí gran empeño de justicia y amistad, que ocupara un puesto entre nosotros, sin más dilaciones, aquel varón ilustre cuyo nombre nunca se pronuncia por los que le conocieron y ad miraron, sin profunda pena y nunca amortiguada veneración.

Bien comprenderéis que me refiero a don Eduardo Saavedra.

Deseaban todos mis compañeros, tanto como yo, que Saavedra fuese elegido sin esperar nuevas vacantes. Pero él, por entonces, se había dedicado más a las matemáticas puras que a las ciencias físicas, y prefería ingresar en la Sección de aquéllas, en vez de ocupar la vacante directa. Yo facilité la solución del pequeño con flicto académico, pasando a la Sección de Ciencias Físicas y dejando en la de Exactas puesto, para el cual, por unanimidad y con entusiasmo, fue elegido don Eduardo Saavedrai.

Para finalizar este apartado dedicado a Echegaray académico de Ciencias diré que participó activamente en la vida de la Academia: por 
un lado, con artículos en la Revista de los Progresos de las Ciencias y en la sucesora de ésta, la Revista de la Real Academia de Ciencias; contestando a discursos de entrada de muchos nuevos académicos (replicó a los de José Morer [1867], Eduardo Saavedra [1869], Manuel Fernández de Castro [1878], Gumersindo Vicuña [1883], José Rodríguez Carracido [1888], Alberto Bosch [1890], Amos Salvador y Rodríguez [1893], Francisco de Paula Rojas [1894], José Rodríguez Mourelo [1903], Blas Cabrera [1910] y Augusto Krahe [1914]); y, finalmente, presidiéndola desde 1901 hasta su fallecimiento en 1916 . Había sido vicepresidente varias veces (desde 1884 a 1886 , de 1890 a 1892 y de 1894 a 1896) y también presidente de la sección de Físicas.

\section{Introductor de nuevas ideas matemáticas}

Las obras matemáticas de Echegaray que he mencionado hasta el momento aportaban muy poco el panorama matemático español de la época en que aparecieron; eran, fundamentalmente, ayudas para el estudio de ciertas asignaturas. Pero tras su entrada en la Academia de Ciencias, sus aportaciones a la matemática española cambiaron de cariz, hasta el punto de hacer exclamar a Rey Pastor (1915: 15), tal vez algo exageradamente pero con argumentos: «Para la Matemática española, el siglo XIX comienza en 1865, y comienza con Echegaray.»

En realidad, 1865 es mal punto de partida; mucho más adecuado es 1866, el año en que comenzó a publicar en la Revista de los Progresos de las Ciencias Exactas, Físicas y Naturales sus trabajos sobre la geometría superior, que aparecerían en forma de libro el año siguiente con el título de Introducción a la Geometría superior (Echegaray 1867 a) ${ }^{70}$. En esta obra importaba a España el sistema geométrico de Michel Chasles, que por aquellos años gozaba de gran popularidad en Francia y que constituiría más tarde el punto de partida para la «revolución geométrica ${ }^{71}$, operada en España por obra de Eduardo Torroja (1847-1918), a la que también contribuyó, aunque con menos intensidad que Torroja y sus discípulos ${ }^{72}$, Zoel García de Galdeano, y en la que bastantes años más tarde también participaría el joven Rey Pastor ${ }^{73}$. Sobre la idea que el propio Echegaray (1867 a: 3) tenía de su contribución como iniciador de estos estudios, no queda la menor duda cuando se leen sus palabras: «En España desgraciadamente nunca se ha explicado esta materia, ni jamás se ha contado con ella en nuestros programas de enseñanza.» 
José Echegaray: entre la ciencia, el teatro y la política

En lo relativo a qué obras de Chasles había estudiado Echegaray -y cuándo lo había hecho-, tenemos sus Recuerdos, en los que señalaba (Echegaray 1917, tomo 1: 285) que había tomado contacto -cuando tenía "veintiocho o treinta años»-con las ideas de Chasles a través de dos de las obras de éste: el Traité de géometrie supérieure (1852) y el Traité des sections coniques $(1865)^{74}$.

La opinión que el propio Echegaray (1917, tomo 11: 290-291) tenía de su Introducción a la Geometría superior aparece en esos mismos Recuerdos; escribía allí:

«Trátase de un libro hecho con cariño, y me parece que las teorías están expuestas con suma claridad y por métodos que casi son míos, aunque después y en obras posteriores del extranjero he visto métodos análogos.

Nada tienen de maravilloso, ni exigen esfuerzo alguno, y en rigor están contenidas en las obras clásicas que yo estudiaba; pero de todas maneras me parecen muy apropiadas para la propaganda de la alta Geometría...

Mi libro se refería principalmente a los geómetras franceses; por ejemplo, Poncelet y Chasles."

Jean-Victor Poncelet (1788-1867), su maestro, el gran geómetra y administrador Gaspard Monge (1746-1818), la auténtica fuerza motriz en la creación y funcionamiento de la École Polytechnique de París ${ }^{75}$, y Michel Chasles, figuran entre los más destacados defensores del valor en la geometría de los métodos sintéticos (empleado, por ejemplo, por Newton) frente a los algebraicos y analíticos que dominaron esa rama de la matemática desde los tiempos de Descartes ${ }^{76}$. Es significativo, que estos tres matemáticos estuviesen ligados a la École Polytechnique, cuyo modelo siguió la Escuela de Caminos de Madrid. En realidad, el tipo de enfoque geométrico (intimamente ligado a la geometría descriptiva) utilizado por, en especial, Monge y Poncelet, tiene elementos que, independientemente de su indudable sofisticación matemática, le hacen natural, o conveniente, a científicos con intereses aplicados. Asimismo, existe una relación directa entre la fama de la École Polytechnique y el hecho de que la geometría, tan desarrollada y enseñada en esa Escuela, gozase en Francia del prestigio de que carecía en Alemania ${ }^{77}$.

Al discutir e introducir este tipo de problemas geométricos, Echegaray estaba tocando una de las áreas de la matemática que más -y, finalmente, de manera más original- se desarrollaron durante todo el siglo XIX; un área en la que, tras el impulso dado por los matemáticos franceses que acabo de citar, los trabajos (basados en planteamientos tanto sintéticos como analíticos, o, incluso, unificadores) de, entre otros, Augustus Möbius, Jacob Steiner, Julius Plücker, Christian von Staudt y Felix Klein, fueron protagonistas principales ${ }^{78}$. 
Después de su Introducción a la Geometría superior, Echegaray (1868 a) dio un nuevo paso en la introducción de nuevas teorías matemáticas en España con la publicación, en 1868, de su Memoria sobre la teoría de las determinantes. Una vez más, no se hacía demasiadas ilusiones con su libro, que se abre con la siguiente "Advertencia»: "Esta Memoria es un arreglo, y casi pudiera decir que una traducción libre de la parte elemental de la excelente obra del profesor Trudi. No conozco libro mejor escrito que el del profesor italiano: claridad, método, exactitud, todo lo reúne, y lo más a que puedo aspirar es a que en mi trabajo se refleje algo de las brillantes cualidades del original ${ }^{79}$.

La teoría de los determinantes, el más inmediato predecesor de la teoría de los invariantes, fue concebida originariamente por Leibniz, mejorada, entre otros, por Vandermonde en el siglo XVIII y por Cauchy en el XIX, y perfeccionada finalmente por Jacobi y Hesse ${ }^{80}$. El libro de Echegaray -en el que aparte de Trudi no se menciona a ningún otro matemático-constituye una exposición muy completa y clara de, como él mismo reconocía, las partes elementales de la teoría de los determinantes, un instrumento tan útil para la física, la matemática y la ingeniería que ya hace mucho tiempo que se estudia en los primeros cursos de esas carreras. Cumplió Echegaray, por consiguiente, una importante función, pero limitándose a lo más esencial; dejando al margen, por ejemplo, los resultados sobre divisores elementales que James Sylvester había obtenido en 1851, y que entroncaban directamente con la teoría de invariantes (en este caso de formas cuadráticas), que sería una de las áreas de investigación matemática preferentes a finales del siglo pasado y comienzos del $\mathrm{XX}^{81}$.

De hecho, aparentemente sus intenciones eran continuar tratando la teoría de los determinantes, preocupándose, por ejemplo, por sus aplicaciones. Así, un año después de la aparición del libro que acabo de citar, publicó en la Revista de los Progresos de las Ciencias un artículo titulado precisamente "Aplicación de las determinantes» (Echegaray 1869 a), en el que abordaba el tema de la "Resolución de un sistema de ecuaciones lineales», introduciendo lo que en la actualidad se denomina «Regla de Cramer». Este artículo estaba pensado como el primero de una serie, pero, por un motivo u otro, el caso es que su propósito inicial no prosperó. Merece la pena citar los primeros párrafos de este trabajo, ya que en ellos Echegaray se extendió algo más acerca de las fuentes de las que se nutría de lo que hizo en la Memoria sobre la teoría de las determinantes:

«Me propongo en estos artículos dar una sucinta idea de las principales aplicaciones de las determinantes. En cuanto a su teoría puede verse en varias obras elementales, entre las que merecen citarse las siguientes: el Álgebra de Laurent, el Álgebra superior de Serret, el Álgebra superior de Salmon. 
José Echegaray: entre la ciencia, el teatro y la política

También en la Revista de Obras Públicas se halla un extracto de la obra del profesor Trudi [los artículos que forman su Memoria sobre la teoría de las determinantes]. Los primeros capítulos del presente trabajo, son casi la traducción de la segunda parte de dicha obra, incomparable por su método y su claridad; para los restantes he consultado la teoría de las determinantes de Brioschi, y varias publicaciones alemanas."

\section{Político y dramaturgo}

Hasta ahora he estado refiriéndome únicamente al Echegaray ingeniero y científico, pero no es posible continuar sin mencionar otras facetas de su personalidad, otros intereses que coparon durante mucho tiempo gran parte de sus energías y que, aunque dan a su figura un inmenso atractivo, contribuyeron a limitar severamente sus aportaciones a las ciencias físico-matemáticas. Naturalmente, no es esta la ocasión de desarrollar semejante tema, así que me restringiré a unos breves comentarios, con el fin de hacer comprensible la trayectoria vital de Echegaray a partir de 1868 .

Ya desde su regreso a Madrid procedente de Almería, había comenzado a interesarse por temas alejados, al menos en principio, de las ciencias exactas. Así, entró en círculos dedicados a la economía política, defendiendo las ideas de la doctrina librecambista frente al proteccionismo imperante $^{82}$. En unión de Gabriel Rodríguez fundó en $1856 \mathrm{El}$ Economista, revista en la que escribió numerosos artículos, iniciando, de esta manera, una actividad periodística que no abandonaría a lo largo de toda su vida. Asimismo, participó en el establecimiento, en abril de 1859, de la Asociación para la Reforma de los Aranceles. Como consecuencia de estos intereses y relaciones pronunció discursos en las tribunas públicas de la Bolsa y el Ateneo ${ }^{83}$. En sus Recuerdos (Echegaray 1917, tomo II: 278) se refirió a este grupo de la manera siguiente: «El grupo librecambista no figuraba en ningún partido político imperante. Ni éramos progresistas, ni éramos demócratas. Simpatizábamos con unos y con otros, sobre todo con los demócratas: con Rivero, con Martos, con Castelar; pero sin reconocerlos como jefes; formábamos, como vulgarmente se dice, rancho aparte. En la Bolsa, nuestros jefes eran don Luis María Pastor, un antiguo moderado; Figuerola, progresista; Alcalá Galiano, moderado también. En el Ateneo formábamos fila con Castelar, con Paco Canalejas y con otros demócratas; pero conservando nuestra independencia ${ }^{84}$ ".

Al llegar la revolución de septiembre de 1868, conocida como «La Gloriosa» o la «Septembrina», nuestro hombre podía presumir de ser algo 
conocido -no demasiado- en algunos círculos políticos. "Yo era", escribiría muchos años después ${ }^{85}$, «revolucionario, pero teórico; y en la práctica, un revolucionario pacífico, que jamás tomó parte activa en ninguna conspiración ni en ningún trastorno... Amaba la revolución, porque amaba la democracia, en la región de las ideas; porque estaba profundamente convencido de que, en cuanto triunfasen en España la democracia y la revolución, el país forzosamente había de transformarse, o, por mejor decir, había de regenerarse... Abominando de todos aquellos Gobiernos [los anteriores a la revolución del 68], había respetado siempre la ley, había desempeñado a conciencia mis cátedras; y a lo más a que me había lanzado era a pronunciar discursos librecambistas en la Bolsa, o discursos democráticos en el Ateneo.»

Poco después de constituido el primer Gobierno, presidido por Prim, Manuel Ruiz Zorrilla, ministro de Fomento, nombró a Echegaray-que de los tres grandes partidos políticos de entonces, el Progresista, el de la Unión Liberal y el Demócrata, pertenecía a este último- director de Obras Públicas, Agricultura, Industria y Comercio; es decir, de todas las Direcciones del Ministerio de Fomento reunidas en una, con la excepción de la Dirección de Instrucción Pública. Se da el caso de que la Dirección a la que accedió dependía el Cuerpo de Ingenieros de Caminos, con lo que Echegaray -que en 1868 ocupaba el número doce en el escalafón de los ingenieros jefes de $\mathrm{V}$ clase- se encontró con que el Cuerpo al que pertenecía dependía de sus decisiones. De hecho, el primer proyecto con el que se tuvo que enfrentar como director de Obras Públicas fue el de la reforma de las Escuelas Especiales de Ingenieros Civiles, empezando por la de Caminos.

El siguiente proyecto que abordó fue el de bases para las obras públicas, proyecto que tuvo, según él, un "éxito extraordinario», con la consecuencia de que «desde aquel momento [resulté] ministrable... Tanto es así que, al terminar aquella campaña, yo, que nunca había sido político, que entre los políticos apenas tenía alguno que otro amigo; yo, que jamás pedí un distrito... me encontré con que se me ofrecían tres distritos, y al fin no pude negarme a dos de ellos;"; y algunos meses después salí diputado por Asturias y por Murcia» (finalmente optó por el distrito asturiano) ${ }^{86}$.

$\mathrm{Al}$ abrirse las Cortes Constituyentes, que habían de dar a España (el 6 de junio) la Constitución de 1869, Echegaray era, por consiguiente, diputado. Su primera intervención en la Cámara la realizó el 5 de mayo de aquel año (1869), y tuvo como asunto nada más y nada menos que la libertad religiosa, que él defendió en aquella ocasión con ardor, una cierta belleza y sin duda nobleza. «La libertad religiosa», manifestó entonces, 


\section{José Echegaray: entre la ciencia, el teatro y la política}

«es uno de esos derechos anejos al hombre; es uno de estos derechos que proceden de su naturaleza, que proceden de las grandes leyes de la sociedad, que no están sujetos al número; derecho tal, que aunque todos los españoles, menos uno, fueran católicos, y ese uno no fuera católico, ese, en virtud de su derecho, derecho soberano, superior a toda mayoría, podría decir, y tendría razón: "yo puedo adorar al Dios en quien creo de la manera que considere conveniente"... De esta manera, cuando yo con mi trabajo, cuando yo con mi fortuna, cuando yo con mi capital, con lo que es mío, levanto un templo, y dentro de ese templo adoro al Dios en que creo, aquel templo soy yo, aquel templo está protegido de todo embate exterior, proceda del hombre o proceda de las fuerzas colectivas, es decir, de la sociedad; está protegido, digo, por mi derecho; y lo que en ese templo pasa es como si pasase dentro de mí. En una palabra, señores, ese templo es mi conciencia exteriorizada, y si mi personalidad es digna de respeto, y si aquí, dentro de mí, mi conciencia es digna de respeto, lo es también ese templo y el culto que en ese templo doy yo al Dios que adoro" ${ }^{87}$. Como testimonio de algunas de las ideas políticas de Echegaray, el «Documento II» reproduce la transcripción de aquel su primer discurso en las Cortes de la nación, tal y como se publicó en el Diario de Sesiones de las Cortes.

Pronto (tras una crisis), Echegaray entró en el Gobierno, ocupando la cartera de Fomento, de la que tomó posesión el 15 de julio de 1869 y en la que permaneció hasta comienzos de 1871, cuando Amadeo de Saboya, Amadeo I, llegó a España (Echegaray fue uno de los que le recibieron en Cartagena). Sin embargo, no tardaría demasiado en volver a desempeñar la misma cartera: en el verano de 1872 entró en el que había de ser el último Gobierno del hijo de Víctor Manuel, gobierno presidido por Ruiz Zorrilla: ${ }^{8}$ "[Me] hice cargo de la cartera en el verano del 72 sin fe ni esperanza, porque la situación de España era muy difícil. Sublevación separatista en Ultramar, guerra carlista en la Península, los cantonales en puerta, el partido conservador profundamente agraviado y marcando sus hombres más salientes la evolución hacia don Alfonso, nuestro partido sin grandes entusiasmos por don Amadeo y la Hacienda en un estado lamentable» ${ }^{89}$.

A raíz de la abdicación, en febrero de 1873, de Amadeo, a quien el asesinato de Prim (el 28 de diciembre de 1870) había privado de su principal valedor, el poder legal quedó en las Cortes, que se constituyeron en Asamblea Nacional. Esta Asamblea fue la que proclamó, el 11 de febrero de 1873 y por 258 votos contra 32, la Primera República española. Cuando en junio se reunieron las Cortes Constituyentes, con mayoría de re- 
publicanos federales, se nombró una comisión permanente de la que también formaba parte Echegaray. Precisamente por su participación en aquella comisión, se vio obligado, en la confusión y conflictos de aquellos meses y por motivos de seguridad, a abandonar España. Marchó a París, en donde permaneció seis meses. Fue allí en donde escribió El libro talonario, una comedia de un acto que se estrenó, con su autor ya otra vez en Madrid, en la primavera de 1874, y que significó el inicio de su carrera como dramaturgo ${ }^{90}$. Esa carrera le llevó a la Real Academia Española, en la que entró en 1894 ocupando el sillón e. Para recordar este hecho, y también la dimensión literaria de Echegaray, el «Documento III» reproduce su discurso de entrada en la Docta Casa.

Aunque no es mi intención intentar siquiera entrar en este dominio de las actividades de Echegaray, el que más fama y beneficios materiales le reportó, para no dejar completamente en blanco esta faceta citaré a continuación unos pasajes de un fino y sagaz comentario que el crítico Enrique Díez-Canedo publicó en el diarío El Sol el 1 de octubre de 1930 a raíz de la reposición en el teatro Calderón de Madrid de El gran galeoto: ${ }^{91}$ «El gran galeoto nos parece hoy mucho más lejano que las comedias del siglo XVII», escribía Díez-Canedo. «Es la moda de ayer», continuaba, "caída en desuso y no consagrada aún por el tiempo. Echegaray, hombre de vigoroso ingenio, puso en este drama la trágica cifra de su destino. Aún no abandonaba el verso, que le negó siempre su íntima esencia, y que aceptaba como legado del romanticismo; y cuando al fin cambió por una prosa más directa y expresiva, no llegó a dar con un tema tan dramático como el que en $E l$ gran galeoto adquiere forma y sentido. Lo peor de El gran galeoto es el verso, que va de una fórmula a otra por un aire pedregoso de ripio y relleno, y que da a la acción, sacudida y forzada, un aire convulsivo que casi malogra la idea del drama. En él, sin embargo, tocó Echegaray, fuera ya de las pseudolegendarias ficciones en que el romanticismo se entrega a sus últimos delirios, y atento a un latido de humanidad, su más amplio tema: la mentira difusa, engendradora de la verdad concreta». Y concluía: «Cincuenta años se cumplirán en marzo del año próximo... del estreno de $E l$ gran galeoto. Si hoy vemos claramente sus defectos de gran bulto, aún sentimos por él, con la fuerza de las situaciones violentamente procuradas por el autor, que sin embargo, en la palabra no perdona rodeo - y aun en el título nos da muestras de eufemismo, y en el cuerpo del drama, al insinuar, hasta por medio del consonante, la recia palabra española que cuadraría al asunto-, aún sentimos, digo, en el drama, el aletazo de la ráfaga que conmovió a sus primeros espectadores.» 
José Echegaray: entre la ciencia, el teatro y la política

Después del golpe de Estado -el 3 de enero de 1874- del general Pavía, que llevaría a la disolución de la primera República ${ }^{92}$, el general Serrano ocupó la jefatura del ejecutivo y Echegaray fue nombrado ministro de Hacienda en representación del partido radical. A los tres meses, sin embargo, dejó la cartera. Poco tiempo, pero en su haber hay que señalar un logro importante: el dar al Banco de España estructura de banco nacional; en particular, concederle el monopolio de la emisión de dinero ${ }^{93}$. De los propósitos de Echegaray cuando procedió a tal «recreación» (con la que, incidentalmente, traicionaba sus antiguos ideales librecambistas) dan idea los siguientes párrafos de la parte expositiva del correspondiente decreto (de 19 de marzo de 1874), en el que no puede pasar desapercibida la vena literaria de su autor: «abatido el crédito por el abuso, agotados los impuestos por vicios administrativos, esterilizada la amortización por el momento, forzoso es acudir a otros medios para consolidar la deuda flotante y para sostener los enormes gastos de la guerra... En tan críticas circunstancias... el ministro que suscribe se propone crear un Banco Nacional, nueva potencia financiera que venga en ayuda de la Hacienda Pública.» Como testimonio el «Documento IV» reproduce el texto del discurso que Echegaray pronunció en el Senado el 8 de mayo de 1902 contribuyendo al debate que estaba teniendo lugar sobre un proyecto de circulación fiduciaria, y que aprovechó para recordar algunos aspectos de su participación en la creación del Banco de España ${ }^{94}$.

La situación del país era, efectivamente, caótica. España se encontraba en el último episodio de la guerra carlista, que tardaría todavía algunos años en finalizar ${ }^{95}$. En Cuba se luchaba contra los insurrectos, que no depondrían las armas hasta 1878. En semejante coyuntura, los apuros financieros del Gobierno eran apremiantes; había que conseguir fondos para la exhausta Hacienda hispana y no se encontraba quien quisiera prestarla dinero: el Banco de España iba a cumplir esta función prestamista $^{96}$.

La circulación fiduciaria única, esto es, la concesión del monopolio de emisión de dinero al nuevo banco nacional, privando de este privilegio a los catorce o quince restantes bancos emisores que funcionaban en el país al amparo de la ley de 1856, fue desarrollada en un decreto que apareció, firmado también por Echegaray, el 24 de marzo ${ }^{97}$. Semejante monopolio era, en realidad, una condición casi imprescindible, o por lo menos conveniente, para fortalecer suficientemente al Banco de España, y para que así pudiese cumplir los fines que se proponía. De hecho, al dar aquel paso Echegaray estaba siguiendo la pauta marcada hacía ya tiempo por naciones como Gran Bretaña (Escocia aparte) o Francia. 
632

Una vez fuera del Gobierno, Echegaray se dedicó cada vez con mayor intensidad al teatro, en el que brilló con luz propia. De hecho, en 1904 se le concedió el premio Nobel de Literatura, compartido con el poeta provenzal Federico Mistral. Fue, en consecuencia, el primer español en recibir tan preciado galardón (Santiago Ramón y Cajal sería el segundo: lo recibió -el de Fisiología o Medicina- en 1906). Nunca, sin embargo, abandonó la política y el mundo que la rodeaba por completo. En 1876, todavía boyante su espíritu progresista, figuró entre los socios accionistas fundadores de la Institución Libre de Enseñanza ${ }^{98}$. El 1 de abril de 1880 firmó, junto con Martos, Salmerón y otros, el manifiesto del que nació el partido republicano progresista. Otra intervención célebre suya fue el discurso que pronunció el 10 de noviembre de 1898 en el Ateneo de Madrid (del que era presidente desde el 23 de junio de aquel año), titulado «¿Qué es lo que constituye la fuerza de las naciones?» (Echegaray 1898). Expuso allí los medios que creía necesarios para la regeneración del país. También fue durante algunas legislaturas diputado por el distrito de Quintanar de la Orden. Ocasionalmente ocupaba alguna tribuna pública para pronunciar conferencias: en el curso 1879-1880, por poner un ejemplo, dictó una en el Círculo de la Unión Mercantil, titulada "Aplicación de las fuerzas naturales a la industria y al comercio" (Echegaray 1881) ${ }^{99}$. Después de que se le concediese el premio Nobel, y siendo ya una figura mítica, aceptó, en 1905, el ofrecimiento de Eugenio Montero Ríos para ocupar, por poco tiempo, la cartera de Hacienda. Obviamente, por entonces sus anteriores fervores republicanos habían decaído considerablemente (como tantos de sus correligionarios del 68, Echegaray terminaría aceptando sin mayores problemas la Restauración). También fue senador vitalicio, presidente del Consejo de Instrucción Pública y, en 1908, director de la Compañía Arrendataria de Tabacos y Timbre.

\section{Más matemáticas}

Una de las facetas de Echegaray que más admiración producen es la de su capacidad de simultanear su aficción por las matemáticas con otros intereses. Acabamos de ver, por ejemplo, como su vida sufrió un cambio radical a partir de $1868^{100}$, y, no obstante, continuó estudiando y efectuando contribuciones al conocimiento de la matemática en España. Una de esas contribuciones (en realidad varias, ya que inicialmente fueron artículos en la Revista de los Progresos de las Ciencias, volúmenes XXI y XXII) fue la monografía que publicó en 1887: Disertaciones matemáticas 


\section{José Echegaray: entre la ciencia, el teatro y la política}

sobre la cuadratura del círculo. El método de Wantzel y la división de la circunferencia en partes iguales (Echegaray 1887).

Uno de los pocos problemas (data de al menos los tiempos de Anaxágoras, circa 460 a. C.) cuya fama ha traspasado los límites de las matemáticas, digamos profesionales, ha sido el de la cuadratura del círculo; más concretamente, el de si es posible construir, utilizando únicamente un compás y un cartabón, un círculo cuya área sea igual a la de un cubo. Este problema fue el que abordó Echegaray en la publicación que acabo de citar, pero antes de pasar a ese trabajo es conveniente explicar algo de la historia del problema.

Comenzaré refiriéndome a los números racionales (cocientes de números enteros) ${ }^{101}$. Los racionales son siempre raíces de una ecuación lineal del tipo $\mathrm{ax}+\mathrm{bx}+\mathrm{c}=0$, donde $a, b$ y $c$ son enteros. Ahora bien, es obvio que ecuaciones de este tipo son muy poco generales; están también, por ejemplo, los números irracionales, que no son soluciones de esas ecuaciones. Desde Euclides se sabía que las raíces de una ecuación cuadrática, $a x^{2}+b x+c=0$, donde $a, b$ y $c$ son múltiplos enteros de una longitud dada, se pueden construir geométricamente con regla y compás (método euclídeo). Por otra parte, están las más generales ecuaciones de la forma $a x^{n}+b x^{n-1}+\ldots+p x+q=0$. Las raíces de una ecuación algebraica como ésta, siendo $n>0$, reciben el nombre de "números algebraicos», y como todo número racional es raíz de una ecuación de ese tipo con $n=1$, surge de manera natural la cuestión de si todo número irracional será o no raíz de una ecuación de esa forma, para algún $n$ mayor o igual que 2. En 1844 Liouville construyó una amplia clase de números reales no algebraicos, contestando de esa manera negativamente a la anterior pregunta. A los números reales no algebraicos se les denomina "números trascendentes".

Demostrar que un número real concreto, tal como $e o \pi$, es trascendente, es muy difícil. Siguiendo el camino abierto por Liouville, Hermite consiguió demostrar en 1873 que $e$ no podía ser raíz de ninguna ecuación polinómica con coeficientes enteros; es decir, que era trascendente. El problema con el número $\pi$ resultó más difícil. Lambert en 1770 y Legendre en 1794 habían demostrado que $\pi$ y $\pi^{2}$ son irracionales, pero esta demostración no puso término a la vieja cuestión de la cuadratura del círculo; quedaba por demostrar la trascendencia de $\pi$, porque en ese caso $\pi$ no sería raíz de una ecuación de segundo grado y, por consiguiente, no se podría construir con regla y compás. Fue Ferdinand Lindemann quien, en una memoria publicada en los Mathematische Annalen en 1882, bajo el título «Über die Zahl $\pi$ » («Sobre el número 70 ), demostró

- niventemente que $\pi$ era un número trascendente. 
634

Pues bien, cuando se intenta precisar la fecha exacta en que llegó a España la noticia del descubrimiento de la trascendencia de $\pi$, o de la imposibilidad de la cuadratura del círculo, se observa que -como señaló Rey Pastor (1915)- antes de 1886 se encomía por todos la dificultad de la cuadratura, que se consideraba como "descomunal empresa». Así, nada menos que en el Anuario de la Academia de Ciencias de Madrid Miguel Merino (1885) afirmaba en 1885 que, desgraciadamente, no era posible «tomar resolución alguna que aparte la turba de los cuadradores del círculo", como habían hecho algunas corporaciones extranjeras, teniéndose que resignar «a examinar con paciencia cuantas singularidades se les ocurra presentar» ${ }^{102}$. "Nos encontramos tan atrasados», señalaba otro académico, esta vez nada menos que Eduardo Saavedra (1885), «que en realidad no se puede contestar en nombre de la Ciencia, que cierto número de investigaciones sea totalmente absurdo".

Esta era la situación cuando Echegaray publicó un artículo, «Sobre la imposibilidad de la cuadratura del círculo», en el volumen correspondiente (el XXI) a 1886 de la Revista de los Progresos de las Ciencias, artículo que abre la obra Disertaciones matemáticas (Echegaray 1887). Un dato a tener en cuenta con relación al artículo de Echegaray en que éste no leyó el trabajo de Lindemann: "Como a pesar de mis deseos y de mis esfuerzos", escribió, "no he podido ver la Memoria original del insigne matemático, he tenido que limitarme a sospechar lo que su demostración podrá ser; aclaración que importa, para que el lector sepa a qué atenerse, y que importa además, porque la materia es un tanto sutil y sobre ella no se ha dicho la última palabra» ${ }^{103}$.

Echegaray supo acerca de la investigación de Lindemann a través del tomo 1 de la $5^{\text {a }}$. edición del Tratado de Geometría de Rouché y Comberousse ${ }^{104}$, en el que no aparecía con todo rigor la demostración de Lindemann, de ahí que su contribución fuese realmente una reconstrucción. En medio de sus intensos trabajos literarios de aquellos años, Echegaray daba, de verdad, acaso por primera vez, talla de matemático. A pesar de no haber podido acceder al artículo de Lindemann, no fue la suya una contribución original (jamás fue, repito una vez más, un matemático original, creativo), pero no importa, se había acercado más que nunca a las investigaciones de la matemática de su tiempo. Es comprensible, aunque un tanto exagerado, por consiguiente, que Rey Pastor (1915: 11-12), que siempre demostró tener una especie de predilección por Echegaray ${ }^{105}$, exclamase años más tarde: «en todas las regiones de la Ciencia... a cada idea o hecho nuevo, corresponde una fecha y un nombre propio; como a cada nueva estrella y a cada cometa, va inseparablemente unido el nom- 
José Echegaray: entre la ciencia, el teatro y la política

bre de su descubridor en los cielos. En la esfera mucho más modesta de la historia científica de un país, le corresponden también dos coordenadas geográficas que determinan su introducción en él; y en este ejemplo, son: una fecha, 1886, y un nombre: Echegaray.»

En lo referente al resto de Disertaciones matemáticas, lo más destacable es la explicación que daba Echegaray de algunos teoremas desarrollados por Pierre L. Wantzel en el Journal de Liouville en 1837, y que eran necesarios para la demostración de Lindemann.

\section{Echegaray, el Ateneo y la teoría de Galois}

La siguiente obra matemática importante de Echegaray me obliga a efectuar algunos comentarios sobre una institución a la que, como ya apunté antes, el polifacético don José estuvo ligado: el Ateneo Científico y Literario de Madrid ${ }^{106}$. Fundado (con 329 socios) en 1835, el Ateneo era una Sociedad científica, literaria y artística con el triple carácter de Academia, Escuela de Estudios Superiores y Círculo Literario (de hecho también se convirtió en una de las principales tribunas de la vida política española). Como Academia inicialmente se dividió en tres secciones, pasando en 1884 a cuatro: Ciencias Morales y Políticas, Ciencias Naturales, Ciencias Matemáticas y Literatura y Bellas Artes (en 1894 se aumentaron hasta seis). En estas secciones se leían y discutían trabajos considerados de interés y actualidad por los ateneístas. Echegaray, un ateneísta destacado (ya indiqué que llegó a ser presidente de la institución, en 1898-1899), participó tanto en los debates políticos y culturales que se celebraron allí, como en cursos que se organizaron ${ }^{107}$. Únicamente me ocuparé de estos últimos aquí.

Siendo una de las funciones del Ateneo la de actuar como Escuela de Estudios Superiores, muchos de los personajes más prestigiosos de España, en las ciencias, las letras y las artes, explicaron temas avanzados en sus aulas, especialmente a finales del siglo XIX. Segismundo Moret (presidente del Ateneo en 1884-1886 y 1899-1913) resumió de la siguiente manera lo que se pretendía con esta Escuela de Estudios Superiores, en el discurso que pronunció al inaugurarse la misma en 1896:

«El carácter de la enseñanza oficial es el exclusivamente destinado para la vida práctica, para el resultado inmediato, para obtener un título académico y ejercer una carrera, pero el cultivo de la ciencia por la ciencia es raro y difícil, y más en nuestro país.

Sin perjuicio de que más adelante se llegue a los estudios monográficos, es decir, de aplicación y de aspectos particulares de las diversas ciencias, estas enseñanzas 
han de ser sintéticas, encaminadas a completar, equilibrar y organizar los conocimientos de la generación actual, y para lograrlo han de abarcar todo lo que se enseña, y enlazarse con todas las escuelas y centros en que de alguna manera se prepara a la juventud. Es preciso que todo hombre que piense y sepa algo encuentre aquí atractivo y llamamiento, y vea que por su cooperación en esta obra le es fácil lo que ha sido imposible aun a grandes personalidades por su solo esfuerzo individual: influir en la dirección de la cultura de su época, en cuya amplia esfera comprende, naturalmente, las Universidades y Escuelas de provincia, las cuales, más aún que las que en $\mathrm{Ma}$ drid radican, necesitan se las llame y traiga a este Centro Superior, pidiendo a cuantos fuera de la capital cultivan la ciencia, su valiosa cooperación.»

Leopoldo Alas, Adolfo Álvarez Buylla, Gumersindo Azcárate, Ignacio Bolívar, José Canalejas, Manuel Bartolomé Cossío, Joaquín Costa, Zoel García Galdeano ${ }^{108}$, Eduardo Hinojosa, José Marvá, Marcelino Menéndez y Pelayo, Ramón Menéndez Pidal, el propio Moret, Emilia Pardo Bazán, Santiago Ramón y Cajal, José Rodríguez Carracido, José Rodríguez Mourelo, Eduardo Saavedra ${ }^{109}$ y Luis Simarro, aparte, naturalmente, de Echegaray, figuran entre los que dictaron cursos en aquella Escuela entre 1896 y $1902^{110}$.

Echegaray fue uno de los que comenzaron a dictar cursos al abrirse la Escuela. Como tema eligió el de "Resolución de las ecuaciones de grado superior y teoría de Galois». Aquel curso (1896-1897) el interés que despertó la iniciativa fue considerable, registrándose cifras de matrícula muy elevadas: el más numeroso fue el curso de Emilia Pardo Bazán, para el que se apuntaron 825 personas, pero también nos encontramos con que a los cursos de, por ejemplo, Cajal, Simarro, o Gumersindo de Azcarate asistieron, respectivamente, 221, 167 y 243 alumnos. En cuanto al curso de Echegaray, la matrícula fue 122 (cifra increíblemente alta, dada la temática abordada), y el número de lecciones dictadas $21^{111}$.

Augusto Krahe (1916: 480), que asistió a aquel curso, describió, años más tarde, cómo fue evolucionando la asistencia al mismo:

«Con las conferencias tuvo más de una desilusión. A don José, como es de suponer, le gustaba reunir público numeroso y entendido; al principio vio colmados sus deseos. De los numerosos asistentes a sus primeras lecciones tan sólo una mínima parte podía seguir sus explicaciones con fruto; pero el resto de los asistentes, que creían, sin duda de buena fe, que con los recuerdos de lo que estudiaron en la segunda enseñanza y la mágica palabra de Echegaray iban a salir gratis y cómodamente de las conferencias, con más sapiencia en substituciones que el propio Camilo Jordan, se desengañaron pronto y abandonaron al maestro. A éste, si bien le escoció la huida, no le abatió, pues con el mismo brío juvenil que arremetió en la primera lección, dio fin a la última.

A sus conferencias finales asistían ocho o diez personas, entre las cuales estaban León y Ortiz, el general Benítez, Amós Salvador, Octavio de Toledo y el querido amigo Juan V. Alonso." 


\section{José Echegaray: entre la ciencia, el teatro y la política}

El siguiente curso (1897-1898) Echegaray continuó con el mismo tema, aunque la cifra de estudiantes con que contó fue ya más razonable, 32 , siendo 23 las lecciones dictadas (en general todos los cursos vieron reducidos drásticamente el número de asistentes). El año siguiente (18981899) el interés se apagó considerablemente, y no sólo en número de alumnos, sino también en cursos impartidos (16 frente a 28 el año anterior). Esa vez Echegaray varió de tema, abordando el de «Estudio de las funciones elípticas» (tuvo 24 alumnos y dio 14 clases), con el que prosiguió el curso siguiente. De hecho, continuó ocupando una cátedra en la Escuela Superior del Ateneo todos los años hasta el curso 1904-1905 ${ }^{112}$, en el que eligió el tema de «Ecuaciones diferenciales en general y, en particular, las lineales». A partir de entonces, sus cursos en la Facultad de Ciencias de la Universidad Central, como nuevo catedrático de Física matemática, absorberían sus energías didácticas. Pero queda claro, de los anteriores comentarios, que durante unos cuantos años fueron las tribunas del Ateneo las que le permitieron, alejado como estaba desde hacía mucho tiempo de las aulas de la Escuela de Caminos, continuar su labor docente en matemáticas.

En al menos una ocasión Echegaray (1904: 137) se refirió a sus cursos en el Ateneo, mencionando algo del carácter que les quiso dar, así como de su contenido:

«Hace bastantes años que vengo explicando en el Ateneo de Madrid y en las clases de estudios superiores, una serie de lecciones sobre teorías matemáticas, que son, al mismo tiempo, de altas matemáticas, y de propaganda.

De altas matemáticas, porque en dichas lecciones me ocupo en problemas de orden superior; y de propaganda, porque parto siempre de los conocimientos que pueden adquirir los jóvenes en nuestras Universidades y en nuestras escuelas especiales.

Es un trabajo, por decirlo así, de transición, entre lo elemental y lo más elevado de la Ciencia.

En esta serie de cursos, he explicado las materias siguientes: la teoría de las substituciones y los métodos de Galois; las funciones elípticas, desde los trabajos de Legendre hasta los métodos modernos de Weierstrass; la teoría de las funciones abelianas; y en el curso anterior, empecé el estudio de la integración de ecuaciones diferenciales, ocupándome únicamente en el de la ecuación $\mathrm{dy} / \mathrm{dx}=\mathrm{X}(\mathrm{x}, \mathrm{y}) . »$

Pasemos ahora a los cursos que Echegaray dedicó a la «Resolución de ecuaciones de grado superior y teoría de Galois» y a las «Funciones elípticas» (el de "Integración de ecuaciones diferenciales» es menos interesante, y, además, no parece que lo desarrollase mucho) ${ }^{113}$. Comenzaré por el primero, que el propio Ateneo publicó en dos volúmenes con el título de Resolución de ecuaciones y teoría de Galois (Echegaray 1897 a, 1898-1902) ${ }^{114}$.

El problema de la resolución algebraica de ecuaciones figura entre los más antiguos de la matemática. Desde los inicios del álgebra moderna se 
desarrollaron varios métodos para resolver ecuaciones de hasta cuarto grado (los trabajos de, entre otros, Diofanto, Tartaglia, Cardano, Ferrari, Descartes, Gauss o Vandermonde), pero tales procedimientos, en general aislados entre sí y basados en artificios de cálculo, difícilmente podían ser considerados como constituyentes de una teoría ${ }^{115}$. Más profundas, sino por los problemas que resolvieron en una primera instancia, sí por los caminos que abrieron, fueron las ideas y contribuciones de Lagrange $^{116}$. A lo más que pudo llegar el gran matemático francés fue a argumentar que la solución de ecuaciones generales de grado superior a 4 $(n>4)$ mediante operaciones algebraicas era probablemente imposible. No obstante el poco éxito conseguido por Lagrange en respuestas definitivas, el método que empleó iluminó los motivos por los cuales se podía resolver el problema para $n<4$ y $n=4$ y no para $n>4$; tal contribución fue importante para Abel y Galois. Además, la idea de Lagrange de que se debe considerar el número de valores que toma una función racional cuando se permutan sus variables, conduciría posteriormente a la teoría de los grupos de permutación o sustitución.

Sería Niels Henrik Abel (1802-1829) ${ }^{117}$, «el Newton del Norte» como le denominó Echegaray (1905 b, 1910 a), quien demostraría que es imposible resolver algebraicamente, por radicales ${ }^{118}$, las ecuaciones generales de quinto grado ${ }^{119}$. Buscando cuales son las ecuaciones particulares susceptibles de ese tipo de resolución, Abel (1829) obtuvo, asimismo, una clase de ecuaciones que hoy llevan, a propuesta de Kronecker, su nombre: abelianas.

Los resultados de Abel no fueron sino el preludio de unos descubrimientos más importantes para la teoría de la resolución de ecuaciones, descubrimientos que asentarían esa teoría sobre una base definitiva. Me estoy refiriendo a la obra de Evariste Galois (1811-1832).

Lo que Galois se propuso fue desarrollar la teoría general de las ecuaciones algebraicas que pueden ser resueltas por medio de ecuaciones auxiliares de grado menor. Galois (1846) se dio cuenta, y este es el punto capital de sus investigaciones, de que este difícil problema está regido en cada caso particular por un cierto grupo de sustituciones, en el cual se reflejan las propiedades más importantes de la ecuación algebraica considerada. Este descubrimiento, que los sucesores de Galois, y en particular Camille Jordan (1870), esclarecerían y desarrollarían, tiene consecuencias que afectan a un área más vasta de la matemática que la teoría de resolución de ecuaciones. Como señaló Sophus Lie (1895): «El gran alcance de la obra de Galois se deriva de este hecho: que su teoría, tan original, de las ecuaciones algebraicas es una aplicación sistemática de 
dos nociones fundamentales como son la de grupo e invariante... la noción de invariante es evidente en los trabajos de Vandermonde, Lagrange, Gauss, Ampère y Cauchy. Por el contrario, es Galois el primero, me parece, que introdujo la idea de grupo; y en todo caso, él es el primer matemático que ha profundizado en las relaciones existentes entre las ideas de grupo y de invariante.»

Pasando ya al curso de Echegaray en el Ateneo, es preciso señalar, en primer lugar, que en él nuestro polifacético ingeniero de Caminos estaba plasmando intereses que se remontaban a bastantes años atrás: como mínimo a 1866. En efecto, el 15 de noviembre de aquel año apareció en la Revista de Obras Públicas (tomo XIV, pp. 261-264) un artículo titulado "Sobre la reforma de la Facultad de Ciencias y de las Escuelas especiales», que aunque no iba firmado se debía claramente a su pluma. En aquel trabajo, una dura crítica a un R. D. de 22 de octubre en el que se reformaba la enseñanza en la Facultad de Ciencias y en las Escuelas especiales, Echegaray hacía referencia explícita al área de la matemática que treinta años después iba a explicar en el Ateneo:

“¿Dónde está en el programa de la Facultad de ciencias una clase de Álgebra superior como la que -no ya hoy, sino dieciocho años ha-explicaba brillantemente Mr. Serret en la Sorbonne?

En la Facultad no aparece esta clase, porque no lo es, ni puede serlo, lo que en la Gaceta del día 22 se llamaba CLASE DE ÁLGEBRA, y de COMPLEMENTO DE ÁLGEBRA en la del 24. Esta asignatura titulada complemento de Álgebra será, cuando más, teoría general de ecuaciones con la extensión de las obras elementales; pero no comprenderá la teoría de los determinantes, ni las congruencias, ni las factoriales, ni la teoría de las sustituciones, ni los trabajos de Abel, Galois, Hermite y tantos otros geómetras.»

Otro punto preliminar que conviene mencionar es que aunque Echegaray fue, con la publicación de su curso del Ateneo, el primer español en dedicar una obra que, independientemente de sus limitaciones, desarrollaba de manera sistemática una parte importante de las investigaciones de Galois, no es cierto que antes de él no se hubiese hablado de ellas en España (y olvidándonos ahora del artículo de la Revista de Obras Públicas que acabo de mencionar). Frente a la opinión de Rey Pastor (1916: 11), que llegó, a decir que «Echegaray trajo las obras de Serret, Salmon, Jordan...", hay indicios suficientes como para manifestar que la obra de Galois (y de algunos de sus sucesores) ya había atraído la atención de matemáticos españoles antes del curso de Echegaray en el Ateneo. En su breve pero elegante Las modernas generalizaciones expresadas por el Álgebra Simbólica, las Geometrías no-euclideas y el concepto de hiper-espacio, Zoel García de Galdeano (1896: 48-49), que ya en su Tratado de Ál- 
gebra de 1886 y en su Crítica y síntesis del Álgebra de 1888 había citado el teorema de Galois, escribía después de enunciar, una vez más, ese teorema:

«y con el fin de no prolongar estas indicaciones harto conocidas respecto á la teoría edificada por Lagrange, Abel y Galois sobre las ecuaciones, sólo recordaremos que, establecidas por Abel las condiciones de resolubilidad, Galois llegó á emplear su método de la adjunción sucesiva de raíces de ciertas ecuaciones que, reduciendo el grupo de la ecuación propuesta, conduce a su resolución por medio de radicales.

Nuestro propósito al enumerar estos trabajos reunidos en la obra magistral de $\mathrm{M}$. Camille Jordan, Traité des substitutions et des équations algebriques, y de los que han hecho recientemente elegantes resúmenes los señores Borel y Drach en su Introduction á l'étude de la théorie des nombres et de l'Algébre supérieure, y el señor Vogt en su obra Leçons sur la résolution algébrique des équations, no es otro que el señalarlos como precedentes de las importantes investigaciones del sabio matemático noruego Herr Sophus Lie... a las que deben unirse las del eminente geómetra F. Klein "120.

Para analizar, aunque sea someramente, el contenido de Resolución de ecuaciones y teoría de Galois es preciso dar más detalles acerca de los resultados obtenidos por Galois; en concreto, sobre su memoria «Sur les conditions de résolubilité des équations par radicaux ${ }^{121}$. En este trabajo se ve que el proceso a través del que Galois llegó al resultado según el cual «para que una ecuación irreducible, de grado primo ${ }^{122}$, sea resoluble por radicales, es necesario y suficiente que, conocidas dos cualesquiera de sus raíces, las demás puedan expresarse racionalmente en función de ellas", pasaba por la obtención de varios resultados preliminares. El primero era el que Echegaray denominó «teorema de Galois», aunque el propio matemático francés señalaba en su artículo que había sido citado sin demostración por Abel en su memoria póstuma sobre las funciones elípticas $^{123}$. Mientras que Galois incluía este resultado, en forma de cuatro lemas, en la primera parte de su artículo "Sur les conditions...», Echegaray llegaba a él en la lección decimoséptima de las veinte que comprende el primer volumen de sus cursos ${ }^{124}$. El enunciado que el español dio allí del teorema de Galois es el siguiente:

«Supongamos una ecuación cualquiera del grado $n$, $\mathrm{x}^{\mathrm{n}}+\mathrm{p}_{1} \mathrm{x}^{\mathrm{n}-1}+\mathrm{p}_{2} \mathrm{x}^{\mathrm{n}-2}+\ldots+\mathrm{p}_{\mathrm{n}}=0$

ecuación que, para abreviar, representaremos por $\mathrm{f}(\mathrm{x})=0$. Supondremos expresamente que sus raíces son todas desiguales, $\mathrm{y}$ las designaremos por $\mathrm{x}_{,}, \mathrm{x}_{2}, \ldots, \mathrm{x}_{\mathrm{n}}$.

Formemos una función, $V$, de estas raíces, función que supondremos racional y que designaremos por $\mathrm{V}=\varphi\left(\mathrm{x}_{,}, \mathrm{x}_{2}, \ldots, \mathrm{x}_{\mathrm{n}}\right)$.

Esta función ha de cumplir con esta condición: que para todas las permutaciones de las raíces ha de dar valores distintos. Es lo que hemos llamado una función de $\mathrm{N}$ valores, siendo $\mathrm{N}=1,2,3 \ldots \mathrm{n}$.

Si aplicamos a $\varphi\left(x_{1}, x_{2}, \ldots, x_{n}\right)$ las $N$ sustituciones de las raíces $\mathrm{x}$, obtendremos $\mathrm{N}$ valores para $V$, que representaremos por $V_{1}, V_{2}, \ldots, V_{N}$. 
José Echegaray: entre la ciencia, el teatro y la política

Formemos con estos $\mathrm{N}$ valores, como raíces, la ecuación resolvente $\left(\mathrm{V} \cdot \mathrm{V}_{1}\right)\left(\mathrm{V} \cdot \mathrm{V}_{2}\right) \ldots$ $\left(\mathrm{V}-\mathrm{V}_{\mathrm{N}}\right)=0$

Se cumple entonces que cualquier raíz de la ecuación propuesta, por ejemplo $x_{1}$, es función racional (por tanto del dominio de racionalidad dado) de una cualquiera de las raíces $V_{h}$ de la resolvente.»

Con este resultado, Echegaray consiguió (en la lección decimonovena) introducir la noción, fundamental tanto para la teoría de Galois como para la matemática posterior, de "grupo de una ecuación $\mathrm{f}(\mathrm{x})=0$ ", y demostrar la siguiente proposición fundamental: ${ }^{125}$ "Dada una ecuación algébrica cuyas raíces se suponen desiguales, existe siempre un grupo de sustituciones de estas raíces tal que toda función de estas raíces invariable por las sustituciones del grupo es racionalmente conocida, y, recíprocamente, toda función de las raíces determinable racionalmente, queda invariable por la aplicación de esas sustituciones. El grupo de sustituciones que goza de esa propiedad se denomina grupo de la ecuación.»

Una vez demostrada esta proposición, todavía se está relativamente lejos de poder demostrar el teorema de la resolubilidad de ecuaciones por radicales, pero se ha dado un paso decisivo en esa dirección. De hecho, Echegaray tampoco llegó a completar tal programa en el primer volumen de Resolución de ecuaciones y teoría de Galois. Esto era algo que reservaba para el curso siguiente. Seis meses después de finalizar aquel primer curso sobre la resolución de ecuaciones y la teoría de Galois, comenzó uno nuevo sobre la misma cuestión. Antes de hablar de él, debo advertir que la información que he conseguido reunir sobre su contenido es incompleta; la única copia que he podido localizar de las transcripciones de aquel curso incluye únicamente ocho lecciones (192 páginas), faltando, de hecho, páginas de la última lección ${ }^{126}$. Dada la rareza de esta fuente, y también el que constituía la exposición de la culminación de la teoría de Galois, me extenderé algo en el análisis de su contenido.

Comenzaba Echegaray (1898-1902: 5-6) recordando a sus «oyentes, si es que este descanso de medio año no ha borrado por completo sus recuerdos, que en una de las últimas conferencias decíamos, que en el nuevo curso, que es este que hoy empieza, nos sería forzoso cambiar el punto de vista desde el cual habíamos considerado la invariabilidad de las funciones racionales de las raíces de una ecuación. En casi todas las conferencias del curso precedente, al hablar de la invariabilidad de una función, cuando se le aplica una sustitución cualquiera de sus raíces, nos referíamos a la invariabilidad de la forma. En cambio en el presente curso, siguiendo la teoría del joven e inmortal matemático francés, hemos de prescindir de la forma para atender ante todo al valor numérico. De suerte, que cuando digamos que una sustitución aplicada a determinada fun- 
ción de las raíces la deja invariable, querremos decir que no altera su valor numérico, aunque altere y modifique su forma algebraica.» Tras recordar que en el curso anterior había demostrado la existencia del grupo de Galois, esto es, la existencia del grupo de sustituciones propio de una ecuación dada, señalaba que este grupo «no sólo existe siempre y para toda ecuación (que podemos suponer de raíces desiguales, porque de no ser así, fácil sería, como se sabe por Álgebra, descomponer dicha ecuación en otras varias de raíces sencillas), sino que el mismo método que hemos dado para demostrar la existencia del grupo de que se trata, constituye un verdadero método de determinación» ${ }^{127}$, pasando a continuación a revisar el método, para terminar concluyendo: "Claro que el método será impracticable casi siempre; pero en teoría es riguroso» ${ }^{128}$.

Aunque en la lección segunda se demostraban resultados importantes (por ejemplo, el teorema de Lagrange generalizado para el caso de invariabilidad numérica), es a partir de la lección tercera cuando se entra más directamente en el tema de la resolución de ecuaciones. Sin embargo, es la lección cuarta, de las ocho que han sobrevivido, la fundamental. Demostraba allí Echegaray dos teoremas: el primero le permitía «hallar directamente el grupo de la ecuación, cuando se agregan al dominio de racionalidad propuesto algunas o todas las $\varphi{ }^{129}$; el segundo le facilitaba encontrar de una manera directa el grupo de la ecuación $B(\varphi)=0$. «Son los dos [teoremas] fundamentales del método de Galois, ya para resolver la ecuación dada por radicales, cuando esto es posible, ya para reconocer, como veremos ${ }^{130}$, que las raíces de la propuesta son de orden transcendente» ${ }^{131}$.

En la lección quinta se exponían de nuevo las líneas generales del método de Galois, demostrándose varios teoremas ${ }^{132}$ e introduciéndose las nociones de grupos transitivos e intransitivos, probando asimismo proposiciones como la de que «cuando el grupo de una ecuación es transitivo, la ecuación es irreducible» ${ }^{133}$. Los resultados obtenidos permitían que Echegaray finalizase esa lección con una importante conclusión: ${ }^{134}$

«En suma: tanto da decir que una ecuación es reducible o irreducible, como decir que su grupo es intransitivo o transitivo.

Basta con lo dicho para que vean mis oyentes cómo las propiedades de la ecuación fundamental están íntimamente ligadas con su grupo, y cómo su resolución, si es posible, y su simplificación, en todo caso, depende del estudio y transformación del grupo de Galois».

Las dos lecciones siguientes, las últimas de que he podido disponer, son claramente de transición; en ellas se exponen nuevas propiedades y conceptos de la teoría de grupos (por ejemplo: subgrupos invariantes del grupo principal; grupo invariante máximo, o grupos permutables), dán- 
José Echegaray: entre la ciencia, el teatro y la política

dose también algunos ejemplos. Por lo que podemos leer en la lección octava, Echegaray se disponía a «reanudar o, mejor dicho... completar la exposición del método de Galois» ${ }^{135}$. Desgraciadamente, no me es posible ofrecer ningún detalle de cómo lo hizo.

Antes de abandonar este apartado de la obra matemática de Echegaray, diré que, en mi opinión, en ningún otro lugar nuestro personaje llegó a alturas matemáticas comparables. Se enfrentó con una de las teorías más difíciles de la matemática del siglo XIX, con notable retraso, es verdad ${ }^{136}$, pero, y a pesar de las indudables simplificaciones en que incurrió al desarrollar las correspondientes demostraciones, lo hizo con dignidad y dando, al mismo tiempo, una lección de ambición científica a sus, en general, mucho más jóvenes colegas.

Como ya indiqué antes, Echegaray dedicó sus cursos de los años 18981900 en la Escuela de Estudios Superiores a la «Teoría de las funciones elípticas» ${ }^{137}$. Aunque no publicó sus lecciones, disponemos de un resumen de las mismas que Juan González Piedra (1899) publicó en la Revista de Obras Públicas, así como de unos recuerdos de Luis Octavio de Toledo (1932). Tomando como base la exposición de Legendre, uno de los fundadores de la teoría, Echegaray definió la forma de las funciones elípticas y las transformaciones de cálculo, para llegar a los tres tipos clásicos, terminando con las transformaciones de las funciones elípticas (teorema de Abel). No fue aquel el único año que Echegaray dedicó en el Ateneo a las funciones elípticas, y aunque en las Memorias de la institución madrileña se puede averiguar el contenido de los cursos que se dictaron, transcribo como curiosidad una copia de una carta que Echegaray escribió a Segismundo Moret, presidente del Ateneo, en la que decía: ${ }^{138}$

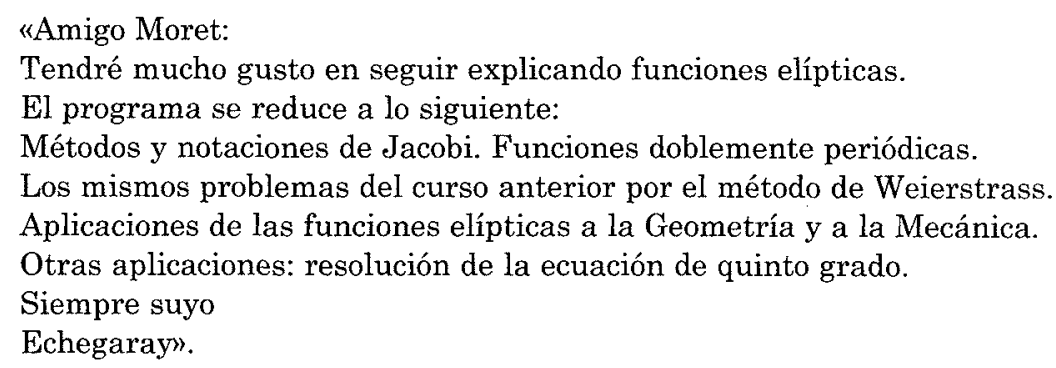

\section{Echegaray y la física matemática}

Un vistazo a la lista de publicaciones de Echegaray que incluyo más adelante, bastará para comprobar que la física figuró de manera promi- 
nente entre sus intereses científicos. Desde luego, y al igual que en matemáticas, pero en este caso de manera todavía más acusada, Echegaray fue simplemente un expositor de teorías desarrolladas por otros; él nunca contribuyó con investigaciones propias. Más aún, como veremos, en física fue plena, y a veces un tanto patéticamente (aunque se tratase de un patetismo noble), un hombre del siglo XIX, pero del siglo XIX que sólo con dificultad, pocas veces y de manera incompleta, pudo ver más allá de la imagen clásica, newtoniana (a lo sumo electromagnética) de la naturaleza. Si recurrimos como patrón de medida al temporal, entonces sus trabajos en física se pueden dividir en dos fases: la primera llega hasta 1905, año en que fue nombrado catedrático de Física matemática de la Facultad de Ciencias de la Universidad Central, cubriendo la segundã el período que va desde 1905 hasta su muerte, en 1916.

Con respecto a la primera fase, ya me he referido a los artículos que publicó, en 1853-1854, en la Revista de Obras Públicas acerca del movimiento continuo; del resto hay que decir que la mayor parte de lo que publicó en física a lo largo de aquellos años fueron artículos de divulgación. Inicialmente aparecían en revistas como España, El Imparcial, Revista Hispano Americana, El Liberal, Diario de la Marina de La Habana, Ilustración Artística, o Revista de Obras Públicas, por citar algunas, y luego en forma de libro ${ }^{139}$. Tal fue el origen de Teorías modernas de la Física. Unidad de las fuerzas materiales (tres volúmenes; alguno con más de una edición) y de Ciencia popular. En los 107 artículos contenidos en estos libros ${ }^{140}$, se comprueba la gran cantidad y variedad de conocimientos científicos y tecnológicos de Echegaray, así como su habilidad para presentarlos a un público general. Con respecto a la variedad, basta con echar un vistazo a los respectivos índices para encontrarse con temas tan diversos como la "Navegación aérea», "Por qué se quema el carbón», "Las energías del radium», "El barón Cauchy», "La bicicleta y su teoría», "Los rayos X», «El calor», «Telegrafía sin hilos», «Del cuerpo humano como máquina de transformación del pensamiento en fuerza material», "Análisis espectral», «El telescopio Dussaud», «Sobre las teorías modernas de la luz», o «Exposición de la electricidad en París. 1881». Ayudado por la garra de su verbo (en general cursi y almibarado para nuestros gustos actuales, y cuya lectura nos permite comprender con facilidad las críticas que le dedicaron jóvenes literatos que comenzaban sus carreras con el nuevo siglo), Echegaray contribuyó eficazmente a que pudiesen acceder a una parte del mundo de la ciencia y de la tecnología de finales del siglo XIX muchos lectores españoles. Evidentemente, fue aquella una labor positiva para la cultura nacional, pero por mucho mérito que le adjudique- 
mos (con justicia) no debe ocultar el hecho de que nuestro hombre mostró con frecuencia - no siempre, evidentemente - en aquellos trabajos su escasa profundidad, su muy limitada percepción filosófica y los abusos a los que le conducía su demasiada florida prosa (en la que constantemente repetía los mismos adornos). Una lectura superficial de, por ejemplo, dos de esos artículos, «Los rayos catódicos» y «Un espacio de muchas dimensiones» ${ }^{141}$, permite comprobar algunos de sus aciertos y de sus defectos. En el primero se ve fácilmente la habilidad de Echegaray para acercar al lector medio un tema que demostraría ser una pieza clave para la física; abusaba algo del lenguaje, pero en su época y para los lectores que buscaba, muy probablemente fuese eficaz. No entraba en grandes profundidades, pero tampoco decía tonterías. El segundo, el de los espacios de muchas dimensiones, revela su escasa percepción o refinamiento filosófico, y ello no tanto porque se opusiera a la posibilidad de espacios de dimensiones diferentes a tres (Einstein y sus relatividades estaban todavía en el futuro), sino por la simplicidad de sus argumentos, por la «filosofía del sentido común» que con sus palabras mostró cultivar. El párrafo final de este artículo es un magnífico ejemplo de lo que estoy diciendo:

«Es lo cierto, que no acabaríamos nunca de relatar las novedades, asombros y maravillas de los espacios de diversas dimensiones, si no creyéramos que hemos soñado bastante con los soñadores, y que, después de todo, lo que el sentido común aconseja es que nos acomodemos de la mejor manera posible en este espacio de tres dimensiones en que nos colocaron, hasta que no llegue el día de que podamos volar por la cuarta dimensión, que, por ahora, no se ve por ninguna parte.»

Con tales manifestaciones, Echegaray estaba llamando, implícitamente, soñadores a pensadores del calibre de Gauss, Lobatchewsky, Bolyai, Helmholtz, Clifford, Riemann, Klein, Karl Pearson y Bertrand Russell, que, creyeran o no en la posibilidad real de espacios de más de tres dimensiones, dedicaron parte de su tiempo a meditar sobre diferentes aspectos de la geometría, física y matemática, n-dimensional ${ }^{142}$.

Además de todos esos artículos, Echegaray publicó, a lo largo del período que ahora estoy considerando, dos libros y un pequeño folleto de setenta páginas que tienen mayor interés desde el punto de vista de las ciencias físicas. Según el propio Echegaray (1917, tomo II: 289), esas obras eran de "propaganda científica, no de ciencia popular... sino de alta ciencian. La primera fue un Tratado elemental de termodinámica, publicado en $1868^{143}$. De esta obra dijo Echegaray (1917, tomo II: 289), en unos comentarios preciosos a la hora de estudiar la introducción de la termodinámica en España, que «estaba inspirada en los trabajos más modernos, por entonces, del extranjero, y era materia desconocida en España y 
que no se enseñaba en ninguna parte, ni en Escuelas especiales, ni en Institutos; por descontado, ni en los libros de Física de entonces, ni en las Universidades tampoco aparecía.»

Comenzaba Echegaray, como es habitual en muchos de sus trabajos, efectuando comentarios que permiten identificar el tema específico que iba a abordar, así como algunas de las fuentes en que se basaba: «Vamos a estudiar al calor en algunos de sus efectos, y éstos son de dos clases: conviene, pues, distinguir unos de otros. Se mueve el calor, si se nos permite esta manera de expresarnos, dentro de un mismo cuerpo; o pasa de unos a otros cuando están en contacto; o irradia en el espacio salvando distancias. Pero en todos estos casos el calor se mueve, el fenómeno marcha, conservándose el mismo en su apariencia, y a este primer conjunto de hechos, estudiados por Fourier, Poisson, Lamé y otros insignes matemáticos, se les ha dado el nombre de Teoría analítica del calor» ${ }^{144}$.

No era, sin embargo, de este tipo de fenómenos de los que se quería ocupar, sino de aquellos en los que «la acción del calor se manifiesta por la remoción de obstáculos, es decir, por efectos mecánicos; en una palabra, por el desarrollo más o menos grande de un trabajo. En tales casos, el calor no sólo marcha, sino que se transforma en efecto útil, venciendo resistencias; y por este motivo algunos dan a la nueva teoría el nombre de Transformación del calor, mientras otros, atendiendo a que cuando así obra es en rigor una fuerza, adoptan la denominación de Teoría mecánica del calor o la de Termodinámica... Los fundadores de este nuevo orden de conocimientos son Carnot, Mayer (Mayer sobre todo), Joule, Thomson, Rankine, Clausius y algunos otros; y el lector que quiera ampliar las nociones que presentemos en estos artículos, puede consultar principalmente las obras de Hirn, Combes, Saint-Robert ${ }^{145}$, y las notables Memorias de Clausius, publicadas en el Journal de Liouville» ${ }^{146}$.

En conjunto, el capítulo I del Tratado elemental de Termodinámica se ocupa de introducir una serie de nociones generales (temperatura, unidades de calor, leyes de Mariotte y Gay-Lussac, y cambios de estado). En el capítulo II («Principios fundamentales»), Echegaray se dedicaba a lo que consideraba el problema fundamental de la Termodinámica: ${ }^{147}$ "¿Cómo están enlazadas entre sí todas estas cantidades? He aquí el problema más general de la Termodinámica. Debemos, pues, buscar relaciones analíticas entre los siguientes elementos: presión; volumen; temperatura; cantidad de calor; trabajo externo y trabajo interno."

Esa búsqueda la llevaba a las «dos ecuaciones... [que] expresan los dos principios fundamentales de la teoría moderna del calor; el primero, la transformación siempre proporcional del trabajo en calor, y de éste en 
José Echegaray: entre la ciencia, el teatro y la política

aquél» ${ }^{148}$, y el segundo que afirma que "cuando un cuerpo se pone en contacto con una serie de focos de calor a temperaturas diversas $t_{0}, t_{1}, t_{2}, \ldots$; y de ellos recibe, o bien les cede, cantidades de calor $Q_{0}, Q_{1}, Q_{2}, .$. , si el cuerpo vuelve a su estado inicial, la suma de los cocientes que resultan de dividir cada cantidad de calor por una función constante, $f$, de la temperatura correspondiente, es igual a cero» ${ }^{149}$. Definiciones no demasiado refinadas, pero suficientes para el propósito de su autor. En los capítulos III y IV, presentaba una serie de ecuaciones termodinámicas importantes. Para ello, utilizaba las dos leyes que acabamos de enunciar, con el fin de relacionar los seis coeficientes fundamentales. Finalmente, en el capítulo $\mathrm{V}$ se ocupaba de «Diversos efectos del calor sobre los cuerpos»; por ejemplo, el problema de cuál será el estado final, y cómo se habrá dividido el calor en calor efectivo, efectos moleculares y trabajo externo, cuando se suministra una cierta cantidad de calor a un cuerpo. Tomado en su conjunto, y por lo que yo conozco, el pequeño tratado de termodinámica de Echegaray no tuvo rival, en cuanto a contenido y nivel, durante bastante tiempo en la bibliografía producida por científicos españoles.

Pasando ahora al segundo de los textos mencionados antes, la Teoría matemática de la luz, publicada en 1871 como libro y en artículos en distintos tomos de la Revista de los Progresos de las Ciencias, nos encontramos con que en él Echegaray (1871 a, "Advertencia inicial») se proponía: «hacer sobre la teoría matemática de la luz un trabajo del mismo género que el que hicimos tiempo ha sobre la Geometría superior: es decir, condensar en breves páginas lo más elemental de dicha teoría, para que pueda servir de introducción al estudio de las obras clásicas, y particularmente a los admirables trabajos de Cauchy."

En realidad el título del libro puede conducir a ideas equivocadas acerca de su contenido, ya que poca o ninguna física incluía; sus tres capítulos estaban dedicados a: "Fórmula de Fourier» (desarrollo de funciones en series trigonométricas), «Teoría de los residuos y aplicaciones» y «Cambio de variables bajo el signo integral y otras cuestiones matemáticas.»

El folleto al que me refería antes es uno titulado Observaciones y teorias sobre la afinidad química (Echegaray 1901). Para ver de qué trataba, lo mejor es citar algunos pasajes extraídos de sus primeras páginas:

"Aún cuando llegan las ciencias a cierto estado de perfección, se necesitan fuerzas diversas para explicar los hechos naturales.

Para la astronomía se necesita la gravitación. Para la física, la cohesión. La afinidad para la química...

Todavía puede considerarse a la cohesión como una forma de la gravitación universal. Pero la afinidad química se resiste con resistencia invencible a formar parte de otras unidades. 
Es que en rigor la afinidad química presenta caracteres, al menos en la apariencia, si no opuestos, totalmente distintos de aquellos que acompañan a la atracción newtoniana. ...[En gravitación a] mayor masa, mayor atracción... Nada de esto sucede con la afinidad química: casi pudiéramos decir que sucede lo contrario.

La afinidad no es universal entre todas las sustancias: unas se atraen químicamente, otras no; bien al contrario de lo que sucede en la gravitación...

Diríase, pues, dadas estas diferencias radicales entre la atracción newtoniana y la afinidad física, que ambas fuerzas son de naturaleza radicalmente distintas.

Pero ¿lo son en realidad? ¿No habrá medio de ponerlas en relación? Cuando la afinidad acaba, ¿empezará la gravitación y no habrá medio de establecer cierta ley de continuidad entre ambas?"

De manera más explícita, lo que Echegaray (1901: 10) se preguntaba era si no sería posible «convertir la química en una mecánica racional de los átomos». Aunque no se le ocultaba «que el problema es de una dificultad inmensa; que acaso no le ha llegado su tiempo; que tal vez pasarán siglos antes de que aparezca el Newton de la química", Echegaray se lanzó, con una ingenuidad admirable, a efectuar algunos comentarios sobre el problema: «Como el lector podrá observar, estas breves páginas no tienen la pretensión de explicar matemáticamente ninguno de los grandes problemas de la química, ni aspiramos tampoco a fijar el carácter de la fuerza de afinidad. No son una explicación... sino un conjunto de reflexiones sobre el fenómeno químico en sí mismo. Reflexiones provocadas por esta pregunta: ¿podrá algún día el problema de la química reducirse a un problema de mecánica? Creemos que sí. Y nuestras observaciones tienen una orientación en este sentido» ${ }^{150}$.

No sólo fueron comentarios de orden general los que realizó Echegaray en estas Observaciones y teorias sobre la afinidad química, también reflexionó sobre leyes de fuerza del tipo de la que rige la atracción gravitacional en la teoría newtoniana, aunque dejando libre la forma específica de la dependencia de las distancias. Para ello introdujo «masas (M) de centros ponderables» y "masas (m) de atmósfera de éter»; las $M$ atrayéndose entre sí, las $m$ repeliéndose, y cada $M$ siendo atraída y atrayendo a todas las $m$. Entre otras aplicaciones de sus ideas, analizó el fenómeno de la electrolisis. Su hipótesis era que «las atracciones entre el éter y la materia ponderable dependen de potencias superiores de la distancia en el denominador de la fórmula [newtoniana]» ${ }^{151}$, y con ella aspiraba a explicar el fenómeno de la disociación de un electrolito. Con la excepción de dos breves trabajos debidos a Francisco Cebrián (1909) y a Rafael Vilar Fiol (1911), no tengo noticia de que sus ideas suscitasen reacción alguna ${ }^{152}$. De hecho, el contenido de este opúsculo refleja con claridad el mundo, entre newtoniano y maxwelliano en el que se movía nuestro personaje. La mecánica racional y el electro- 
José Echegaray: entre la ciencia, el teatro y la política

magnetismo (en el que la interacción mecánica entre carga y éter/campo constituyen elemento básico), eran los pilares del universo físico de Echegaray. Aspiraba, ya lo vimos, a convertir a la química en «una mecánica racional de los átomos», y creía que todavía podían transcurrir siglos antes de que apareciese «el Newton de la química». No lo sabía, naturalmente, pero los Newton (los nuevos, porque el primero fue Lavoisier) de la química ya habían nacido y, algunos, comenzado a trabajar cuando escribía aquellas líneas: eran los Planck, Einstein ${ }^{153}$, Sommerfeld, Bohr, Heisenberg y Schrödinger ${ }^{154}$, y todos aquellos que construyeron -no en siglos, sino en, escasamente, un cuarto de centuria- la mecánica cuántica, la teoría que haría que, al menos a nivel de primeros principios, la química se pudiese considerar como un apartado de la física ${ }^{155}$.

\section{La cátedra de física matemática de la Universidad Central}

Paso a continuación a tratar el segundo período al que me referí antes, período que estuvo dominado por la designación, en 1905, de Echegaray como catedrático de Física matemática de la Universidad Central.

La historia de la cátedra de Física matemática se remonta a 1858. En efecto, una asignatura con ese nombre formaba parte del programa general de estudios de la Facultad de Ciencias Exactas, Físicas y Naturales que se aprobó por R.D. el 11 de septiembre de aquel año ${ }^{156}$, y con el que se desarrollaba la creación de esa Facultad el año anterior (la ley Moyano). En concreto, la Física matemática era una de las dos asignaturas (la otra era la Astronomía física y de observación) que debían cursar los licenciados en Ciencias Exactas que aspirasen al doctorado ${ }^{157}$. La situación cambió con el tristemente célebre ministro de Fomento, Manuel de Orovio. En un decreto debido a él, aparecido en octubre de 1866, se reducían a dos las secciones de la Facultad de Ciencias: ${ }^{158}$ Ciencias FísicoMatemáticas y Químicas, y Ciencias Naturales, y desaparecían las asignaturas Tratado de fluidos imponderables (correspondiente a la licenciatura de Ciencias Físicas) y Física matemática». Sería en 1870, con Echegaray de ministro de Fomento, cuando se volvió a incorporar la Física matemática a los programas de estudios del doctorado. En tanto que la Instrucción Pública era competencia del Ministerio de Fomento, hay que concluir que tal recreación fue obra de Echegaray. Y no sólo por motivos de dependencia administrativa: con anterioridad me he referido a un artículo publicado en 1866 en la Revista de Obras Públicas, titula- 
do «Sobre la reforma de la Facultad de Ciencias y de las Escuelas especiales", que aunque no iba firmado escribió, todo lo indica así, Echegaray. En este escrito se incluyen unos párrafos que constituyen un claro precedente programático de la creación de la cátedra de Física matemática en 1870. Los reproduzco a continuación:

«Qué se ha hecho en el nuevo plan de la clase de Física-matemática? En Francia ha desempeñado, y creemos que aún desempeña esta clase importantísima, más que importante, necesaria, absolutamente necesaria, el ilustre matemático $\mathrm{Mr}$. Lamé... En España existía una asignatura con este mismo nombre, pero en el nuevo plan se suprime por completo, dando por única razón que no es de absoluta necesidad en el cuadro de la enseñanza. Sin duda, al suprimir esta clase no han meditado los autores de la reforma con suficiente madurez, ni sobre la importancia de la materia en sí misma, ni en el mal efecto que semejante resolución ha de producir necesariamente, ni aun sobre las interpretaciones poco favorables al decoro científico de nuestra patria a que puede dar ocasión.

Nosotros tenemos el profundo convencimiento de que la clase de Física matemática es de absoluta necesidad en la primera Universidad de España. Y, en efecto, no hay en Europa facultad alguna de ciencias, que merezca tal nombre, en que no exista esta asignatura. Hace treinta y seis años la explicaba Cauchy en el pequeño reino de Cerdeña, y hoy en Roma, en Francia, en Italia, en Inglaterra, en Alemania, en Bélgica se explica...»

Cuando la cátedra de Física matemática, correspondiente al doctorado de Ciencias Exactas ${ }^{159}$, salió a oposición en 1870, Echegaray fue nombrado, a propuesta de la Facultad de Ciencias, vocal del Tribunal. Al constituirse éste fue elegido presidente, siendo los vocales Antonio Aguilar, Agustín Monreal, Pedro Lallave, Eduardo Mariategui, Miguel Merino y Dionisio Gorroño. Hubo un solo opositor, Francisco de Paula Rojas. Tras efectuarse la oposición, el 1 de julio de 1871 se verificó la votación. Votaron en favor del opositor los tres primeros vocales y en contra los otros tres; sería Echegaray, con su voto afirmativo, quien adjudicaría la cátedra a Rojas. Si creemos a Antonio Vela (1916) el mismo Echegaray había figurado, inicialmente, entre los posibles destinatarios de la cátedra: "Cuando se creó la cátedra de Física matemática en la Universidad Central, se habló de que se encargaría su explicación al ilustre ingeniero, ya muy conocido como profesor eminente y como escritor científico de gran relieve». En 1905, al pedir la jubilación Rojas, el Gobierno ofreció la cátedra de Física matemática a Echegaray, con una renumeración compatible con cualquier otra clase de haberes (téngase en cuenta que el año anterior Echegaray había recibido el premio Nobel de Literatura, y que constantemente estaba recibiendo homenajes de la España oficial; una manifestación de estos homenajes fue el que, como ya vimos, ese mismo año de 1905 volvería 
José Echegaray: entre la ciencia, el teatro y la política

a ser, cediendo a los insistentes ruegos de Eugenio Montero Ríos, ministro de Hacienda).

«En el mes de mayo de 1905», recordaba Vela (1916), «tuve el honor de acompañar al señor Rojas en su visita al señor Echegaray para acordar con éste la campaña que había de comenzar el curso próximo. Reunidos en el saloncillo del teatro español, don José nos indicó que estaba dispuesto a explicar la asignatura desde el próximo otoño, pero no a intervenir en exámenes, grados ni acto alguno que tuviera carácter administrativo. Su plan consistía en explicar una lección cada semana, publicándola inmediatamente y repartiéndola entre los alumnos y personas que asistiesen a las conferencias.» Sería el propio Antonio Vela (1916: 481), por entonces profesor auxiliar de la Facultad de Ciencias, quien se encargó de redactar y explicar el programa oficial, y de cuanto se relacionaba con la validez académica de los estudios; semejante arreglo se mantuvo hasta la muerte de Echegaray, con la única variante de la sustitución de Vela -cuando éste «tuvo que dedicar su tiempo a otras atenciones de la enseñanza»- ${ }^{160}$ por Pedro Carrasco, quien en 1918 obtendría, por oposición, la cátedra que habían ocupado Rojas y Echegaray (la mantendría hasta la Guerra Civil) ${ }^{161}$.

Antes incluso de que Echegaray dictase su primera lección de Física matemática en la Facultad de Ciencias, se presentó públicamente ante el claustro de la Universidad Central, ya que fue elegido - un homenaje más- para pronunciar el discurso académico en la inauguración del curso 1905-1906. Tenía entonces, es interesante recordarlo, setenta y tres años. El discurso se tituló La ciencia y la critica y constituye una muestra magnífica de la visión de la naturaleza que Echegaray mantenía por entonces. Aunque no pretendo resumir este largo discurso, que se reproduce íntegro en el «Documento V», sí se puede señalar que lo que más destaca de él es la constatación del conflicto personal en el que se veía sumido su autor al reconocer en la física una crisis cuya naturaleza no entendía realmente, y cuya salida era incapaz, por supuesto, de adivinar. Para alguien como él, que comenzaba su discurso definiendo la física matemática como «ciencia prodigiosa, de hermosura incomparable, derivación e imitación casi de la Mecánica celeste» ${ }^{162}$, era difícil asimilar y aceptar las críticas que se estaban efectuando (en realidad, en 1905 ya eran unas críticas relativamente viejas) a conceptos como los de acción a distancia, fuerzas centrales, fuerza y masa, sobre los que se basaba la mecánica clásica. Más aún, el propio espacio -el de «toda la vida», el cartesiano-euclideano- estaba en entredicho: ${ }^{163}$ "Y por si con esto no bastase, citemos el espacio de $n$ dimensiones, ante el cual el viejo espacio de tres 
dimensiones a que estamos acostumbrados, con ser infinito según unos, con ser incomprensible según otros, con reducirse a una forma de nuestra sensibilidad en opinión de muchos, y con ser puramente relativo según los más, aparece como un modestísimo y vulgar espacio, viejo burgués del Cosmos, ante los formidables anarquistas de la extensión cuyas dimensiones, no pudiéndose contar por números, acuden a las letras del alfabeto».

Para empeorar las cosas, Echegaray se daba cuenta de que las críticas a su física procedían de los mejores científicos: ${ }^{164}$

"Y he de señalar una circunstancia gravísima... que da a todos los resultados una fuerza verdaderamente excepcional; y es que la nueva Crítica la ejercitan sabios eminentes, los de más competencia en asuntos matemáticos, los de razón más sólida, los que han alcanzado mayores triunfos en las Matemáticas puras, en la Mecánica y en la Física Matemática, los que no censuran ni por malhumorados con una Ciencia que les fuera ingrata, ni por ligereza de carácter. Y el movimiento crítico se extiende a todas las naciones que marchan a la cabeza de la civilización.

$\mathrm{Al}$ ver a maestros ilustres, que parecían tener el monopolio y ejercer la hegemonía en las Ciencias exactas, afirmar que no son tan exactas como parecen ser, que están plagadas de definiciones arbitrarias, de resultados contradictorios, de numerosos convencionalismos y de postulados indemostrables, hay que respetar la severidad de su pensamiento y la abnegación de sus declaraciones; pero confesemos que se presentan ante los humildes creyentes, como sacerdotes que reniegan de sus propios ídolos y que derriban sus propios altares.

$\mathrm{Al}$ ver a tantos y tantos ilustres críticos descargando, uno tras otro, repetidos y tremendos golpes de ariete contra la Ciencia del siglo XIX, recuerdo, por no sé qué extraña asociación de ideas, la memorable noche del 4 de Agosto, en que la nobleza de Francia, y aun el clero y todos los órdenes de la Asamblea, arrastrados por una fiebre noble y patriótica, y queriendo demostrar a la Justicia y al Derecho, abdican en tropel y en competencia sus privilegios, sus prerrogativas, sus antiguos derechos, arrojando las ruinas del viejo mundo feudal, aristocrático y absolutista ante la nueva Justicia y el nuevo Derecho.»

Tomando en su conjunto, el discurso de apertura de curso de Echegaray muestra, por un lado, su escasa capacidad para someter a conceptos y teorías fundamentales de la física del siglo XIX a un análisis metódico, profundo y original, así como para establecer interconexiones entre diferentes campos-(la mecánica, el electromagnetismo, la termodinámica, la física estadística). Pero también se puede comprobar leyendo aquella exposición que su autor estaba relativamente informado de los aspectos más generales y aparentes de la crisis en que se veía sumida la física ${ }^{165}$; así, aparecen referencias a las experiencias de Walter Kaufmann y a los cálculos de Max Abraham sobre la variación de la masa con la velocidad $^{166}$, a los experimentos de Michelson (camuflados con un « ¿Es que la atmósfera se lleva consigo la onda luminosa que por ella circula?») ${ }^{167}$; a 
José Echegaray: entre la ciencia, el teatro y la política

pérdida de «impenetrabilidad y solidez» de los átomos; o a los probleas que estaba ocasionando la radiactividad:

«Pero el radium se presenta -y esta es ya la frase admitida-, con tendencias tan revolucionarias, mejor dicho, tan anarquistas, que toda la Ciencia se alarma...

Para no citar más que dos ejemplos, recordaremos, en primer lugar, que el radium emite calórico, al parecer de una manera indefinida, como si su energía interna fuese infinita; y además que no parece respetar aquel axioma, o por lo menos aquel postulado, según el cual, el calórico no pasa espontáneamente sino de un cuerpo a otro a temperatura inferior...

Además, el radium está emitiendo constantemente, no sólo energía, sino elementos de su propia sustancia, radiaciones y emanaciones, sin que su masa parezca disminuir. Falta saber si disminuirá en unos cuantos siglos; mas experiencia es ésta, cuyo resultado final está reservado a las generaciones futuras» ${ }^{168}$.

Diez años después de pronunciar este discurso, los puntos de vista de Echegaray (1915) no habían experimentado cambios sustanciales, como se puede comprobar leyendo su artículo «Serie de negaciones» ${ }^{169}$. Aparecían allí referencias a nuevos problemas o contribuciones; por ejemplo, a las investigaciones de Max Planck [en el texto está escrito Plomck] en las que introdujo sus cuantos de energía ${ }^{170}$, así como a «uno de los problemas más profundos que se agitan a la hora presente: el problema de la relatividad, $y$ la negación de la Cinemática clásica, por ejemplo, los admirables atrevimientos de Einstein» ${ }^{171}$, pero la sustancia era la misma de su intervención en la inauguración del curso 1905-1906. (Con respecto a Echegaray y a la relatividad especial, hay que decir que ya en el curso de Física matemática correspondiente al año 1913-1914 se había referido a esa teoría [ver pp. 18-19], aunque en aquella ocasión no había mencionado más que a Lorentz) ${ }^{172}$.

Un punto que quiero mencionar a propósito de los dos trabajos que acabo de comentar es el de la influencia de Henri Poincaré en Echegaray (en lo que sigue nos encontraremos con frecuencia referencias a obras de Poincaré que manejó, y en el curso de Física matemática es citado constantemente). En realidad, es este un tema que va más allá de los dos trabajos en cuestión, por mucho que en ellos el gran matemático francés fuese citado con profusión, más que cualquier otro científico. En Poincaré, Echegaray encontró un modelo de lo que debía ser la física, la matemática y la filosofía científica ${ }^{173}$. Aparentemente, no era el único español en profesar semejante admiración; así nos encontramos con que cuando, en 1910, la Academia sueca solicitó al claustro de la Facultad de Ciencias de la Universidad Central que propusiese candidatos para el premio Nobel de Física ${ }^{174}$, todos, sin excepción, propusieron a Poincaré: Blas Cabrera, 'ncé de Castro Pulido, Bartolomé Feliú, Ignacio González Martí, Eduar- 
do Lozano, José Ruiz Castizo y el propio Echegaray. De las 138 propuestas recibidas de todas partes del mundo, 34 correspondieron a Poincaré; fue, con mucho, quien más propuestas recibió. El Comité Nobel, no obstante, otorgó el premio de Física de aquel año a Johannes Diderik van der Waals ${ }^{175}$.

\section{El curso de Física matemática}

Por último, me referiré al curso de física matemática que desde el cadémico 1905-1906 hasta el 1914-1915 desarrolló Echegaray en la Facultad de Ciencias de la Universidad Central de Madrid, y del que tengo que decir que a pesar de su indudable interés y de que constituyó el esfuerzo docente más importante realizado en física matemática en España, por los datos que conozco no parece que cambiase radicalmente la situación en que se encontraba esa rama de la física y de la matemática en nuestro país; la física que se hizo en España durante la primera mitad del siglo XX fue, a lo sumo y sobre todo, física experimental. Sería imposible analizar aquí de manera medianamente completa los diez tomos (4.412 páginas) de este curso, un auténtico monumento a la física del siglo XIX, a una física que pretendió dar acomodo en su estructura y principios a la avalancha de nuevos fenómenos que desde finales del XIX se venían observando, pero que, finalmente, perdió, clara e irrevocablemente, la partida frente a una física nueva, la de la relatividad y la mecánica cuántica. Me limitaré, por consiguiente, a unos breves comentarios.

Si nos preguntamos, antes de entrar en el contenido específico de los diferentes volúmenes, por lo que perseguía Echegaray con su curso, podemos encontrar una respuesta bastante clara en la primera lección del curso correspondiente al año 1910-1911, el sexto que dictaba. Decía allí el premio Nobel de Literatura de 1904: ${ }^{176}$

\footnotetext{
«el objetivo final de mis tareas [es] publicar una Enciclopedia de Física matemática, que [abarque]: $10^{\circ}$ las principales teorías de la Física matemática clásica, las de Cauchy, Poisson, Fourier, Lamé, Ampère, Helmholtz, Gauss, Weber, Fresnel, y para no hacer interminable esta lista, la de todos los grandes maestros que a la creación de la Física matemática dedicaron sus esfuerzos en los dos primeros tercios del siglo $\mathrm{XIX}$; y $2 .^{\circ}$ las principales teorías modernas y modernísimas de esta misma ciencia, es decir, de la Física matemática, que es a la que yo debo consagrar mis trabajos en esta clase que desempeño.

Las teorías modernas y modernísimas, repito, las que han creado Maxwell, Hertz, Poincaré, Duhem, Lorentz, Larmor, Heaviside, Lord Kelvin, J. J. Thomson, Carnot, Gibbs, y aquí también la lista es interminable...
} 


\section{José Echegaray: entre la ciencia, el teatro y la política}

Toda una enciclopedia.

¡Una enciclopedia de Física matemática clásica y moderna! ...

Quiero, o querría, y hasta donde pueda llegaré, publicar una Enciclopedia de Física matemática; pero no con la pretensión de agotar la Ciencia, que hoy es inmensa, sino de ir exponiendo las principales teorías, de ir despejando el camino y haciendo posible o, por lo menos, más fácil a mis alumnos el estudio de las memorias originales, o de las grandes obras de los maestros.

Esto que yo llamo Enciclopedia, dándole nombre sobrado ambicioso, no pasa de ser un trabajo de propaganda, o si se quiere, de preparación, para ir extendiendo en España, en la medida de mis fuerzas, el estudio y la afición al estudio de las altas cuestiones de una de las ciencias más admirables que haya podido crear el ingenio humano.»

En cuanto al contenido del curso, veremos enseguida lo que alcanzó a enseñar a lo largo de los diez años que ocupó la cátedra, pero es instructivo también saber qué es lo que deseaba poder llegar a enseñar, o, en otras palabras, cuál era su programa ideal. De nuevo, el volumen sexto, el de 1910-1911, contiene una explicación bastante detallada (pp. 5-8):

«He aquí una lista de materias, las principales, que han formado, y que me propongo que sigan formando el contenido de mis conferencias:

I. El estudio, ilustrado con ejemplos, de los caracteres propios de la Física experimental y de la Física matemática.

II. La Teoría de la Elasticidad, considerada desde tres puntos de vista diversos, o, mejor dicho, según tres métodos.

1. ${ }^{\circ}$ El de Cauchy. $20^{\circ}$ El de Lamé. $30^{\circ} \mathrm{El}$ de Poincaré.

III. Aplicación de la Teoría de la Elasticidad a las vibraciones sonoras.

IV. Teoría de la luz, expuesta según tres métodos.

$1 .^{\circ}$ El que sintetizaré con los nombres de Verdet y Mascart. $2 .^{\circ}$ Según el método de Cauchy, en el que pueden seguir de guía, ya la Introducción a la alta óptica, del doctor Beer, profesor de la Universidad de Bonn; ya el Ensayo sobre la teoría matemática de la luz, de Briot ${ }^{177}$. $3 .^{\circ}$ Según el método de Poincaré en su Théorie mathématique de la Lumiére ${ }^{178}$.

Y bien se observa, que en la exposición de la Teoría de la luz nos proponemos seguir una marcha, por decirlo así, paralela a la que hemos seguido en la Teoría de la Elasticidad.

V. Teoría matemática del calor, o sea de su movimiento como fluido, tomando por modelo las tres obras fundamentales de Lamé y por descontado la de Fourier ${ }^{179}$.

VI. Teoría del calor como energía, o si se quiere, exposición de la Termodinámica.

VII. Y como complemento deberán consagrarse algunas conferenciás al estudio de la obra de Mr. Boussinesq, titulada Teoría analítica del calor, puesta en relación con la Termodinámica y con la teoría moderna de la luz ${ }^{180}$.

VIII. Aplicaciones de la Termodinámica a la Química y Análisis de los principales trabajos de Gibbs, Duhen [sic, es Duhem], Poincaré, etc.

IX. Teoría de la capilaridad.

$\mathrm{X}$. Teoría de los torbellinos.

XI. Diversas teorias de la Gravitación; para alguna de ellas y para el estudio de los trabajos de Maxwell convendrá exponer previamente la teoría de los cuaternios. 
XII. Electrostática clásica. Teorema de Dirichlet y Neumann. Métodos de Poincaré y Fredholm.

XIII. Electrodinámica clásica y trabajos de Ampère.

XIV. Electrostática moderna. Teoría de Maxwell. XV. Magnetismo. Teoría de Ampère.

XVI. Los dieléctricos. Teoría de Poisson. Estudio de Poincaré.

XVII. Electrodinámica moderna. Teoría de Maxwell.

XVIII. Teoría de la inducción.

XIX. Teoría electrodinámica de Weber.

$X X$. Teoría de Helmholtz. Conservación de la energía.

XXI. Teorías de Hertz.

XXII. Teoría de Lorentz. Constitución de la materia. Para estas últimas, el trabajo del profesor está hecho de antemano, al menos en sus líneas generales, con sólo acudir a la gran obra de Mr. Poincaré titulada Electricité et Optique (2. ${ }^{\mathrm{a}}$. edición). ${ }^{181}$

XXIII. Teoría de Larmor; sobre todo, la exposición que hace en su obra Aether and Matter ${ }^{182}$.

XXIV. Teoría electromagnética de la luz.

XXV. Teoría de los electrones, según la obra de Mr. Lorentz titulada The Theory of Electrons ${ }^{183}$, y el estudio de la Memoria de Max Abraham sobre los principios de la dinámica del electrón ${ }^{184}$.

XXVI. Ondas Hertzianas, tomando por guía la obra de Mr. Poincaré, del mismo título ${ }^{185}$.

XXVII. Teorías modernas sobre los iones, rayos catódicos, rayos X y radioactividad.

Esto, sin contar estudios complementarios de los anteriores, como son, por ejemplo, los trabajos sobre elasticidad de Duhen [sic], Volterra y Corserat.

La teoría girostática de la luz.

Y como estudio general aplicable a las teorías anteriores, un curso sobre la potencial newtoniana.

Sin contar, por último, porque alguna vez he de concluir esta desordenada e improvisada lista, varias teorías matemáticas de gran uso en la Física, como son:

La teoría fundamental de los vectores y, como ampliación, la de los tensores.

La teoría y notaciones de Grassmann.

La teoría de las funciones complejas o imaginarias.

Los cuaternios ya citados, y su ampliación a cantidades complejas de muchas claves. Las funciones armónicas: funciones esféricas.

La integración, por fórmulas simbólicas: de la que encontramos ejemplos notables en la obra ya citada de Briot, y en las Memorias de Heaviside; véase, por ejemplo, el Philosophical Magazine, de 1899.

El fundamental teorema de Fourier, y la serie trigonométrica.

Las funciones de Bessel, etc.

Todas estas teorías deben constituir, a mi entender, en el estado actual de la ciencia, lo indispensable de una enciclopedia de Física Matemática.»

Pasando ya a los distintos tomos publicados que constituyen las Conferencias sobre Física Matemática, nos encontramos con que el primer volumen (curso 1905-1906) es una "Introducción a la Física Matemática». Aunque sus intenciones iniciales eran mucho más amplias, al final se li- 


\section{José Echegaray: entre la ciencia, el teatro y la política}

mitó a disertar acerca: «Del carácter de la Física experimental, y del de la Física matemática... estableciendo sus diferencias fundamentales y sus relaciones necesarias" (p. 6).

Para llevar a cabo semejante propósito, recurría a diversas partes de la física (aunque la mecánica ocupaba casi siempre un lugar predominante). Por ejemplo, en la conferencia tercera presentaba la noción de equilibrio de temperaturas en la física experimental, señalando que allí no era "más que un hecho» (p. 79). "La física experimental», continuaba (p. 80), «no dice... ni puede tener la pretensión de conocer lo que el calor sea y lo que es la temperatura... La Física Matemática, tampoco puede tener la pretensión de conocerlo; pero puede hacer hipótesis, que en este caso, como en casi todos, son hipótesis mecánicas». Y pasaba a ilustrar sus argumentos con muestras del tratamiento del calor y la temperatura en física matemática. En otros lugares de aquel curso utilizó la teoría de la luz, la electrostática o la electrodinámica para desarrollar sus tesis.

Los tres cursos siguientes (1906-1907, 1907-1908 y 1908-1909) están dedicados a la «Teoría de la Elasticidad». El primer año expuso la teoría clásica de la elasticidad por el método de Cauchy, aplicándola después a diversos ejemplos (equilibrio de una capa cilíndrica, de un prisma, etc.). El segundo año explicó la elasticidad por los métodos de Navier, Poisson, Lamé y Clebsch ("Teoría de la Elasticidad, según Lamé y su escuela», la denominó [p. 4]), mientras que el tercero lo dedicó al método de Poincaré. ${ }^{186}$ Para explicar las principales características de esos tres métodos, recurriré a lo que dejó escrito en el curso de 1910 a 1911:

«[El método de Cauchy] es el que más francamente acepta la hipótesis mecánica, es el más atrevido, el más natural... Considera a todo cuerpo dividido en elementos, o más bien que dividido, compuesto de partículas materiales aisladas, y entre estas partecillas imagina fuerzas, que las enlazan dos a dos y que están representadas por el producto de las masas de ambos puntos y de una función de las distancias (p. 21).

[El método de Lamé es] una especie de término medio entre la hipótesis mecánica, y cierta tendencia al método experimental... No divide el cuerpo elástico en puntos materiales de masa determinada $\mathrm{m}, \mathrm{m}$ ' ..., ni establece las ecuaciones de equilibrio de estos diferentes puntos como hace Cauchy.

Toma como elemento un paralelepípedo infinitamente pequeño en el interior del cuerpo elástico... De modo, que así como Cauchy establecía las ecuaciones de equilibrio para cada punto, y tres ecuaciones eran bastantes, Lamé tiene que establecer las ecuaciones de equilibrio del sólido elemental sometido a las reacciones sobre sus seis caras y a la fuerza exterior, que actúe en su centro de gravedad...

Las ecuaciones de equilibrio no serán tres, sino seis, porque no se trata de un punto, sino de un sólido... (pp. 24-25).

[El método de Poincaré se aproxima más] al método de Cauchy que al de Lamé, y... tiene cierta tendencia hacia la Física Matemática moderna, en el sentido de prescindir de algunas de las condiciones... que son dominantes en la hipótesis mecánica. 
La principal diferencia entre el método de Poincaré y el de Cauchy, es que el primero de estos dos matemáticos prescinde de la restricción que establece las fuerzas centrales.

Cauchy suponía que las fuerzas que se desarrollaban en el interior de un cuerpo elástico eran centrales.

Mr. Poincaré resuelve el problema más en general, puesto que lo resuelve sean o no sean centrales dichas fuerzas, y aún marca cierta tendencia a prescindir de la acción a distancia» (p. 27).

Para las teorías de la elasticidad que presentó entre 1906 y 1909 no se necesitaban sino las técnicas matemáticas más elementales, pero para los temas con los que pensaba continuar era diferente, por lo cual en el curso 1909-1910 creyó "conveniente dar una especie de introducción de análisis para los cursos sucesivos en que estudie la electricidad y el magnetismo» (p. 37). El programa que tenía en mente, y que incluía la teoría de los cuaterniones (cuaternios para Echegaray), "para facilitar el estudio de las obras inglesas», las fórmulas de Fourier, así como varias ecuaciones diferenciales, "como son las que dan origen a las ecuaciones de Bessel y al célebre teorema de Dirichlet» (p. 31), era mucho más ambicioso del que finalmente siguió, ya que se limitó a exponer algo de cálculo vectorial, y a deducir la fórmula de Green (que permite pasar de integrales de volumen a integrales de superficie) y la de Stokes (que relaciona integrales de superficie e integrales de línea) ${ }^{187}$.

El que no cumpliera su proyecto inicial para aquel curso, se debe en gran parte a que se entretuvo demasiado con aplicaciones de los teoremas de Green y Stokes al electromagnetismo, e, incluso, con exposiciones de esa rama de la física, sin que mediaran de por medio los mencionados teoremas. En particular, trató con cierta amplitud la teoría de Ampère, basada en la fórmula que determina la acción entre dos elementos de corriente; también discutió cuestiones como la polarización de los dieléctricos, la ecuación de Laplace en electricidad, resolvió diversos problemas de electrostática, e introdujo alguna de las ecuaciones de Maxwell.

El siguiente curso (1910-1911), uno de los más completos, lo dedicó a la «Teoría de los torbellinos», o, como él mismo apuntaba, a la «Hidrodinámica y teoría de torbellinos». Para un científico clásico, y Echegaray lo era, el tema de los torbellinos (también denominados vórtices) era importante, especialmente si recordamos los resultados matemáticos obtenidos e ideas físicas propuestas a lo largo del último tercio del siglo XIX por, principalmente, Helmholtz y Kelvin. En efecto, Hermann von Helmholtz (1858) había conseguido demostrar matemáticamente que el movimiento de vórtices era estable, cuando éstos se formaban en un fluido perfecto (sin fricción e incompresible). Para lord Kelvin (en- 
tonces todavía William Thomson), que había estado jugando con la posibilidad de átomos vorticiales: ${ }^{188}$ "Si existe a través de todo el espacio un fluido perfecto, que constituya la sustancia de toda la materia, un anillo vorticial [uortex-ring] sería tan permanente como los átomos sólidos y duros supuestos por Lucrecio... para explicar todas las propiedades permanentes de cuerpos (como el oro, plomo, etc.), así como las diferencias entre sus caracteres".

Se trataba, en definitiva, de intentar explicar la materia (los átomos) y sus movimientos en base a vórtices, entre cartesianos y maxwellianos, del éter, y he aquí lo que sobre esta cuestión decía Echegaray (pp. 40-41):

"la teoría de los torbellinos, que ha dado origen a los numerosos e importantes trabajos de Kirchhoff, de lord Rayleigh, de J. Thomson y de lord Kelvin, se presta al estudio del programa antes enunciado y a la sustitución de la acción a distancia por las acciones, primero de contacto y luego transmitidas.

Así el ilustre lord Kelvin ha buscado en los movimientos de los torbellinos una explicación mecánica del Universo. El Universo está lleno, según opinión de muchos sabios, por una materia continua, y lo que nosotros llamamos materia, materia propiamente dicha, no es más que un conjunto de torbellinos: átomos-torbellinos les llama el ilustre autor, átomos que, según Helmholtz, son indestructibles y eternos.

Verdad es, que según los descubrimientos de la radioactividad, el átomo puede destruirse y se destruye de hecho; pero en todo caso no hay más que correr la escala y suponer que es el electrón, ese átomo-torbellino cuya existencia civil había usurpado el átomo de la Química.

... Las observaciones que preceden, justifican y explican la elección que hemos hecho de la hidro-dinámica y de la teoría de los torbellinos como materia para el presente curso. El asunto es interesante en sí mismo... [adquiere] aún más importancia por sus relaciones con la electro-dinámica, por lo menos de forma y de representación, que son a veces el camino para realizar grandes síntesis y para llegar a grandes unidades, aunque en un principio estas relaciones sean, por decirlo así, puramente externas y no pasen de ser meras analogías.

Por último, la teoría en cuestión, es decir, la de los torbellinos, y otros problemas de la hidro-dinámica, vienen a dar soluciones al gusto moderno respecto á la manera de interpretar la gravitación universal al negar la acción a distancia, y hay que reconocer que todo esto constituye materia propia de la Física matemática."

Estudió aquel curso Echegaray el movimiento y el equilibrio de los fluidos perfectos, especialmente el movimiento ${ }^{189}$, ya que del equilibrio de un punto arbitrario del fluido solamente presentó las ecuaciones fundamentales ${ }^{190}$. También aprovechó para "recordar dos problemas de análisis», que utilizaría a la hora de deducir la ecuación de continuidad: la teoría de los determinantes y el cambio de variables en integrales múltiples. Un resultado importante incluido en este curso fue la demostración, en la conferencia decimotercera, del teorema de Helmholtz - el teorema fundamental de la teoría de los torbellinos-, que expresa la constancia a lo lar- 
go de una curva cerrada de la circulación del fluido (este teorema es uno, acaso el principal, de los resultados matemáticos a los que me refería antes) ${ }^{191}$.

De "Teorías diversas» trata el volumen correspondiente al curso 1911-1912. En realidad, el tema que abordó Echegaray aquel año fue el de la teoría del potencial newtoniano, tanto para masas ponderables discretas como continuas. Naturalmente, una buena parte del curso giró en torno al estudio de la ecuación de Laplace, y algo de la de Poisson, prestando particular atención al problema de Dirichlet, que Echegaray definía de la manera siguiente (p. 288): «Determinar una armónica $U,{ }^{192}$ que satisfaga a la ecuación diferencial de Laplace, y que en cada punto de la superficie tenga un valor determinado: $U_{0}$ para $a_{0} ; U_{1}$ para $a_{1} \ldots$, en general $U$ para $a{ }^{193}$. Para desarrollar este tema, comenzó utilizando el ejemplo clásico de la transmisión del calor. Su táctica era la siguiente (p. 310):

«El problema de Dirichlet es... teorema importantísimo para varias cuestiones de la Física Matemática. Se demuestra su posibilidad experimentalmente y pudiéramos agregar: substituyendo al concepto abstracto de la armónica, concepto de puro análisis matemático, el concepto concreto y experimental de temperatura. Se parte... de este hecho: que en un cuerpo sólido homogéneo e isótropo en el cual se conservan los diferentes puntos de la superficie a temperaturas fijas, determinadas y continuas, se establece para cada punto del interior una temperatura fija, determinada y única; y como esta temperatura, según la ecuación de Laplace, que es la que rige la distribución de temperaturas en los cuerpos sólidos, representa una armónica, la solución es única y existe en la teoría de las temperaturas y existirá, por lo tanto, en el problema del análisis".

El problema era, naturalmente, que «esto, y con razón, no satisface a los matemáticos». Había, por consiguiente, que tratar el problema desde el punto de vista del análisis, aunque no estuviese resuelto completamente: "Así, varios de los teoremas que vamos a explicar son, en cierto modo, exploraciones alrededor del problema principal: son trabajos de aproches [sic]" (p. 312).

Aprovechaba Echegaray el problema de Dirichlet para resolver algunos ejemplos concretos, así como para iniciar el estudio de las funciones de Green como medio de resolver el problema de Dirichlet.

Las últimas lecciones están dedicadas a desarrollar algunos ejemplos concretos relativos a la teoría del potencial: potencial de una superficie homogénea; atracciones de una superficie esférica ponderable y homogénea para cualquier punto interior o exterior; potencial y atracción de una capa esférica; y potenciales de un elipsoide macizo y homogéneo, de un pequeño imán, y de una doble hoja eléctrica o magnética. Como colofón, 


\section{José Echegaray: entre la ciencia, el teatro y la política}

la última lección introducía al lector a los polinomios de Legendre y a las funciones esféricas de Laplace.

El octavo curso (1912-1913) tuvo como tema las «Ecuaciones de la Mecánica», en particular las ecuaciones canónicas de Hamilton. Para Echegaray era (pp. 18-19):

«indispensable, que en la empresa que tuve el atrevimiento de acometer, en este propósito de escribir una enciclopedia, siquiera elemental, muy elemental, de las teorías generales de la Física Matemática clásica y de la Física Matemática moderna, como preparación para más amplios estudios; es indispensable, repito, que dedique un curso entero a... [las] Ecuaciones generales de la Mecánica.

$\mathrm{Y}$, en efecto, yo vengo desarrollando, y he de desarrollar en los límites de lo posible, la que sigo llamando, para abreviar la expresión, Física Matemática clásica. Pero si no toda ella, casi toda ella, con un cortísimo número de excepciones, se funda en la hipótesis que dominó durante la pasada centuria, que venía dominando desde los orígenes de la ciencia moderna, y que hoy, aunque rudamente combatida, no arrió su bandera y aún hace marcar su influencia poderosa, como hemos demostrado y como seguiremos demostrando: y aún obtiene ante la ciencia modernísima más de una victoria que señalaremos a su tiempo... la hipótesis mecánica".

Este curso de 1912 a 1913 constituye, en general, un buen y bastante completo tratado de mecánica analítica: principio de D’Alembert, ecuaciones de Lagrange, ecuaciones de Hamilton, corchetes de Poisson y sus propiedades, diferenciales totales, condiciones de integrabilidad, ecuación de Hamilton-Jacobi (para Echegaray, simplemente ecuación diferencial de Jacobi), algo de soluciones de ecuaciones en derivadas parciales (cuestión obligada para abordar la resolución de la ecuación de Hamilton-Jacobi), teorema de Liouville, y teoría de los invariantes integrales, son los apartados principales de la obra ${ }^{194}$.

La última conferencia dictada aquel curso es particularmente interesante, puesto que en ella vemos como el anciano profesor (tenía ya ochenta años), atisbaba algo de la dirección por donde iba a ir la física en el futuro, demostrando, al mismo tiempo, una información bastante actualizada de algunas cuestiones. Así, buscando apoyos para la mecánica racional en los desarrollos más recientes de la física, señalaba (pp. 531-532):

«Precisamente entre los trabajos más modernos se encuentran los muy notables, curiosísimos y muy dignos de estudiar, del reciente congreso o consejo (así se llama) de Física que se ha celebrado no hace mucho en Bruselas ${ }^{195}$.

Allí se ha tratado ampliamente de la teoría de los gases y de las radiaciones en general.

Pero estas cuestiones se enlazan íntimamente con la mecánica estadística, la que a su vez se apoya en las ecuaciones de Lagrange y en las canónicas de Hamilton.

En esas discusiones, a la par que se habla y se discute sobre la hipótesis atrevidísima y original de los Quanta, es decir, del atomismo universal, no ya del átomo 
ponderable, no ya del átomo eléctrico, sino del átomo de la energía, y aún, agrega Mr. Poincaré ${ }^{196}$, con sus dejos de ironía, del átomo del tiempo, a la vez, repetimos, se habla de las ecuaciones canónicas de Hamilton.

No son, pues, tales teorías vejeces gloriosas; serán, en todo caso, vejeces que piden su puesto entre los grandes problemas del modernismo.

El programa de este curso no ha sido, lo repetimos una vez más, inoportuno».

Aparentemente, Echegaray también analizó, durante el curso que ahora estoy considerando, la teoría de los cuantos, pero suprimió esa parte de sus conferencias al dar a la imprenta el texto del curso. "La he suprimido, en primer lugar, para no destruir ni perturbar la unidad del programa y, además, porque todos los problemas de la Física moderna, que he discutido, he de tratarlos, si me es posible, y con mucha más amplitud, en otros cursos» (p. 533). Desgraciadamente, no le fue posible, y lo único que nos ha llegado son unos pocos comentarios en los que, a modo de conclusión, mostraba las aguas turbulentas en las que estaba navegando; el patético esfuerzo de un hombre educado en la ciencia clásica por salvar algo de su mundo (pp. 533-534):

«Después de todo, aunque bien suprimida está en las conferencias impresas esta parte a que me refiero, en las explicaciones orales creo que no formaba con el resto de las explicaciones un dualismo chocante; al menos, he procurado armonizar unas con otras.

Era poner frente a frente, casi por exigencia lógica, toda la Física matemática clásica y la Física modernísima; que ya me parece poco llamarla simplemente moderna.

Era contrastar la afirmación con la negación; la fe antigua con el descreimiento moderno; el principio de la discontinuidad ante la ya célebre hipótesis de Mr. Planck. Contra las ecuaciones diferenciales se eleva, con evidente hostilidad, la escuela moderna, que es alzarse, acaso sin quererlo, contra dos siglos de gloriosos triunfos.

Y, pues la legitimidad y la eficacia de las ecuaciones diferenciales en la ciencia fisica se ponen en duda, no fuera generoso ni prudente abandonarlas de pronto.

Yo no niego ni la legitimidad relativa de la nueva escuela, ni el rigor lógico de algunas de sus afirmaciones, que más que afirmaciones son negaciones.

No pongo en duda la fecundidad de la nueva orientación; pero lo que sí niego, es que por seguir esta orientación, sea preciso ni conveniente abandonar las maravillosas orientaciones de los siglos XVIII y XIX».

El año siguiente, 1913-1914, volvió a la «Teoría de los torbellinos». Tras recordar algo del contenido del curso 1910-1911, en el que había comenzado a estudiar los torbellinos, Echegaray pasaba a estudiar problemas que ya había tratado entonces, pero adoptando ahora un tratamiento más general: por ejemplo, en 1910-1911 había resuelto el problema de los movimientos del agua del mar que rodea a un barco, para el caso de torbellinos rectilíneos y paralelos; en 1913-1914 abordaba el mismo problema como parte del estudio de fluidos incompresibles y de densidad constante y uniforme, situados en un espacio (ilimitado) de tres 
José Echegaray: entre la ciencia, el teatro y la política

dimensiones. El procedimiento que seguía para resolver este tipo de problemas se basaba en lo que denominaba "problema inverso de la teoría de los torbellinos», en el que suponía que se conocen inicialmente las tres componentes de cada torbellino en función de $\mathrm{x}, \mathrm{y}, \mathrm{z}, \mathrm{y}$ del tiempo, $\mathrm{t}$, para un instante dado, y partiendo de estos datos se obtiene el movimiento general del fluido en toda su extensión. En realidad, aquel curso se puede considerar como una buena aunque relativamente anticuada y, desde luego, lejos de ser completa, exposición de la hidrodinámica, una exposición en la que se prestaba bastante atención a los desarrollos matemáticos. Da una idea del talante de la exposición de Echegaray el que basase sus desarrollos en las obras e investigaciones de Appell, Poincaré, Horace Lamb, y, en el punto más avanzado de su curso, cuando estudió movimientos en fluidos viscosos, George Gabriel Stokes, uno de los más finos, precisos y fiables físicos del siglo XIX, pero que, no obstante, no pudo ni supo vislumbar los caminos por los que iba a ir en el futuro la física ${ }^{197}$. En más de un sentido, y tanto por el talante como por algunos de los temas seleccionados, existe un cierto parecido, salvando, naturalmente, las distancias, entre este volumen del curso de Echegaray y las Baltimore Lectures on Molecular Dynamics and the Wave Theory of Light que Kelvin (1884) desarrolló en 1884.

Y llegamos así al último curso dictado por Echegaray, el décimo, el del año académico 1914-1915; un curso que, si nos atenemos a lo publicado, se vio interrumpido en la lección decimonovena, para no reanudarse más (el 14 de septiembre de 1916 Echegaray falleció). El tema abordado aquel año fue el de la "Teoría cinemática de los gases», y para su desarrollo tomó como "guía ... la obra elemental de Watson en su segunda edición, que es del año 1893»; es decir, se basó en el A Treatise on the Kinetic Theory of Gases de Henry W. Watson, cuya primera edición publicó Clarendon Press (Oxford) en 1876, aunque reconocía que el texto indiscutible para una discusión más completa eran las Vorlesungen über Gastheorie de Boltzmann (1896-1898) ${ }^{198}$.

Comenzaba Echegaray considerando un ejemplo en el que se suponía al gas sustituido por un sistema de «esferillas sumamente pequeñas, de igual [y muy pequeño] radio, de igual masa» (p. 134), formando un volumen muy pequeño con relación al volumen total del espacio en el que se agitan, y resolvía dos problemas: encontrar el "valor medio de la velocidad en un sistema de esferillas» y el "valor medio del cuadrado de las velocidades» (p. 116); esto es, básicamente lo que ahora denominamos "función de distribución de velocidades». Pasaba entonces a estudiar otro ejemplo, más complicado, en el que el gas se suponía compuesto «no 
de un sistema, sino de dos sistemas distintos de esferillas elásticas que, mezcladas entre sí, se agitan y chocan" (p. 134). Una vez calculado el "cuadrado medio de las velocidades para las esferillas de ambos sistemas o de un número cualquiera de sistemas» (p. 182), llegaba a la conclusión (una forma del teorema de equipartición) de que (p. 183): «Si están mezclados muchos gases o, en nuestro simbolismo, muchos sistemas de esferillas, y el conjunto de sistemas ha llegado a un estado permanente, la energía media o la semifuerza viva de las esferillas del primer sistema será igual a la energía media del segundo, y del tercero, y de todos los sistemas. En suma, la energía total se habrá dividido por partes iguales entre todos los sistemas. Subsiste el principio que ya indicamos de la equipartición de la energía entre todos los sistemas. Y, por fin, si la semifuerza viva representa la temperatura o una cantidad proporcional, podemos afirmar que la temperatura media de cada sistema es la misma".

Al llegar a este punto, es conveniente señalar que Echegaray pasó con más pena que gloria por un problema, el del teorema de equipartición, que resultó ser central para la nueva física cuántica ${ }^{199}$. En efecto, ya Maxwell (1860) -antes que él Waterston, aunque pasarían bastantes años hasta que el trabajo de éste fuese rescatado del olvido y publicadose dio cuenta en su clásico artículo «IIlustrations of the dynamical theory of gases", de que la equipartición energética conducía a problemas; en concreto: producía discrepancias entre los calores específicos calculados y los medidos, tanto para gases diatómicos como para los poliatómicos ${ }^{200}$. Tan serio era el problema del teorema de equipartición que Kelvin (1901) lo incluyó como la "nube II" en su célebre artículo "Nineteenth century clouds over the dynamical theory of heat and light», en el que resumía los problemas básicos que obstaculizaban el progreso de la física clásica en el comienzo del nuevo siglo.

Pronto se vio que el teorema de equipartición estaba también en la base de las dificultades que plagaban la teoría del cuerpo negro (que buscaba encontrar la ley de distribución de radiación). La equipartición energética llevaba a la ley de Rayleigh-Jeans, que, aunque impecable desde el punto de vista de la física clásica, estaba afectada por problemas tan serios como el de la «divergencia infrarroja». La ley de distribución que Planck encontró en 1900 no resolvió las dificultades, ya que su justificación teórica era más que dudosa ${ }^{201}$. El tema del teorema de la equipartición de la energía fue discutido intensamente en el Congreso Solvay de 1911 al que me he referido antes, y cuyas actas Echegaray mostró conocer ya desde el curso 1912-1913. Significativa- 
José Echegaray: entre la ciencia, el teatro y la política

mente, la conferencia inaugural de aquella reunión, a cargo de $\mathrm{H}$. A. Lorentz, uno de los grandes líderes de la física de entonces, se titulaba "Sur l'application au rayonnement du théoréme de l'équipartition de l'énergie». De manera análoga, una breve carta de lord Rayleigh -que no había podido asistir al congreso-, incluida en las actas después de la intervención de Lorentz, tenía al mencionado teorema como uno de sus principales protagonistas; finalmente, y para no alargar demasiado estos comentarios, el siguiente artículo, de J. H. Jeans ("La théorie cinétique de la chaleur spécifique d'aprés Maxwell et Boltzmann») tenía como primera sección una titulada "Le théoréme d'équipartition". A falta de otros datos, el que Echegaray no efectuase, en el curso que estamos analizando, ningún comentario acerca de la importancia que para la física de aquellos años tenía el teorema de equipartición, se puede, razonablemente, interpretar como una muestra de la superficialidad que caracterizaba a la mayoría de sus tratamientos: había pasado, al tener en sus manos las actas del Consejo Solvay, ante reiteradas discusiones relativas a la importancia crucial que los problemas que suscitaba el teorema de equipartición tenían para el futuro de la física, $y$, aparentemente, no se había enterado. Tal vez, porque involucraban unos conceptos y unos problemas que se alejaban cada vez más de los conceptos y problemas con los que él se sentía cómodo.

Continuando con su curso 1914-1915, tenemos que otra cuestión que estudió entonces fue la del «número de choques que se realizan en la unidad de tiempo y en la unidad de volumen entre las esferillas $e$ cuyo número es $N$, del primer sistema y las esferillas $e$ ' en número ' $N$ ' del segundo sistema» (p. 197); problema que una vez resuelto permitía abordar el de la determinación del «camino medio que recorre cada esferilla entre choque y choque» (p. 208), una cuestión básica para la física estadística. También sustituyó las «esferillas» formadas por discos circulares, elásticos, moviéndose en un plano, chocando unos con otros, hasta llegar a un estado de movimiento constante, tratando después el caso de cuerpos de forma arbitraria pero continua (cuestión que le obligaba a discutir los momentos de inercia y otros teoremas del movimiento de un cuerpo sólido). Es en estos temas en donde se detiene el curso. Y también este estudio centrado en la admirable figura de José Echegaray. 


\section{Notas}

1 "Discurso del Excmo. Sr. D. Santiago Ramón y Cajal», en Discursos leídos en la solemne sesión celebrada bajo la presidencia de S. M. el Rey D. Alfonso XIII para hacer entrega de la medalla Echegaray al Excmo. Señor D. Santiago Ramón y Cajal el día 7 de mayo de 1922 (Real Academia de Ciencias Exactas, Físicas y Naturales, Madrid 1922), pp. xxix-xxxv; pp. xxix-xxxi.

2 Gino Loria (1919) y José María Plans (1926) han utilizado, refiriéndose a Echegaray, García de Galdeano y Torroja, el término de "período de los sembradores".

3 Entre los estudios que se ocupan de la matemática en España antes de 1850, merecen citarse: Cuesta Dutari $(1974,1983)$, Sánchez Pérez $(1929)$ y Garma $(1978,1988)$

4 Para una visión variada de algunos de los principales problemas que aquejaron a la ciencia española del período que va de la Ilustración a la guerra civil de 1936, ver los trabajos incluidos en Sánchez Ron, ed. (1988).

5 Sobre García de Galdeano, ver Hormigón (1981, 1982, 1988).

6 Entre las fuentes documentales que tratan la vida y obra de Echegaray se encuentran las siguientes: los Recuerdos de Echegaray (1917), que sólo cubren hasta la llegada a Cartagena, en 1870, de Amadeo de Saboya; las biografias de Antón del Olmet y García Carraffa (1912), de Martínez Olmedilla (1949) y Fornieles Alcaraz (1989); los artículos publicados a raíz de su muerte (por ejemplo, en Madrid Científico, ${ }^{\circ}$. 896, pp. 478-484, o García de Galdeano (1916) y Rodríguez Mourelo (1916), o con ocasión de la celebración, en 1932, del centenario de su nacimiento (como ejemplos están el de Sánchez Pérez (1932), el de Ibérica 4, 338-341, o los incluidos en la Revista de Obras Públicas (LXXX, 201-230; de especial interés son los trabajos de V. Machimbarrena, "Echegaray, alumno y profesor de la Escuela de Caminos», pp. 201-206, y A. Peña Boeuf, "Echegaray, matemático", pp. 210-212), o el folleto editado por la Academia de Ciencias de Madrid recogiendo los discursos de L. Torres Quevedo, P. Carrasco, M. de Sandoval, P. González Quijano, y los hermanos Alvarez Quintero; finalmente recordemos también la voz "Echegaray» en la Enciclopedia Universal Ilustrada Espasa-Calpe, vol. 19, pp. 10-15 (Madrid, 1915), así como García de Galdeano (1905), Rey Pastor (1916), Rodríguez Carracido (1917) y Garma (1983 a).

7 Estrictamente lo que sucedió es que la Sociedad Económica de Amigos del País creó en Murcia una cátedra de Agricultura, dotada con 6.600 reales, que se incorporó al Instituto de la localidad. Echegaray Lacosta fue elegido titular de la misma, pronunciando el 10 de enero de 1837 el discurso inaugural. En 1845, a instancias suyas, se estableció una cátedra de Griego, de la que se ocupó de forma gratuita. Escribió también el padre de Echegaray obras como Informe sobre el estado del ramo de sedas en la provincia de Murcia, y Memorias sobre las causas de la sequía en las provincias de Almería y Murcia, y las medidas para atenuar sus efectos. Datos incluidos en Fornieles Alcaraz (1989:51-52).

8 Para más datos acerca de los estudios de Echegaray en Murcia, ver Machimbarrena (1932).

9 Echegaray (1917, vol. 1: 10-11).

10 Echegaray (1917, vol. 1: 404).

11 Ibíd. Sin duda que Echegaray se refería a José Mariano Vallejo (1779-1846); autor de textos como Adiciones a la Geometría de D. Benito Bails (Madrid, 1806), Memoria sobre la curvatura de las lineas en sus diferentes puntos, sobre el radio de curvatura y sobre las evolutas (Madrid, 1807), Tratado elemental de Matemáticas, 5 vols. (Madrid, 1813) y Compendio de Matemáticas puras y mixtas (Mallorca, 1819). Sería ya en Madrid, estu- 


\section{José Echegaray: entre la ciencia, el teatro y la política}

diando con Ángel Riquelme, cuando Echegaray comprendería con claridad la geometría analítica.

${ }^{12}$ Merece la pena recordar que en aquella época se tardaba quince días en ir (en una diligencia arrastrada por mulas) de Murcia a Madrid.

${ }^{13}$ Lo que hoy denominaríamos cálculo diferencial e integral.

${ }^{14}$ En su, por otra parte, magnífico libro Peset, Garma y Pérez Garzón (1978) afirman que el primer escalafón de catedráticos de la Universidad española fue el preparado por Gil de Zárate en 1851. Puede llevar a una imagen más deformada de la necesaria, el que basándose en dicho escalafón hablen de que por entonces solamente existían dos catedráticos de Matemáticas en las universidades españolas: Travesedo y Juan de Cortázar. Más indicaciones relativas a profesores y cátedras de Matemáticas existentes en España (no necesariamente en la Universidad) antes de la ley Moyano se encuentran, aunque dispersas, en Moreno González (1988), en donde se habla también de otros escalafones anteriores al de Gil de Zárate.

${ }^{15}$ Nótese el término empleado por Echegaray: matemáticas elementales.

${ }^{16}$ Una diferencia importante entre la Escuela de Caminos y la École Polytechnique es que esta última ofrecía instrucción únicamente durante dos años, tras los cuales aquellos que deseaban convertirse en ingenieros debían pasar otros dos años en alguna de las diversas escuelas técnicas; por ejemplo, la École des Ponts et Chaussées, la École des Mines, la École de Génie (militar) o la École d’Artillerie.

17 Ver Klein (1928).

${ }^{18}$ Las distintas épocas de la Escuela de Caminos (hasta el siglo XIX) han sido estudiadas por Rumeu de Armas (1980).

${ }^{19}$ Como ha señalado Lusa Monforte (1985), los Decretos Fundacionales de las Escuelas de Ingenieros fundadas en aquellos años reflejan bastante claramente lo que la emergente burguesía española esperaba de los nuevos titulados: «Hay que crear escuelas para abrir nuevos caminos a la juventud ansiosa de enseñanza, dirigiéndola hacia las ciencias de aplicación y hacia las profesiones para las cuales hay que buscar en las naciones extranjeras personas que sepan ejercerlas con todo el lleno de conocimientos que exigen» (R. D. Fundacional de la carrera de Ingenieros Industriales, 4 de septiembre de 1850).

${ }^{20}$ Estos datos aparecen en el artículo de Machimbarrena (1932: 201), basado en el expediente de Echegaray existente en la Escuela de Caminos.

21 Echegaray (1917, tomo I: 20-21).

22 En sus Recuerdos, Echegaray (1917, tomo I: cap. XXIII) se refirió a Juan Subercase como «la figura por entonces más respetable y más importante del Cuerpo de Caminos». Sobre Subercase, véase Sáenz Ridruejo (1990: 53-98).

${ }^{23} \mathrm{El}$ programa que se cita es el correspondiente al año 1848; posteriormente se introdujeron modificaciones, aunque no las trato aquí puesto que involucraban cambios relativamente menores (véase, en este sentido, Rumeu de Armas [1980: 546 y ss.], o los distintos volúmenes de la Revista de Obras Públicas).

${ }^{24}$ Esto era consistente con el hecho, ya mencionado, de la influencia de las Escuelas Técnicas francesas en las españolas.

${ }^{25}$ Echegaray (1917, tomo II: 74). Y otro tanto sucedía en literatura, como señalaba inmediatamente (ibid., p. 76): "Víctor Hugo, Lamartine, Dumas padre, Dumas hijo, Federico Soulié, Balzac, Eugenio Sue y otros inmunerables escritores, todos franceses, formaban los dioses mayores y menores de mi Olimpo literarion.

${ }^{26}$ Por lo que sé, a la hora de estudiar autores no franceses Echegaray también recurría, siempre que podía, a traducciones de sus obras al francés. Así estudió, como ve- 
remos, las Disquisitiones Arithmeticae de Gauss en una versión francesa. Hay que tener en cuenta además que todo indica que Echegaray no sabía alemán (afirmación de Tomás Rodríguez Bachiller en Glick [1982]).

27 En la época de Echegaray, cuando alguien terminaba sus estudios de ingeniería de Caminos, pasaba a formar parte del Cuerpo de Ingenieros de Caminos, estando a partir de ese momento a las órdenes de la dirección del cuerpo. Se entraba de esta manera en una carrera en la que se iba subiendo en el escalafón -y en emolumentos- desde Ingeniero Segundo hasta Inspector General. En 1855, por ejemplo, existían 12 inspectores generales, 20 ingenieros jefes de primera clase, 30 ingenieros jefes de segunda clase, 50 ingenieros primeros y 26 ingenieros segundos (Revista de Obras Públicas III, 7 [1855]).

28 Echegaray (1853 b, 1854).

29 En general, en la Revista de Obras Públicas predominaron los trabajos de índole técnica; en este sentido, y aunque no fue el único, Echegaray no se ajustó a la línea predominante en la revista.

${ }^{30}$ Aquí entiendo por «originalidad», nueva aportación al cuerpo de conocimientos universal.

31 Echegaray (1917, tomo I: 126). Ese tercer artículo lo escribió Echegaray durante su estancia en Almería, a la que pronto me referiré.

32 Véase, en este sentido, Hiebert (1962).

33 Echegaray (1853 a: 44).

34 Echegaray (1853 b: 98 ).

35 Una de las pocas ocasiones en que Echegaray se refirió a Helmholtz durante su "primera época» (hasta comienzos del siglo XX), fue en un artículo que publicó en 1867 en la Revista de Obras Públicas y que luego incluyó en el tomo 1 de Teorías modernas de la Física. Se lee allí (Echegaray 1867 b, 1873: 58): «Sería necesario que citásemos libros enteros: las obras de Mayer, de Joule, de Thomson, de Clausius, de Zeuner, de Helmholtz, de Rankine, de Reech, de Grove, de Laboulaye, de Favre, de Hirn...»

${ }^{36}$ La familia de Echegaray se había trasladado desde Murcia a Madrid poco después de que éste iniciase sus estudios de Caminos. En Madrid, el padre de Echegaray fue profesor en la Escuela de Veterinaria.

37 Echegaray (1917, tomo I: 401).

38 Ibíd., pp. 405-406.

39 Ibíd., pp. 125.

${ }^{40}$ Nótese, como ya indique antes, que del libro de Gauss, Echegaray daba el título de una traducción al francés (se publicó una en 1807).

${ }^{41}$ Sobre las Disquisitiones arithmeticae y su importancia, véase Kline (1972, cap. 34), Collette (1985 tomo II, cap. 7), Bühler (1981, caps. 3 y IV) y Wussing (1984, cap. 3).

42 El pronunciamiento de 1854 (el general Dulce se sublevó con más de dos mil hombres y el conde de San Luis, jefe del Gobierno, envió fuerzas contra los rebeldes).

43 También, al ser el profesor más joven, se le dio el cargo de Secretario.

44 Ver Revista de Obras Públicas III, 7 (1855). Por lo que sé, el más distinguido de estos profesores fue Eduardo Saavedra (1829-1912), quien, aparte de otros títulos, fue miembro de la Real Academia de Ciencias. Se da el caso además que cuando Saavedra entró en la Academia (fue elegido en marzo de 1868, tomando posesión en junio de 1869), ocupó la medalla $n .^{\circ} 6$, perteneciente a la sección de Ciencias Exactas, sustituyendo al propio Echegaray, que pasó (en enero de 1868) a la medalla n. ${ }^{\circ} 15$, perteneciente a la sección de Ciencias Físicas. De las relaciones que Saavedra mantuvo con Echegaray da idea el que cuando éste fue nombrado Director de Obras Públicas, designó a Saavedra para la 


\section{José Echegaray: entre la ciencia, el teatro y la política}

jefatura del Negociado de Ferrocarriles; pocos meses después, con Echegaray ya ministro de Fomento, pasó a sustituir al nuevo ministro en la Dirección de Obras Públicas que éste dejaba vacante. Asimismo, fue Echegaray quien pronunció el discurso de contestación al de entrada en la Academia de Ciencias de Saavedra (Echegaray 1912 a). Sobre Saavedra, ver Sáenz Ridruejo (1990: 341-347).

45 En una ocasión, por enfermedad del profesor titular, y durante unos meses, explicó también Construcción.

46 Echegaray (1917, tomo 11: 74).

47 Ibíd., pp. 74-76.

${ }_{48}$ Es interesante esta referencia al Journal de Mathématiques pures et appliquées, dirigido por Liouville, ya que en esa revista se publicaron, en 1846, las obras matemáticas de Evariste Galois, a las que, como veremos más adelante, dedicaría Echegaray su atención a finales de siglo.

49 Cournot (1841).

50 El Traité élémentaire de la théorie des fonctions... de Cournot dedicaba dos capítulos al cálculo de variaciones (pp 113-155 del segundo volumen).

51 Ibíd., p. 288.

52 Él mismo así lo reconoció al referirse al Cálculo de variaciones como un «tratadito... que en rigor no tenía mérito intrínseco, pero que para la enseñanza me pareció utilísimo" (Echegaray, 1917, tomo II: 28). En lo referente a sus ventas, éstas fueron muy modestas: no se vendieron -según Echegaray-, en total, más de veinte ejemplares.

53 Ver Woodhouse (1810).

54 En la época a la que nos estamos refiriendo ahora, esto no era raro entre profesores de Escuelas de ingenieros.

55 Echegaray calculaba que con una academia de este tipo podría obtener una renta anual de más de cien mil pesetas, frente a las 3.250 pesetas que ganaba por entonces.

56 Echegaray (1917, tomo II: 19).

57 A su regreso a España, preparó un informe titulado «Idea general sobre el sistema de perforación del túnel de Mont-Cenis», que fue publicado en 1862 por la Revista de Obras Públicas. Posteriormente, la Escuela de Caminos lo editó como una monografia: Memoria sobre los trabajos de perforación del túnel de los Alpes escrita en el año 1860 (Echegaray 1863). Echegaray se basó en los datos de las máquinas que había memorizado al verlas, ya que, por motivos de seguridad, no se le permitió tomar notas.

58 Esta exposición se inauguró el 1 de mayo de 1862, clausurándose el 15 de noviembre. Fue visitada por 6.211.000 personas. Sobre ella, ver Findling, ed. (1990: 23-30).

${ }^{59}$ El discurso de Echegaray fue contestado por Lucio del Valle (1815-1874).

60 Ver, en este sentido, Camarero y Camarero, comps. (1970).

61 Este artículo aparece reproducido en Camarero y Camarero, comps. (1970). Es interesante señalar que Picatoste poseía notables conocimientos de la historia de la ciencia en España (ver, en este sentido, Picatoste [1891]).

62 El caso de Rey Pastor es, probablemente, el más notable de todos (debido a la importancia de este matemático en la historia de la matemática contemporánea en España). En su participación en la polémica de la ciencia matemática en España, Rey Pastor tomó posición al lado de Echegaray, aunque, eso sí, demostrando un conocimiento histórico mucho mejor que el de aquél. Ejemplo paradigmático de las opiniones de Rey Pastor es su frase: "España no ha tenido nunca una cultura matemática moderna», pronunciada en su célebre discurso de apertura de curso en la Universidad de Oviedo (Rey Pastor 1913: 65). 
63 Algunos datos sobre Vera se encuentran en Pecellín Lancharro (1988).

${ }^{64}$ Recuérdese sus cuatro tomos dedicados a la Historia de la Matemática en España (Vera 1929, 1931, $1933 \mathrm{a}, \mathrm{b}$ ).

${ }^{65}$ No obstante los comentarios críticos y mordaces que Vera (1937: 530) dedicaba a Echegaray en su conferencia del Ateneo, le reconocía, junto a García de Galdeano, como «el introductor de la Matemática moderna en España».

66 Echegaray (1917, tomo II: 277).

67 Echegaray (1917, tomo II: cap. XLVIII).

68 Seguramente se refería a Marcelino Menéndez y Pelayo (1894).

69 Realmente, Echegaray no estaba siendo justo aquí con algunos de sus críticos; Picatoste, por ejemplo, sin ser, por supuesto, ni de lejos un matemático de la calidad de Echegaray, tenía algunas habilidades y conocimientos matemáticos.

70 Dada la irregular secuencia de publicación de la Revista de los Progresos de las Ciencias, los artículos sobre la "Introducción a la Geometría superior» aparecieron entre 1866 y 1869 (ver la bibliografía de escritos de Echegaray incluída en el presente estudio).

71 Así la denominó Rey Pastor (1916).

72 Entre los discípulos de Torroja hay que destacar a Miguel Vegas, profesor en la Universidad de Madrid, quien en 1894 publicó un Tratado de Geometría analítica (Vegas 1894).

73 Ver, por ejemplo, Torroja $(1893,1899)$ y García de Galdeano $(1891,1892,1895)$. También hay que citar a Eulogio Giménez (1878-1881) (o Jiménez) con el curso que desarrolló en la Institución Libre de Enseñanza entre 1878 y 1881 dedicado a «Introducción a la Geometría sintética" (en la versión, especialmente, de Steiner, enriquecida con puntos de vista de Favaro). En este curso Jiménez, un hombre de ideas políticas avanzadas y que participó en las luchas de la revolución del 68, trató multitud de cuestiones, tales como puntos, ejes y planos de semejanza, puntos, rectas y planos de igual potencia, polarización, etc., tomando como base de toda la exposición el estudio de la "razón armónica». Sobre Torroja y sus ideas y aportaciones a la geometría, ver Garma (1983 b); acerca de García de Galdeano, Hormigón (1982), y sobre Eulogio Jiménez, Octavio de Toledo (1912).

${ }^{74}$ Muy probablemente, también leyó el Aperçu historique sur l'origine et le developpement des méthodes en géometrie (1837), obra que logró gran popularidad.

75 Hacia 1840 ya se utilizaban en la Escuela de Caminos traducciones de textos de Monge (cf. Rey Pastor 1915: 13).

${ }_{76}$ Las obras más representativas de estos geometras (Chasles, ya mencionado, aparte) son: el Traité de géometrie descriptive (1799) de Monge y el Traité des propriétés projectives des figures (1822) de Poncelet. Sobre esta última obra es interesante, e ilustrativo del enfoque característico de la geometría sintética, el siguiente comentario de Chasles (1837: 215): «Le Traité des propriétés projectives des figures de M. Poncelet, qui a pour but, comme l'indique le titre, la recherche des propriétés qui se conservent dans la transformation des figures par voie proyective; et oú, par l'usage heureux de trois doctrines puissantes, le principe de continuité, la théorie des polaires réciproques, et la théorie des figures homologiques il deux et á trois dimensions, le savant auteur a su démontrer, sans un mot de calcul, toutes les propriétés connues des lignes et des surfaces du second degré, et un grand nombre d'autres qui lui sont dues, et dont plusieurs sont regardées déjà comme des plus importantes de cette riche théorie».

${ }_{77}$ La tradición investigadora de los Monge, Poncelet, Chasles o Dupin, se mantuvo en Francia hasta finales del siglo XIX (ver Daston 1986). Acerca de la situación en Alemania, ver Rowe (1989). 


\section{José Echegaray: entre la ciencia, el teatro y la política}

78 Para exposiciones generales del desarrollo de la geometría, véanse Boyer y Merzbach (1989, cap. 24), Kline (1972, cap. 35) y Klein (1928). En lo relativo a Klein recuérdese en particular su "programa de Erlangen" de 1872. La geometría proyectiva sintética de Staudt tuvo como introductor en España a Torroja, quien en 1884, dentro de sus cursos en la Facultad de Ciencias de Madrid, sustituyó el sistema geométrico de Chasles por el de Staudt.

79 Se refiere a Trudi (1862).

${ }^{80}$ Los dos artículos básicos de Jacobi sobre esta materia aparecieron en 1841 (vol. 22) en el Journal de August L. Crelle (Journal für die reine und angewandte Mathematik); sus títulos eran: "De formatione et proprietatibus determinanium" ("Sobre la formación y propiedades de determinantes») y «De determinantibus functinalibus» ("Sobre determinantes funcionales»).

${ }^{81}$ Recuérdense, en este sentido, los nombres de Cayley, el mismo Sylvester, Gordan, Clebsch o Max Noether.

82 Sobre este apartado de la biografía de Echegaray, ver Fornieles Alcaraz (1989: caps. V, VI y VII).

${ }^{83}$ Por ejemplo: «Examen de los principios del sistema protector bajo el punto de vista filosófico" (una copia de esta conferencia se encuentra en la biblioteca del Ateneo de Madrid). En el Ateneo debutó a finales de 1857 con una conferencia sobre «Astronomía popular».

84 En el grupo en cuestión figuraban, entre otros: Figuerola, Gabriel Rodríguez, Moret y San Román.

85 Echegaray (1917, tomo II: 324-326).

86 Echegaray (1917, tomo III: 103).

87 El texto de la intervención de Echegaray está recogido en Diario de Sesiones de las Cortes Constituyentes, 5 de mayo de 1869, pp. 1633-1639; cita en p. 1635.

${ }^{88}$ En diciembre de 1872, Echegaray pasó a ocupar la cartera de Hacienda.

89 Citado en Antón del Olmet y García Carraffa (1912: 141).

90 No fue esta obra la primera que escribió; como cuenta en sus Recuerdos, intentos anteriores terminaron en fracasos a la hora de buscar quien las representase.

91 Díez-Canedo (1930); reproducido en Díez-Canedo (2004: 5-6).

92 Sexía el 28 de diciembre de 1874 cuando la República llegó, estrictamente, a su final. Fue entonces cuando, en Sagunto, Martínez Campos proclamó como nuevo Rey de España a Alfonso de Borbón.

93 Banco de España es el nombre que se dio al Banco de San Fernando en 1856.

94 El texto de la intervención de Echegaray se reproduce en Diario de las Sesiones de Cortes. Senado, 8 de mayo de 1902, pp. 625-630. También se incluye en Galvarriato (1932: 360-381).

${ }^{95}$ La III guerra carlista (1872-1876) fue el último intento carlista por lograr el poder mediante las armas.

${ }_{96}$ Para más información acerca de la creación del Banco de España, ver Tortella Casares (1970).

97 Este decreto ha sido reproducido en facsímil por Gabriel Tortella (1970).

98 Ver Cacho Viu (1962: 415) y Jiménez-Landi (1973: cap. XLIII); en estas obras Echegaray aparece con cierta frecuencia a propósito de sus actividades políticas en los años sesenta y setenta. Otro ejemplo, anterior, de las preocupaciones de Echegaray por la mejora de la enseñanza en todos los niveles, lo constituye su participación en 1869 en las «Conferencias dominicales sobre la educación de la mujer» que se celebraron en la 
Universidad de Madrid y en las que tomaron parte muchos futuros institucionistas. La conferencia de Echagaray (1869 b) tuvo lugar el 11 de abril y se tituló «Influencia del estudio de las Ciencias Físicas en la educación de la mujer".

99 Gumersindo Vicuña, Laureano Figuerola y Segismundo Moret, figuran entre los que ocuparon aquel curso la misma tribuna que Echegaray.

100 Parece, aunque no he podido confirmarlo, que durante un período de tiempo muy breve, tras abandonar España Amadeo de Saboya, Echegaray volvió a la Escuela de Caminos.

101 Para más información sobre estos puntos, ver Boyer (1986: cap. XXV) y Collette (1985, tomo II: cap. 8).

102 Merino era doctor en Exactas; también fue director del Observatorio de Madrid y académico de Ciencias.

103 Echegaray (1887, "Advertencia" inicial). Sin pretender necesariamente poner en duda la afirmación que hace aquí Echegaray, diré que en la Academia de Ciencias de Ma. drid sí se encuentran los Mathematische Annalen correspondientes al período comprendido entre 1869 y 1936 (ver Catálogo de revistas y publicaciones periódicas recibidas en su Biblioteca, Real Academia de Ciencias, Exactas, Fisicas y Naturales [Madrid, 1954]). Es posible, por supuesto, y yo no he podido comprobar este punto, que se recibiese la revista con posterioridad a 1887. Nótese también el último comentario de Echegaray (usobre ella no se ha dicho la última palabra») que acaso pueda interpretarse como reveladora de las limitaciones matemáticas de nuestro polifacético personaje.

104 Este es el título que daba Echegaray en las Disertaciones, el título real es el de Leçons de Geometrie.

105 Y por Zoel García de Galdeano.

106 Sobre el Ateneo madrileño hay bastante literatura; véase, por ejemplo, García Martí (1948) y Villacorta Baños (1985)

107 Véase, como ejemplo de una de las conferencias pronunciadas por Echegaray en el Ateneo, el discurso que leyó, en esta ocasión como presidente, el 10 de noviembre de 1898, titulado: “¿Qué es lo que constituye la fuerza de las naciones?» (Echegaray 1898).

108 El título del curso de García de Galdeano fue "La moderna organización de las Matemáticas».

109 Habló sobre «Historia de las Matemáticas».

110 Para una lista completa, ver García Martí (1948: 195-197).

111 Villacorta Baños (1985: 289).

112 Datos acerca de alumnos y sesiones en Villacorta Baños (1985: 292 y ss.).

113 Ver, en cualquier caso, Echegaray (1904).

114 Partes del contenido de curso de Echegaray aparecieron también, en resúmenes preparados por M. Luiña, alumno de la Escuela de Caminos, en la Revista de Obras Públi. cas ("Conferencias del Sr. Echegaray en el Ateneo de Madrid»), XLIV, tomo I, 4-5, 45-49, 146 148, 392-395, 422-425, 490-492, 517-518, 547-551(1897); ibid. tomo II,103-105,132-133, 182183, 394-396 (1897); XLV, 479-480, 555-556 (1898); XLVI, 4-6 (1899). Santiago Garma (1979, 1987) ha analizado algunos aspectos del primer volumen del curso de Echegaray (1897 a); su tratamiento es, sin embargo, demasiado breve, extendiéndose más en la historia de los trabajos de Abel o Galois, así como de sus predecesores, que en Echegaray.

115 Sobre la historia de la teoría y solución de ecuaciones, véanse Octavio de Toledo (1914), Wussing (1984), Boyer (1986), Kline (1972) y Ribnikov (1987). Son interesantes también los comentarios que Jordan (1870) efectuó en el prefacio de su Traité des substitutions et des équations algébriques. 


\section{José Echegaray: entre la ciencia, el teatro y la política}

116 Ver, por ejemplo, su artículo «Réflexions sur la résolution algébrique des équations» (Lagrange 1770), o su Traité de la résolution des équations numériques de toutes les degrés (Lagrange 1826).

117 También habría que recordar, entre otros, los trabajos (menos completos, profundos y originales que los de Abel) que de manera independiente realizó Paolo Ruffini.

118 El término "resolver por radicales» aparece constantemente al estudiar las aportaciones de Abel y Galois. He aquí la definición que dio de él Echegaray (1897 a: 13-14) en su curso del Ateneo: "Se sabe, y está demostrado, que sólo para las ecuaciones de los cuatro primeros grados puede expresarse el valor de $\mathrm{x}$ en función algebraica de los coeficientes; es decir, por medio de una función que sólo contenga aquellas operaciones que consisten en sumas, restas, multiplicaciones, divisiones, potencias y raíces de índice entero; lo cual se expresa abreviadamente, diciendo que las ecuaciones superiores al cuarto grado no pueden resolverse por radicales, en el caso generaly.

119 Abel $(1826,1839,1881)$. Es interesante señalar que en 1896 dos de las principales memorias de Abel fueron traducidas al castellano por Luis Gonzaga Gascó, bajo el título: Memorias sobre la resolución de las ecuaciones algébricas. -I y II.- Sobre la imposibilidad de la resolución algébrica de las ecuaciones, 40 pp. (Valencia).

120 Cursivas añadidas.

121 Ver Galois (1846: 417-433). También es útil la famosa carta que Galois escribió a Auguste Chevalier el 29 de mayo de 1832, la víspera de su muerte (incluida asimismo en Galois 1846, pp. 408-415).

122 En su memoria, Galois se refirió únicamente a grado 1.

123 Echegaray citó también este comentario de Galois.

${ }^{124}$ En las lecciones anteriores Echegaray había presentado los teoremas más elementales del álgebra sobre las raíces, las teorías de las sustituciones y de los grupos, así como la descomposición de las funciones en factores racionales, y divisibilidad. En forma de notas incluyó en su curso interesantes aclaraciones sobre el teorema de Cauchy, las sustituciones semejantes, la fórmula de Lagrange y el teorema de Fermat sobre los números primos.

125 Esta es, esencialmente, la "Proposición I» del artículo de Galois que estoy mencionando. El enunciado que cito es el de Octavio de Toledo (1914: 18-19), puesto que Echegaray no da un enunciado determinado.

${ }^{126}$ La copia en cuestión se encuentra en el fondo antiguo de la biblioteca de la Facultad de Matemáticas de la Universidad Complutense. Es patente que las ocho lecciones de que consta el ejemplar que he manejado fueron impresas por separado en forma de cuadernillos; sobreviven cuatro de las cubiertas de los correspondientes cuadernillos: la primera está fechada en 1898 , la de la lección cuarta en 1899, la de la séptima en 1901 y la de la octava en 1902. A pesar de que el curso se dio en el Ateneo de Madrid, en la biblioteca de esta institución no se conserva ningún ejemplar de este segundo volumen de las Lecciones sobre resolución de ecuaciones y teoría de Galois (Echegaray, 1898-1902).

127 Echegaray (1898-1902; 9).

128 Ibíd., p. 19.

129 Ibíd., p. 85.

130 Este «como veremos» no se plasma en ninguna de las ocho lecciones que conozco.

131 Echegaray (1898-1902: 85).

132 Por ejemplo, el que dice que «el grupo de la ecuación general del grado $n$ es el grupo simétrico" (p. 104).

133 Echegaray (1898-1902: 113). 
134 Ibíd., p. 116.

135 Ibíd., p. 169.

136 Téngase en cuenta que Liouville publicó en su Journal los trabajos de Galois en 1846; esto es, medio siglo antes de que tuviese lugar el curso de Echegaray en el Ateneo. De todas maneras, una medida temporal más adecuada es el año de la publicación del Traité des substitutions de Jordan: 1870.

137 No fue Echegaray el único matemático español que se ocupó por aquellos años de las funciones elípticas; una década antes lo había hecho José Ríus y Casas, un catalán que obtuvo en 1899 la cátedra de Análisis matemático de Zaragoza (que había dejado vacante Luis Octavio de Toledo), y que dirigió la Revista Trimestral de Matemáticas: en 1889 publicó un librito de 101 páginas titulado Origen y propiedades fundamentales de las funciones elípticas, en el que -según manifestaba él mismo- no hacía "más que indicar las propiedades más importantes de una teoría que, siendo hoy el tema favorito de los matemáticos, es todavía bastante ignorada en nuestra Españay (Ríus y Casas 1889: 6).

138 La carta no está fechada, pero probablemente se refiera al curso de 1899 a 1900.

139 Uno de los motivos por los que Echegaray escribió artículos de divulgación científica fue el económico. Así, en sus Recuerdos manifestó (Echegaray 1917, tomo II: 303): «Por lo visto, los libros de ciencia no hacen rico a nadie en España... Los artículos de ciencia popular para los periódicos, ésos ya se portan con más decoro, y por eso he escrito y sigo escribiendo tantos.»

${ }^{140}$ La mayoría incluidos en Ciencia popular (Echegaray 1905 a), libro con el que los ingenieros de Caminos se adhirieron a los homenajes que se dispensaron a su colega con ocasión de habérsele concedido el premio Nobel.

141 Echegaray (1905 a: 577-586, 921-927).

142 Ver, por ejemplo, Russell (1897), en donde se analizan también las opiniones de otros. Acerca de las ideas de Clifford sobre la curvatura del espacio y la teoría espacial de la materia, ver Clifford (1885) y la edición que de esta obra se realizó en 1946, en la que se incluyen interesantes ensayos de Russell y James R. Newman (Clifford 1946).

143 Puede ser conveniente mencionar que sólo he podido localizar (en la Universidad Central de Barcelona y gracias a la ayuda de Antoni Roca) un ejemplar de este libro. Señalaré también que Echegaray publicó artículos (que son partes del Tratado elemental...) dedicados a la termodinámica, en la Revista de Obras Públicas (Echegaray 1868 b y 1871 b).

144 Echegaray (1868 c: 3 ).

145 La Termodinámica de Paul Saint-Robert fue una de las obras que Echegaray citó con mayor profusión en el Tratado elemental. Nótese que no mencionaba a Helmholtz.

146 Ibíd.

147 Echegaray (1868 c: 13).

148 Ibíd., apartado número 60 (fuera de paginación).

149 lbíd., p. 34.

150 Ibíd., p. 12.

151 Ibíd, p. 66.

152 El artículo de Vilar Fiol es el más ambicioso. La siguiente cita de él (p. 71) muestra con claridad sus pretensiones: «En el capítulo [XIX de Observaciones y teorías sobre la afinidad química] y con extraordinaria claridad, explica [Echegaray] el hecho de la combinación, tanto en las reacciones exotérmicas como en las endotérmicas; el por qué del desarrollo de calórico por vibración de las atmósferas etéreas, y además ciertas particularidades de la combinación química, referentes a la paralización de la afinidad a muy 


\section{José Echegaray: entre la ciencia, el teatro y la política}

baja temperatura, al hecho de dos cuerpos que, a pesar de su afinidad no se combinan sin el concurso de una energía extraña y, finalmente, a la afirmación de la Termoquímica cuando dice que la cantidad de calórico que se desarrolla en una combinación, mide en cierto modo la intensidad de la afinidad. Partiendo de sus mismos principios, pretendemos explicar el equilibrio químico con todos sus caracteres fundamentales. Para ello es preciso estudiar a fondo el asunto; de este estudio veremos surgir el verdadero concepto de las reacciones exotérmicas y endotérmicas, esa batallona cuestión de tan gran importancia.»

153 El mismo año que Echegaray publicaba las Observaciones..., aparecía el primer artículo científico del joven Einstein (1901), y es curioso -anecdótico realmente- que en él el futuro creador de la teoría de la relatividad se planteaba un problema en el fondo similar al que estaba considerando Echegaray: Einstein, todavía profundamente influido por la imagen mecánica del mundo, quería estudiar el fenómeno de la capilaridad en base a fuerzas intermoleculares que obedeciesen a leyes del tipo de las gravitacionales newtonianas. Entre las múltiples diferencias que separan a Echegaray de Einstein, se encuentra el que éste evolucionó rápidamente (en 1905 ya estaba manejando los cuantos de radiación de Planck), algo que no sucedió con el español.

154 El más joven de todos, Heisenberg, nació precisamente en 1901.

155 Los nombres que Echegaray citaba en Observaciones... eran van't Hoff, Berthollet y Gibbs.

156 Los programas de estudios correspondientes a la segunda enseñanza, enseñanza universitaria, enseñanzas superiores (ingenieros) y profesionales (profesores mercantiles, maestros de obras, aparejadores, etc.), se pueden consultar, agrupados, en Programas generales de estudios aprobados por S. M. en 26 de Agosto y 11 y 20 de Septiembre de 1858, seguidos de todas las Reales Ordenes dictadas para su ejecución (Imprenta Nacional, Madrid 1858).

$157 \mathrm{Al}$ ser una asignatura de doctorado, y sólo poderse cursar éste en Madrid, la Física matemática estaba limitada - como asignatura- a la capital del Reino. En la época a la que me estoy refiriendo, ocupó esta cátedra Gumersindo Vicuña (autor, entre otras obras, de una Introducción a la teoria matemática de la electricidad [1883]).

158 Hasta entonces eran tres: Exactas, Físicas y Naturales.

159 Más tarde, a partir del Plan del ministro Eduardo Chao de 1873, pasó a la Facultad de Física y Química, primero, y a la sección de Ciencias Físico-Matemáticas después; aquí es donde la encontró Echegaray.

160 Vela (1916: 481)

161 Carrasco, un hombre de ideas republicanas, tuvo que exiliarse. En 1940, la cátedra de Física matemática pasó a ser ocupada por Esteban Terradas. Señalemos asimismo que cuando falleció Vela también se confió a Carrasco, en 1927 y en concepto de acumulada, la cátedra de Astronomía física de aquel.

162 Echegaray (1905 c: 9-10).

163 Ibíd., pp. 44-45.

164 Ibíd., pp. 42-43.

165 Más adelante nos volveremos a encontrar con muestras de que Echegaray estaba, efectivamente, bien informado de algunos aspectos de la nueva física.

166 Más tarde, en su discurso inaugural del Segundo Congreso de la Asociación Española para el Progreso de las Ciencias diría (Echegaray 1910 b: 20-21): "La inercia de una masa en movimiento no depende ya sólo de la materia ponderable; depende de la electricidad que al elemento material acompaña y de las influencias de todo campo 
electromagnético sobre esta masa eléctrica en movimiento. Resultando de aquí una especie de inercia aparente y variable con la velocidad, que podrá despreciarse cuando las velocidades de las masas no pasan de cierto límite; pero que adquiere valor e influencia cuando estas velocidades son comparables a las de la luz".

167 Echegaray (1905 c: 61).

168 Echegaray (1905 c: 61).

169 En otras ocasiones (por ejemplo, en varios lugares de su curso de Física matemática), Echegaray también recurrió al término "Serie de negaciones" y a las ideas que mantenía en su discurso de 1905.

170 Más adelante, al comentar el curso de Física matemática correspondiente al año 1912-1913, nos volveremos a encontrar con las opiniones que Echegaray tenía de la teoría cuántica.

171 Echegaray (1915: 345). Este artículo ha sido comentado, en lo que a la relatividad se refiere, por Otero Carvajal (1989). Con respecto a la relatividad einsteniana, diré únicamente que hizo su aparición pública (la teoría especial) en España en el Primer Congreso de la Asociación Española para el Progreso de las Ciencias, celebrado en Zaragoza en 1908; fueron Blas Cabrera y Esteban Terradas los que mencionaron la teoría de Einstein en sus comunicaciones (ver sobre este punto Roca 1981 y Glick 1986). Echegaray (1908) participó en aquella reunión: fue el encargado de ofrecer un «Resumen de los trabajos de la Sección de Ciencias Matemáticas del Congreson; es posible, naturalmente, que asistiese a las charlas de Cabrera y Terradas. La relación de Echegaray con esta Asociación sería otro tema a desarrollar, pero, desgraciadamente, no puedo entrar también en él aqui; basta con decir que en el Segundo Congreso, en Valencia, pronunció (Echegaray 1910 b) el discurso inaugural (él era presidente de la Sección de Ciencias Matemáticas). Más tarde, de 1913 a 1916, fue el segundo presidente de la Asociación, tras su viejo amigo Moret, que había sido uno de los más firmes promotores de la Asociación.

172 En al menos una ocasión (en el último curso, 1914-1915, de Física matemática que dictó) se refirió Echegaray a las investigaciones de Einstein sobre la interacción gravitacional, investigaciones que culminaron cuando en noviembre de 1915 llegó a las ecuaciones definitivas de la teoría general de la relatividad. En aquella ocasión, manifestó Echegaray (p. 35), demostrando que conocía algo de los trabajos de Einstein: "Varios físicos, sobre todo el célebre Einstein en la teoría de la relatividad; afirma ó afirmaba (antes de publicar su teoría de la gravitación), que es imposible que en la Naturaleza exista una velocidad superior a la velocidad de la luz». (Nótese que este comentario, en el que también aludía a la relatividad especial, de Echegaray podía aplicarse a cualquiera de las teorías $\multimap$, mejor, prototeorías- gravitacionales que Einstein había propuesto a partir de 1907.)

173 Ver también la necrología que Echegaray (1912 b) dedicó a Poincaré.

174 Esto es algo que la Academia sueca hacía y hace regularmente: solicitar a instituciones, cada año, diferentes candidatos.

175 Todos los datos que he manejado concernientes a propuestas proceden de Crawford, Heilbron y Ullrich (1987).

${ }^{176} \mathrm{Pp}$. 2-4. En lo que sigue, y para hacer menos engorrosa la bibliografía, me referiré únicamente a la página del volumen del curso de Física Matemática que esté manejando. Las referencias concretas a los diferentes volúmenes se encuentran en la bibliografia de Echegaray que se incluye en el presente trabajo.

177 Briot (1864).

178 Poincaré $(1889,1892)$; obras basadas en las lecciones que dictó en la Sorbona durante los cursos $1887-1888$ y $1891-1892$. 


\section{José Echegaray: entre la ciencia, el teatro y la política}

179 Fourier (1822) y, probablemente, Lamé (1836).

180 Boussinesq (1901-1903).

181 Esta obra de Poincaré (1890, tomo I) está constituida (tomando el conjunto de los dos volúmenes que la constituyen) por las clases que dictó en la Sorbona en 1888, 1890 y 1899, y sirvió para introducir a la mayoría de los físicos franceses a la teoría maxwelliana del campo electromagnético.

182 Larmor (1900).

183 Lorentz (1909), basado en las conferencias que pronunció en la Universidad de Columbia en la primavera de 1906.

184 Sobre el tema de la dinámica de los electrones Abraham publicó un buen número de trabajos; teniendo en cuenta el título que daba Echegaray, podía estar pensando en Abraham (1902 a, 1903). Es también posible que Echegaray conociese los trabajos de Abraham (y otros, como, por ejemplo, los de Larmor) a través de las traducciones al francés reunidas en H. Abraham y Langevin (1905); en esta obra se incluían M. Abraham (1903, 1902 b).

$185 \mathrm{Si}$ consideramos los libros de Poincaré, entonces tendremos que concluir que Echegaray se estaba refiriendo aqui a Les oscillations électriques, el curso dictado en la Sorbona en 1892-1893, en donde Poincaré (1894) describía las experiencias de Hertz, daba el cálculo del período de las oscilaciones y exponía las discusiones que siguieron a los trabajos de Hertz. Si Echegaray se estaba refiriendo a artículos (lo que es dudoso), entonces las posibilidades son varias, como se puede comprobar sin más que consultar el contenido del tomo X de las Oeuvres de Henri Poincaré (Gauthier-Villars, París 1954).

186 Ver Poincaré (1892); este libro está basado en las lecciones que dictó durante el primer semestre del curso 1890-1891 en la Sorbona.

187 Una vez más, Echegaray recurría a obras de Poincaré como fuente de inspiración: «Hemos demostrado la fórmula de Stokes», escribía (p. 273), "escogiendo para demostración la que indica Mr. Poincaré en su libro de "Electricidad y Óptica", aunque con alguna aclaración para la mejor inteligencia de mis alumnos".

188 William Thomson a Hermann von Helmholtz, 22 de enero de 1867, reproducida en Thompson (1910, vol. I: 514). Ver también Smith y Wise (1989, cap. 12).

189 El movimiento rotacional, sobre todo; solamente al final, hizo Echegaray algunos comentarios acerca del movimiento irrotacional.

190 Con respecto a las fuentes utilizadas por Echegaray, escuchémosle a él mismo (p. 230): "Al exponer la teoría de los torbellinos, pudiéramos dar a nuestros alumnos una larga lista bibliográfica. Preferimos no citar más que tres obras, que son las que tomamos por guía en nuestro trabajo... Estas obras son: $1^{\circ}$ La teoría de los torbellinos de Poincaré. Los capítulos relativos a dicha teoría y los que con ella tienen relación en la obra de $\mathrm{Me}$ cánica de Mr. Appell [1893-19211]; y $3^{\text {a }}$., por último, la obra titulada A Treatise on the Motion of Vortex Rings [Londres 18831, por J. J. Thomson".

191 Recuérdese lo señalado con anterioridad acerca de los resultados matemáticos obtenidos por Helmholtz en 1858.

192 El significado de las funciones armónicas era para Echegaray el siguiente (p. 280): "Así la ecuación de Laplace expresa una propiedad común a multitud de funciones $\mathrm{U}$ de tres variables independientes, $\mathrm{x}, \mathrm{y}, \mathrm{z}$, que son las armónicas».

193 Acerca del problema de Dirichlet, ver, por ejemplo, Iyanaga y Kawada (1980, vol. 1: 419-421) y Monna (1975).

194 Los comentarios de Echegaray en este punto -y en otros lugares del curso- mostraban que conocía la célebre obra de Boltzmann (1896-1898) dedicada a la teoría de los gases. 


\section{José Manuel Sánchez Ron}

678

195 Se refería Echegaray al primer congreso Solvay (o Conseil de Physique), celebrado en Bruselas entre el 30 de octubre y el 3 de noviembre de 1911. Presentaron comunicaciones en aquella histórica reunión, dedicada a La Théorie du rayonnement et les quanta (las actas se publicaron en 1912 [Langevin y de Broglie, eds. 1912]): Lorentz, Jeans, Warburg, Rubens, Planck, Knudsen, Perrin, Nernst, Kamerlingh Onnes, Sommerfeld, Langevin y Einstein (entre los asistentes, muy pocos y por invitación, figuraba también Poincaré). Nótese la rapidez con que Echegaray se informó del contenido de la reunión (aunque, como veremos más adelante, superficialmente), y cómo identificó su importancia.

${ }^{196}$ Los trabajos que Poincaré dedicó a la teoría cuántica son Poincaré $(1911,1912)$.

197 Se puede obtener una idea bastante ajustada del pensamiento y contribuciones de Stokes en Larmor, ed. (1907).

198 En su historia de la teoría cinética de los gases durante el siglo XIX, Stephen Brush (1976) incluye (especialmente en el volumen segundo) varios comentarios relativos a este libro de Watson, así como a otros de sus trabajos.

199 Sobre el principio de equipartición y la física cuántica, ver Sánchez Ron (2001, cap. 1).

200 Los cálculos de Echegaray, con dos sistemas de esferas, se correspondían realmente a gases diatómicos, aunque él apuntó en algún momento que eran fácilmente generalizables a múltiples sistemas de esferas.

201 Este problema no se resolvería definitivamente hasta 1924, cuando Satyendranath Bose publicó el artículo (titulado «La ley de Planck y la hipótesis de los cuantos de luz») que dio origen a la denominada «estadística de Bose-Einstein». 
José Echegaray: entre la ciencia, el teatro y la política

\section{Referencias}

ABEL, NIELS HENRIK (1826), "Beweis der Unmöglichkeit algebraische Gleichungen von höheren Graden als dem vierten allgemein aufunlösen», Journal für die reine und angewandte Mathematik (Journal de Crelle) 1, 65-84. Reproducido en Abel (1881) con el título «Demostration de l'impossibilité de la resolution algébrique des equations generales que passent de quatriéme degré», pp. 66-94.

- (1829), «Memoire sur une classe particuliére d'equations résolubles algébriquement», Journal de Crelle, pp. 478-507 de Abel (1881).

- (1839), Oeuvres complétes de N. H. Abel, mathématicien, B. Holmboe, ed. (Oslo).

- (1881), Oeuvres complétes. Nouvelle édition, L. Sylow y S. Lie, eds., 2 vols. (Oslo).

ABRAHAM, MAX (1902 a), "Prinzipien der Dynamik des Elektrons», Physikalische Zeitsch. rift 57-63.

- (1902 b), «Dynamik des Elektrons», Königliche Gesellschaft der Wissenschaften zu Göttingen. Mathematisch-physikalische Klasse. Nachrichten, 20-41.

- (1903), «Prinzipien der Dynamik des Elektrons», Annalen der Physik 10, 105-179.

ABRAHAM, H. y LANGEVIN, P. (1905), Les quantités élémentaires d'électricité. Ions, Electrons, Corpuscules (Société française de Physique, París).

ANTON DEL OLMET, LUIS $y$ GARCíA CARRAFFA, ARTURO (1912), Echegaray (Madrid).

APPELl, PAUl-EMILe (1893-1921), Traité de mécanique rationnelle, 5 vols. (París).

BoltzManN, Ludwig (1896-1898), Vorlesungen über Gastheorie, 2 tomos (Leipzig).

Boussinesq, J. (1901-1903), Théorie analytique de la chaleur (París).

BOYer, CARL B. (1986), Historia de la matemática (Alianza, Madrid).

Boyer, CARL B. y MerzBach, UTA C. (1989), A History of Mathematics, 2. ${ }^{\text {a }}$ ed. (John Wiley, Nueva York).

BRIOT, ChaRLES A. (1864), Essai sur la théorie mathématique de la lumiére (París). .

Brush, Stephen G. (1976), The Kind of Motion we Call Heat. A History of the Kinetic Theory of Gases in the 19th century, 2 vols. (North-Holland, Amsterdam).

BÜHLER, WALTER K. (1981), Gauss. A Biographical Study (Springer-Verlag, Berlín).

CACHO VIU, VICENTE (1962), La Institución Libre de Enseñanza (Rialp, Madrid).

CAMARERo, ERnesto y CAMARERo, Enrique, comps. (1970), La polémica de la ciencia española (Alianza, Madrid).

CEBRIÁN, Francisco (1909), «Disolución y electrolisis según las teorías de D. José Echegarayn, Actas I Congreso Asociación Española para el Progreso de las Ciencias, tomo III, pp. 139-141 (Madrid).

ClifFoRD, WILLIAM K. (1885), The Common Sense of the Exact Sciences (Londres).

- (1946), The Common Sense of the Exact Sciences, nueva edición (Alfred A. Knopf, Nueva York).

Collete, JEAN-PAUL (1985), Historia de las matemáticas, 2 vols. (Siglo XXI, Madrid).

Cournot, A. A. (1841), Traité élémentaire de la théorie des fonctions et du calcul infinitesimal (París).

Crawford, Elisabeth; Heilbron, J. L. y UllRich, Rebecca (1987), The Nobel Population 1901-1937. A Census of the Nominators and Nominees for the Prizes in Physics and Chemistry (Office for History and Technology of California, Berkeley, and Office for History of Science, Uppsala University, Uppsala).

CUESTA DUTARI, NoRBERTo (1974), El maestro Juan Justo García, 2 tomos (Universidad de Salamanca, Salamanca). 
- (1985)), Historia de la invención del Análisis infinitesimal y de su introducción en España (Ediciones Universidad de Salamanca, Salamanca).

Chasles, Michel (1837), Aperçu historique sur l'origine et le développment des méthodes en Géometrie (Bruselas).

DASTON, LORRAINE J. (1986), «The physicalist tradition in early nineteenth century French Geometry", Studies in the History and Philosophy of Science 17, 269-295.

DíEz-CANEDo, EnRIQUE (1930), "José Echegaray", El Sol, 1 de octubre.

- (2004), Obra crítica (Fundación Santander Central Hispano, Madrid).

EChEgaray, José (1853 a), «Del movimiento continuo (I)», Revista de Obras Públicas, I, 43-44.

- (1853 b), «Del movimiento continuo (II)», Revista de Obras Públicas, I, 97-99.

- (1854), «Del movimiento continuo (III)», Revista de Obras Públicas, II, 145-151.

- (1858), Cálculo de variaciones (Madrid).

- (1863), Memoria sobre los trabajos de perforación del túnel de los Alpes escrita en el año 1860 (Madrid).

- (1865 a), Problemas de Geometría. Primera Parte. Problemas de Geometría Plana (Madrid).

- (1865 b), Problemas de Geometría Analítica. Primera Parte: Analítica de dos dimensiones (Madrid).

- (1866), Historia de las Matemáticas puras en nuestra España (Real Academia de Ciencias Exactas, Físicas y Naturales, Madrid).

- (1867 a), Introducción a la Geometría superior (Madrid).

- (1867 b), «Sobre la teoría moderna del calor», Revista de Obras Públicas, XV, 116-122.

- (1867 c), «Electricidad y magnetismo. Resultados experimentales y teorías diversas», Revista de Obras Públicas, XV, 165-171, 175-177, 185-188.

- (1868 a), Memoria sobre la teoría de las determinantes (Madrid).

- (1868 b), «Termodinámica», Revista de Obras Públicas, XVI, 1-5, 13-17, 25-28, 37-40, 85-86, 101-104, 113-116,125-128.

- (1868 c), Tratado elemental de Termodinámica (Madrid).

- (1869 a), "Aplicación de las determinantes", Revista de los Progresos de las Ciencias Exactas, Físicas y Naturales XVIII, 312-333.

- (1869 b), Influencia del estudio de las Ciencias Físicas en la Educación de la mujer, octava de las Conferencias Dominicales sobre la Educación de la Mujer (Madrid).

- (1871 a), Teoría matemática de la luz (Madrid).

- (1871 b), «Termodinámica», Revista de Obras Públicas, XIX, 89-93, 104-106,119. 120,127-130.

- (1873), Teorias modernas de la Física. Unidad de las fuerzas materiales, segunda edición (Madrid).

- (1881), "Aplicación de las fuerzas naturales a la industria y al comercio», en Conferencias del curso de 1879 a 1880. Círculo de la Unión Mercantil, pp. 105-125 (Madrid).

- (1883), Teorías modernas de la Física. Unidad de las fuerzas materiales, segunda serie (Madrid).

- (1887), Disertaciones matemáticas sobre la cuadratura del círculo, el método de Wantzel y la división de la circunferencia en partes iguales (Madrid).

- (1897 a), Resolución de ecuaciones y teoría de Galois (Madrid).

- (1897 b), «La Escuela Especial de Ingenieros de Caminos, Canales y Puertos y las ciencias matemáticas», Revista de Obras Públicas, XLIV, tomo I, 2. 


\section{José Echegaray: entre la ciencia, el teatro y la política}

- (1898), ¿Qué es lo que constituye la fuerza de las naciones? (Ateneo, Madrid).

- (1898-1902), Lecciones sobre resolución de ecuaciones y teoria de Galois (Madrid).

- (1901), Observaciones y teorías sobre la afinidad quimica (Madrid).

- (1904), "Notas sobre ecuaciones diferenciales», Revista de la Real Academia de Ciencias Exactas, Físicas y Naturales, 1, 137-152.

- (1905 a), Ciencia popular (Madrid).

- (1905 b), "El Newton del Norte (Abel)», en Ciencia Popular (Madrid), pp. 461-486.

- (1905 c), La ciencia y la crítica (Madrid).

- (1908), «Resumen de los trabajos de la Sección de Ciencias Matemáticas del Congreso', Actas Primer Congreso Asociación Española para el Progreso de las Ciencias, tomo I, pp. 37-47 (Madrid).

- (1910 a), «El Newton del Norte», en Vulgarización científica (Madrid 1910), pp. 280. 299.

- (1910 b)) «Discurso inaugural», Actas Segundo Congreso Asociación Española para el Progreso de las Ciencias, tomo I, pp. 7-30 (Madrid).

- (1912 a), «Eduardo Saavedra», Revista de la Sociedad Matemática Española, 1, 333353.

- (1912 b), «Poincaré», Revista de la Sociedad Matemática Española, 2, 33-39.

- (1914), «Discurso de contestación al de Augusto Krahe», pp. 33-56 (Real Academia de Ciencias Exactas, Físicas y Naturales, Madrid).

-. (1915), «Serie de negaciones», Madrid Científico, XXII, 341-346.

- (1917), Recuerdos, 3 vols. (Madrid).

EINSTEIN, AlBERT (1901), "Folgerungen aus den Capillaritätserscheinungen», Annalen der Physik, 4, 513-523.

FINDLING, JOHN E., ed (1990), Historical Dictionary of World's Fairs and Expositions, 1851-1988 (Greenwood Press, Nueva York).

FORNIELES AlCARAZ, JAVIER (1989), Trayectoria de un intelectual de la Restauración: José Echegaray (Publicaciones de Cajalmería, Almería).

FOURIER, JOSEPH (1822), Théorie analytique de la chaleur (París).

GALOIS, EVARISTE (1846), "Oeuvres mathématiques», Journal de Mathématiques pures et appliquées, XI, 381-444. Reimpreso en Oeuvres mathématiques publiées en 1846 dans le Journal de Liouville (Editions Jacques Gabay, París, 1989).

Galvarriato, Juan-Antonio (1932), El Banco de España. Constitución, historia, vicisitudes y principales episodios en el primer siglo de su existencia (Banco de España, Madrid).

García de GaLdEANO, Zoel (1891), "Las equivalencias y sustituciones en los teoremas y en los problemas geométricos», El Progreso Matemático, 1, 36-39, 70-72.

- (1892), Geometría general, I. Teoremas, problemas y métodos geométricos (Zaragoza).

- (1895), Geometría general, II. Sistematización de la Geometría (Zaragoza).

- (1896), Las modernas generalizaciones expresadas por el álgebra simbólica, las geometrías noeuclideas y el concepto de hiper-espacio (Madrid).

- (1905), "Echegaray, científico», Revista Trimestral de Matemáticas, V, 33-35.

- (1916), "Echegaray», Revista de la Academia de Ciencias Exactas, Físicas y Naturales de Zaragoza, I, 241-245.

García Martí, Victoriano (1948), El Ateneo de Madrid (1835-1935) (Dossat, Madrid).

GARMA, SANTIAGO (1978), «Producción matemática y cambios en el sistema productivo en la España de finales del siglo XVIII", en Homenaje a Julio Caro Baroja, pp. 431-447 (Madrid). 
- (1979), «La primera exposición de la teoría de Galois en España», Llull, 3, 7-14.

- (1983 a), «Echegaray y Eizaguirre, José», en Diccionario histórico de la ciencia moderna en España, J. M. ${ }^{a}$ López Piñero et al, vol. I, pp. 292-295 (Península, Barcelona).

- (1983 b), «Torroja Caballé, Eduarrdo», en Diccionario histórico de la ciencia moderna en España, J. M. ${ }^{a}$ López Piñero et al, vol. II, pp. 365-367 (Península, Barcelona).

- (1987), "Echegaray y la teoría de Galois», en Cinquanta anys de Ciéncia $i$ Técnica a Catalunya, pp. 149-161 (Institut d'Estudis Catalans, Barcelona).

- (1988), «Cultura matemática en la España de los siglos XVIII y XIX», en José M. Sánchez Ron, ed., Ciencia y sociedad en España, pp. 93-127 (El Arquero, Madrid).

GIL DE ZÁrate, ANTONIo (1855), De la instrucción pública en España (Madrid).

GIMÉNEZ, EuLOGIO (1878-1881), "Introducción a la Geometría sintética", Boletín de la Institución Libre de Enseñanza, II, 11, 35, 77, 91, 116, 168, 111, 23, 30, 39, 71, 78, 84, 110,$117 ; I V, 3,29 ; V, 84,113$. (He escrito Giménez ya que así aparece escrito en el Boletín, pero en general se le citaba como Jiménez.)

Glick, Thomas F. (1982), «In Memoriam. Tomás Rodríguez Bachiller (1899-1980)», Dynamis, 2, 403-409.

- (1986), Einstein y los españoles (Alianza Editorial, Madrid).

GONZÁLEZ PIEDRA, JUAN (1899), «Teoría de las funciones elípticas. Extracto de las conferencias dadas por D. José Echegaray en el Ateneo de Madrid», Revista de Obras Públicas, XLVI, 16-17, 75-76, 84-85, 94, 383-385,391-393.

Helmholtz, Hermann Von (1847), Über die Erhaltung der Kraft. Eine physikalische Abhandlung (Berlín).

- (1858), «Über Integrale der hydrodynamischen Gleichungen welche den Wirbelbewegungen entsprechen', Journal fúr die reine und angewandte Mathematik, 55, 25-55: traducido al inglés por P. G. Tait: «On integrals of the hydrodynamical equations, which express vortex-motion", Philosophical Magazine, 33, 485-511 (1867), con un apéndice de W. Thomson, pp. 511-512.

HIEBERT, ERWIN N. (1962), Historical Roots of the Principle of Conservation of Energy (The Department of History, University of Wisconsin, Madison).

Hormigón, MaRiano (1981), "El Progreso Matemático. Un estudio de la primera revista matemática española», Llull, 4, 87-115.

- (1982), Problemas de historia de las Matemáticas en España (1870 1920). Zoel García de Galdeano. Tesis doctoral Universidad Autónoma de Madrid.

- (1988), "Las matemáticas en Espaaña en el primer tercio del siglo XX», en José M. Sánchez Ron, ed., Ciencia y sociedad en España, pp. 253-282 (El Arquero, Madrid).

IYANAGA, SOKICHI y KaWADA, YukIYOSI (1980), Encyclopedic Dictionary of Mathematics, 2 vols. (The MIT Press, Cambridge, Mass.).

JiMÉnEZ-LANDI, ANTONIO (1973), La Institución Libre de Enseñanza y su ambiente. Los origenes (Taurus, Madrid).

JoRDAN, CAMtLle (1870), Traité des substitutions et des équations algébriques (París).

KELVIN, LORD (WILLIAM THOMSON) (1884), Notes of Lectures on Molecular Dynamics and the Wave Theory of Light (Baltimore). Una reproducción del curso de Kelvin ha sido publicada en 1987 por The M.I.T. Press.

- (1901), "Nineteenth century clouds over the dynamical theory of heat and light», Philosophical Magazine (6) 2, 1-40.

KLEIN, FELIX (1928), Vorlesungen über die Entwicklung der Mathematik im 19 Jahrhun$\operatorname{dert}$ (Berlín). 


\section{José Echegaray: entre la ciencia, el teatro y la política}

KLINE, MORRIS (1972), Mathematical Thought from Ancient Times to Modem Times (Oxford University Press, Nueva York).

KRAHE, AUGUSTO (1916), «Echegaray matemático. Recuerdos anecdóticos», Madrid Científico, XXIII, 479-480.

LAGRANGE, JOSEPH-LOUIS (1770), «Réflexions sur la résolution algébrique des équations», Nouveaux Mémoires de l Académie Royale des Sciences et des Belles-Lettres de Berlin, 134-215.

- (1826), Traité de la résolution des équations numériques de toutes les degrés, $3 .^{\mathrm{a}}$ ed. (París).

Lamé, G. (1836), Cours de Physique de L'École Polytechnique (París).

Langevin, Pierre y DE Broglie, MAURICE, eds. (1912), La théorie du rayonnement et les quanta (Gauthier-Villars, París).

LARMOR, JOSEPH (1900), Aether and Matter (Cambridge University Press, Cambridge).

LARMOR, JOSEPH, ed. (1907), Memoirs and Scientific Correspondence of the late Sir George Gabriel Stokes, 2 vols. (Cambridge University Press, Cambridge).

LIE, Sophus (1895), "Influence de Galois sur le développement des Mathématiques», en Le centenaire de l'École Normale 1795-1895 (Hachette, París). Este artículo de Lie ha sido reimpreso por Editions Jacques Gabay (París) en 1989.

López PiÑero, José María, Navarro Brotons, VíCtor, y Portela Marco, Eugento (1988), "La actividad científica y tecnológica», en Miguel Artola, dir., Enciclopedia de Historia de España, vol. 3, pp. 273-326 (Alianza, Madrid).

LORENTZ, HENDRIK A. (1909), The Theory of Electrons and its Applications to the Phenomena of Light and Radiant Heat (B. G. Teubner, Leipzig).

LORIA, GINO (1919), «Le matematiche in Ispagna ieri ed oggi. Parte seconda: I matematici moderni», Scientia, XXV, 441-449.

LUSA MONFORTe, GUILleRMo (1985), «Las matemáticas en la ingeniería: La obra de Rey Pastor", en Actas I Simposio sobre Rey Pastor, Luis Español, ed., pp. 205-219 (Instituto de Estudios Riojanos, Logroño).

MACHIMBARRENA, VICENTE (1932), «Echegaray, alumno y profesor de la Escuela de Caminos", Revista de Obras Públicas, LXXX, 201-206.

Martínez Olmedilla, Augusto (1949), José Echegaray (El madrileño tres veces famoso). Su vida-Su obra- Su ambiente (Madrid).

MAXWELL, JAMES ClERK (1860), "Illustrations of the dynamical theory of gases", Philosophical Magazine (4) 19, 19-32; 20, 21-37.

MENÉNDEZ Y PELAYO, MARCELINO (1894), «Esplendor y decadencia de la cultura científica española", La España Moderna. Reeditado en La Ciencia Española, tomo II, pp. 403 y ss. (Madrid, 1953), y en García Camarero y García Camarero, comps. (1970), pp. 311-350.

Merino, Miguel de (1885), Anuario de la Academia de Ciencias, p. 116.

Monna, A. F. (1975), Dirichlet's Principle. A Mathematical Comedy of Errors and its Influence on the Development of Analysis (Utrecht).

MORENO GONZÁlEZ, ANTONTO (1988), Una ciencia en cuarentena. La física académica en España (1750-1900) (Consejo Superior de Investigaciones Científicas, Madrid).

OCTAVIO De TOLedo, LuIS (1912), «Eulogio Jiménez», Revista de la Sociedad Matemática Española, 2, 1-5.

- (1914), Algunos de los descubrimientos realizados en la teoría y resolución de ecuaciones durante el siglo XIX. Discurso de entrada en la Real Academia de Ciencias (Real Academia de Ciencas Exactas, Física y Naturales, Madrid). 
- (1932), "Recuerdos de unas conferencias», Revista Matemática Hispano-Americana, $7,59-63$.

O'TERo CARVAJAL, LuIS ENRIQUe (1989), «Madrid Científico: relatividad y relativismo en España», Alfoz, núms. 66-67, pp. 38-51.

Pecellín lancharro, Manuel (1988), Francisco Vera Fernández de Córdoba. Matemático e Historiador de la Ciencia (Diputación Provincial de Badajoz, Badajoz).

PESET, J. L.; GARMA, S., y PÉREZ GARZón, J. S. (1978), Ciencias y enseñanza en la revolución burguesa (Siglo XXI, Madrid).

PICATOSTE, FELIPE (1891), Apuntes para una biblioteca cientifica española del siglo XVI (Madrid).

Plans, José MaRÍa (1926), «Las Matemáticas en España en los últimos cincuenta años», Ibérica, XXV, 172-174.

POINCARÉ, HENRI (1889), Théorie mathématique de la lumière, tomo I (G. Carré \& C. Naud, París).

- (1890), Electricité et optique, tomo I; Les théories de Maxwell et la théorie électromagnétique de la lumiére (G. Carré \& C. Naud, París). El tomo II, al que no se refería Echegaray, trata de Les théories de Helmholtz et les expériences de Hertz (1891).

- (1892), Théorie mathématique de la lumière, tomo II; Nouvelles études sur la diffraction. Théorie de la dispersion de Helmholtz (G. Carré \& C. Naud, París).

- (1892), Leçons sur la théorie de I'Elasticité (G. Carré \& C. Naud, París).

- (1894), Les oscillations électriques (G. Carré \& C. Naud, París).

- (1911), «Sur la théorie des quanta», Comptes rendus de l Académie des Sciences, 153, 1103-1108.

- (1912), «Sur la théorie des quanta», Journal de Physique théorique et appliqué, 2, 534.

ReY PASTOR, Jutio (1913), Historia de la Matemática en España (Universidad de Oviedo, Oviedo). Reproducido en Julio Rey Pastor, Selecta, pp. 463-535 (Fundación Banco Exterior, Madrid, 1988).

- (1915),, "Discurso inaugural», Actas V Congreso de la Asociación Española para el Progreso de las Ciencias, tomo I, pp. 7-25 (Madrid).

- (1916), «Echegaray, científico», España, año II, n. ${ }^{\circ} 87$ (21 de septiembre), pp. 10-11 (Madrid).

RIBNiKov, K. (1987), Historia de las Matemáticas (Mir, Moscú).

RÍUS Y CASAS, JoSÉ (1889), Origen y propiedades fundamentales de las funciones elípticas (Madrid).

ROCA, ANTONI (1981), «La incidéncia del pensament d'Einstein a Catalunya (1908-1923)», en Jornades d'homenatge a Einstein (Institut d'Estudis Catalans, Barcelona), pp. 165-184.

RODRÍGUEZ CARRACIDo, JosÉ (1917). Estudios histórico-críticos de la ciencia española (Imprenta de Alrededor del Mundo, Madrid).

Rodríguez Mourelo, José (1916), «Don José Echegaray», Revista de la Real Academia de Ciencias Exactas, Físicas y Naturales, XV, 121-136.

Rowe, DaVID E. (1989), "Klein, Hilbert, and the Göttingen mathematical tradition», Osiris, 5, 186-213.

RuMEu DE ARMAS, ANTONIO (1980), Ciencia y tecnología en la España ilustrada. La Escuela de Caminos y Canales (Turner, Madrid).

Russell, Bertrand (1897), An Essay on the Foundations of Geometry (Cambridge University Press, Cambridge). Existe traducción al castellano (Aguilar, Madrid 1973). 


\section{José Echegaray: entre la ciencia, el teatro y la política}

SAAVEdRa, EduARdo (1885), Anuario de la Academia de Ciencias, p. 119.

SÁENZ RIDRUEdo, FERnANDo (1990), Ingenieros de Caminos del siglo XIX (Colegio de Ingenieros de Caminos, Canales y Puertos-Editorial AC, Madrid).

SÁNCHEZ PÉREZ, José AUGUSTo (1929), Las matemáticas en la biblioteca del Escorial (Madrid).

- (1932), "Echegaray, rasgos biográficos», Revista Matemática HispanoAmericana, 7, 49-58.

SÁNCHEZ Ron, JosÉ M., ed. (1988), Ciencia y sociedad en España (El Arquero, Madrid).

SÁNCHEZ RON, JOSÉ M. (2001), Historia de la física cuántica. I. El período fundacional (1860-1926) (Crítica, Barcelona).

SMITH, Crosbie y WISE, M. NORTON (1989), Energy and Empire. A Biographical Study of Lord Kelvin (Cambridge University Press, Cambridge).

Thompson, Silvanus P. (1910), The Life of William Thomson, 2 vols. (Macmillan, Londres).

TORROJA, EDUARDO (1893), Reseña de los medios empleados por la Geometría pura actual para alcanzar el grado de generalidad y de simplificación que la distingue de la Geometría antigua. Discurso de entrada en la Real Academia de Ciencias (Real Academia de Ciencias Exactas, Físicas y Naturales, Madrid).

- (1899), Tratado de la geometría de la posición y sus aplicaciones a la geometría de la medida (Madrid).

TORTELLA CASARES, GABRIEL (1970), «El Banco de España entre 1829 y 1929. La formación de un Banco central», en El Banco de España. Una historia económica, pp. 261. 313 (Madrid).

TRUd, NICOLA (1862), Teoria de’ determinanti e loro applicazioni (Nápoles).

VEGAS, Miguel (1894), Tratado de Geometría analítica (Madrid).

VELA, ANTONIO (1916), "Don José Echegaray y la cultura física en España», Madrid Cientifico, XXIII, 481-482.

VERA, Francisco (1929), Historia de la Matemática en España. I. (Tiempos primitivos hasta el siglo XIII) (Madrid).

- (1931), Historia de la Matemática en España. II. (Los precursores del Renacimiento. Siglos XIII, XIV y XV) (Madrid).

- (1933 a), Historia de la Matemática en España. III. (Arabes y judíos. Primera parte. Siglos VIII al XI) (Madrid).

- (1933 b), Historia de la Matemática en España. IV. (Arabes y judíos. Segunda parte. Siglos XII al XVI) (Madrid).

- (1937), Historia de la Ciencia (Joaquín Gil, editor, Barcelona).

VILAR FIOL, RAFAEL (1911), «Explicación del equilibrio químico según las teorías de Echegaray", en Actas II Congreso Asociación Española para el Progreso de las Ciencias, tomo IV, pp. 69-81 (Madrid).

VillaAcorta Baños, Francisco (1985), El Ateneo de Madrid (1885-1912) (Consejo Superior de Investigaciones Científicas, Madrid).

WOODHOUSE, ROBERT (1810), A Treatise on Isoperimetrical Problems and the Calculus of Variations (Cambridge University Press, Cambridge). Reimpreso en 1964 por Chelsea Pub., Nueva York, con el título A History of the Calculus of Variations in the Eighteenth Century.

Wussing, Hans (1984), The Genesis of Abstract Group Theory (The M.I.T. Press, Cambridge, Mass.). 


\section{Bibliografía Científica de José Echegaray}

En la lista que sigue se incluyen únicamente aquellas publicaciones debidas a Echegaray relacionadas con la ciencia, la matemática y la física principalmente, con la excepción de sus, incompletas, memorias y de aquellos trabajos que he citado. En lo relativo a los numerosísimos artículos de divulgación que publicó en diarios y revistas, sólo he tomado en consideración aquellos que aparecieron posteriormente en forma de libro (entre las revistas o diarios en los que colaboró se encuentran El Imparcial, "Almanaque" de El Globo, Revista Contemporánea, Ilustración Artística, Ilustraciones Española y Americana, Revista Hispano Americana, Heraldo de Madrid, Diario de La Marina de La Habana, y El Liberal). Para hacerse una idea del número de artículos de divulgación que llegó a escribir, lo mejor es utilizar sus propios Recuerdos (tomo II, pp. 279-280): «[Con relación] a la serie de artículos que hace más de treinta y seis años que empecé a publicar con el fin de ir popularizando las ciencias matemáticas y físico-matemáticas en nuestra patria ... se cuentan ya estos artículos por centenares y mejor dijera que por miles. Sólo para el Diario de La Marina hace ya más de treinta años que escribo dos crónicas mensuales, de donde resultan veinticuatro crónicas al año, o sea, setecientas veinte en el periódico citado".

Preparar una bibliografía de escritos de Echegaray es, por consiguiente, una tarea com. plicada. No pretendo que la que he compilado, y que presento a continuación, esté libre de omisiones; sí, creo, no obstante, que es más completa que aquellas que conozco.

1) «Del movimiento continuo (I)», Revista de Obras Públicas, I, 43-44 (1853).

2) "Del movimiento continuo (II)», Revista de Obras Públicas, I, 97-99 (1853).

3) "Del movimiento continuo (III)", Revista de Obras Públicas, II, 145-151 (1854).

4) Cálculo de variaciones. Lecciones explicadas en la Escuela de Caminos, Canales y Puertos, 68 pp., una lámina (Imprenta de D. José C. de la Peña, Madrid, 1858).

5) Memoria sobre los trabajos de perforación del túnel de los Alpes, escrita en el año 1860 , 205 pp., 16 láminas (Madrid, 1863):

6) Problemas de Geometría. Primera parte: Problemas de Geometría plana, 151 pp. (Establecimiento Tipográfico de T. Fortanet, Madrid, 1865).

7) Problemas de Geometría Analítica. Primera parte: Analítica de dos dimensiones, 71 pp. (Imprenta de F. Martínez García, Madrid, 1865).

8) Historia de las Matemáticas puras en nuestra España. Discurso de entrada en la Real Academia de Ciencias Exactas, Físicas y Naturales, 33 pp. Contestación (pp. 37-53) a cargo de Lucio del Valle (Madrid, 1866).

9) "Puentes colgados. Teoría de los tirantes superiores al tablero", Revista de Obras Públicas, XIV, 273-278 (1866).

10) Introducción a la Geometría Superior, 201 pp., 17 láminas. (Imprenta y Librería de D. Eusebio Aguado, Madrid, 1867.) Publicado en forma de artículos en la Revista de los Progresos de las Ciencias (XVI, 449-475, 513-535 [1866]; XVII, 1-24, 65-89, 129139, 193-208, 257-264, 321-333, 385-393, 449-460, 513-520 [1867]; XVIII, 1-6, 81-95, $161-166,241-246$ [1869]).

11) Teorias modernas de la Fisica. Unidad de las fuerzas materiales, $136 \mathrm{pp}$. (Imprenta de Francisco Roig, Madrid, 1867). Como se indica más adelante, una segunda edición de este libro apareció en 1873, y una segunda parte en 1883.

12) "Sobre la teoría moderna del calor», Revista de Obras Públicas, XV, 116-122 (1867). 


\section{José Echegaray: entre la ciencia, el teatro y la política}

13) “Sobre las teorías modernas de la luz», Revista de Obras Públicas, XV, 127-133 (Vibraciones del éter), 143-146 (Interferencias y transformaciones), 149-153 (1867).

14) "Electricidad y magnetismo. Resultados experimentales y teorías diversas», Revista de Obras Públicas, XV, 165-171,175-177, 185-188 (1867).

15) Memoria sobre la teoría de las determinantes, 201 pp. (Imprenta de los Conocimientos útiles, Madrid, 1868).

16) Tratado elemental de Termodinámica, $56 \mathrm{pp}$. (Imprenta de los conocimientos útiles Madrid, 1868).

17) «Termodinámica», Revista de Obras Públicas, XVI, 1-5, 13-17, 25-28, 37-40, 85-86 101-104, 113-116, 125-128 (1868); XIX, 89-93, 104-106, 119-120,127-130 (1871).

18) "Aplicación de las determinantes", Revista de los Progresos de las Ciencias Exactas, Fisicas y Naturales, XVIII, 321-333 (1869).

19) Influencia del estudio de las Ciencias Físicas en la educación de la mujer, octava de las Conferencias dominicales sobre la Educación de la Mujer, Universidad de Madrid; 19 pp. (Imprenta y Esteriotipia de M. Rivadeneyra, Madrid, 1860).

20) Teoría matemática de la luz, 175 pp., 2 láminas (Madrid,1871). Publicado en forma de artículos en la Revista de los Progresos de las Ciencias Exactas, Físicas y Naturales (XIX, 1-19, 65-86, 129-151, 193-232, 257-287, 321-327 [1876]; XX, 1-13, 49-64, 97 116 [18791).

21) «Planímetro de Mr. Marcel Duprez», Revista de Obras Públicas, XX, 14-17 (1872).

22) Teorías modernas de la Física. Unidad de las fuerzas materiales, 2.a edición (considerablemente aumentada, 247 pp. (Imprenta y Estereotipia de M. Rivadeneyra, Madrid, 1873).

23) "Aplicación de las fuerzas naturales a la industria y al comercio", en Conferencias del curso de 1879 a 1880. Círculo de la Unión Mercantil, pp. 105-125 (Madrid, 1881).

24) Teorías modemas de la Fisica. Unidad de las fuerzas materiales, segunda serie, 238 pp. (Imprenta y Librería de J. Gaspar, editor, Madrid, 1883).

25) «El determinismo mecánico y la libertad moral», Revista de los Progresos de las Ciencias Exactas, Fisicas y Naturales, XXI, 1-21, 65-77, 257-276 (1886).

26) Disertaciones matemáticas sobre la cuadratura del círculo, el método de Wantzel y la división de la circunferencia en partes iguales, $149 \mathrm{pp}$. (Imprenta de la viuda e hijo de D. E. Aguado, Madrid, 1887). Publicado en forma de artículos en la Revista de los Progresos de las Ciencias Exactas, Físicas y Naturales. ("Sobre la imposibilidad de la cuadratura del círculo», XXI, 493-541 [1886]; «Método de Wantzel para conocer si un problema puede resolverse con la recta y el círculo», XXII, 1-47 [1905]; «División de la circunferencia en partes iguales», $X X I I, 69-120$ [1905]).

27) Teorías modernas de la Fisica. Unidad de las fuerzas materiales, tercera serie, 254 pp. (Librería Fernando Fé, Madrid, 1889).

28) Examen de varios submarinos comparados con "El Peral». Colección de artículos publicados originariamente en El Heraldo de Madrid, 105 pp. (Imprenta de José M. Ducazcal, Madrid, 1891).

29) Informe sobre la producción y distribución de electricidad y sobre el material y servi cio de la Compañía General Madrileña (en colaboración con Ricardo Becerro de Bengua), $16 \mathrm{pp}$. (Tipolitografía de F. Rodríguez, Madrid, 1894). Se trata de un informe que fue solicitado a los autores a raíz de un grave accidente ocurrido en los cables de fluido de la Compañía Eléctrica Madrileña.

30) Resolución de ecuaciones y teoría de Galois, 524 pp. (Imprenta Fundación y Fábrica de Tintas de los Hijos de J. A. García, Madrid, 1897).

31) «La Escuela de Ingenieros de Caminos, Canales y Puertos y las Ciencias Matemáticas", Revista de Obras Públicas, XLIV, tomo I, 2 (1897). 


\section{José Manuel Sánchez Ron}

32) ¿Qué es lo que constituye la fuerza de las naciones? (Ateneo, Madrid, 1898).

33) Lecciones sobre resolución de ecuaciones y teoría de Galois, $192 \mathrm{pp}$. (Imprenta y Fundición de los Hijos de J. A. García (Madrid, 1898-1902).

34) Observaciones y teorías sobre la afinidad química, $70 \mathrm{pp}$. (La Energía Eléctrica, Madrid, 1901).

35) «Notas sobre ecuaciones diferenciales», Revista de la Real Academia de Ciencias Exactas, Físicas y Naturales, I, 137-152 (1904).

36) Ciencia popular, 927 pp. (Madrid, 1905). Colección de artículos de divulgación publicados en su mayor parte en El Imparcial y El Liberal.

37) La ciencia y la crítica. Discurso leído en la Universidad Central en la inauguración del curso académico de 1905 a 1906, 74 pp. (Imprenta Colonial, Madrid, 1905).

38) "Estudios sobre electro-estática y electro-dinámica», Revista de los Progresos de las Ciencias Exactas, Fisicas y Naturales, XXII, 205-223, 261-300, 317-333, 381-403 (1905).

39) Conferencias sobre Física Matemática. Introducción a la Física Matemática, curso de 1905 a 1906, 12 capítulos, $340 \mathrm{pp}$. (Madrid, 1906). Al igual que los restantes volúmenes, los capítulos que forman estas Conferencias aparecieron inicialmente en la Revista de la Real Academia de Ciencias.

40) Conferencias sobre Fisica Matemática. Elementos de la teoría de la elasticidad (primera parte), curso de 1906 a 1907, 14 capítulos, 424 pp. (Madrid, 1907).

41) Conferencias sobre Física Matemática. Elementos de la teoría de la elasticidad (segunda parte), curso de 1907 a 1908, 14 capítulos, 363 pp. (Madrid, 1908).

42) "Resumen de los trabajos de la Sección de Ciencias Matemáticas del Congreso", Actas Primer Congreso Asociación Española para el Progreso de las Ciencias, tomo I, pp. 37-47 (Madrid, 1908).

43) Conferencias sobre Física Matemática. Elementos de la teoría de la elasticidad (tercera parte), curso de 1908 a 1909, 16 capítulos, 398 pp. (Madrid, 1909).

44) Conferencias sobre Física Matemática. Cuestiones de Análisis. Aplicación a la Física Matemática, curso de 1909 a 1910, 17 capítulos, 392 pp. (Madrid, 1910).

45) Vulgarización científica, 320 págs. (Rafael Gutiérrez Jiménez, Madrid, 1910). Con la excepción de uno ("El alma de la industria», pp. 258-263), todos los artículos incluidos en este volumen aparecen en el ya mencionado Ciencia popular.

46) «Discurso inaugural», Actas Segundo Congreso Asociación Española para el Progreso de las Ciencias, tomo I, pp. 7-30 (Madrid, 1910).

47) Conferencias sobre Fisica Matemática. Teoría de los torbellinos, curso de 1910 a 1911 , 20 capítulos, 394 pp. (Madrid, 1911).

48) Conferencias sobre Física Matemática. Teorías diversas, curso de 1911 a 1912, 21 capítulos, 582 págs. (Madrid, 1912).

49) «Eduardo Saavedra», Revista de la Sociedad Matemática Española, 1, 333-353 (1912).

50) «Poincaré», Revista de la Sociedad Matemática Española, 2, 33-39 (1912).

51) Conferencias sobre Física Matemática. Ecuaciones de la mecánica, curso de 1912 a 1913, 22 capítulos, 534 pp. (Madrid, 1913).

52) Conferencias sobre Física Matemática. Teoría de los torbellinos (segunda parte), curso de 1913 a 1914, 23 capítulos, 550 pp. (Madrid, 1914).

53) «Serie de negaciones», Madrid Científico, XXII, 341-346 (1915).

54) Conferencias sobre Física Matemática. Teoría cinemática de los gases (primera parte), curso de 1914 a 1915, 19 capítulos, 435 pp. (Madrid, 1916).

55) Recuerdos, 3 tomos de 414, 410 y 409 pp. (Ruiz Hernandos Editores, Madrid, 1917) Los capítulos de este libro se publicaron con anterioridad en forma de artículos; unos en La España Moderna, y otros en Madrid Científico (ver, por ejemplo, el tomo de esta revista correspondiente a 1914). 


\section{ANEXO DOCUMENTAL}

